\title{
Mapping the Industrial Relations System of Samoa: An assessment of industrial democracy and employee participation in employment relations decisions in a Pacific Island Nation.
}

by

Patricia Ah Chong-Fruean

Submitted to the Victoria University of Wellington

in fulfillment of the

requirements for the degree of

Master of Commerce and Administration

in Human Resource Management and Industrial Relations

Victoria University of Wellington

2010 


\begin{abstract}
This thesis maps out the industrial relations system of Samoa with specific emphasis on industrial democracy and employee participation in the making of rules and decisions affecting workers' employment. The thesis outlines the impacts of the environmental contexts, social, political, legal and economic, of Samoan society on the scope and nature of industrial relations in Samoa.
\end{abstract}

Using data collected through face-to-face interviews, workshop observation and the analysis of various secondary documents that include for example, the study of industrial relations in the South Pacific nations by Prasad, Hince, \& Snell (2003) and several country reports and national policies on employment relations, the thesis utilises Dunlop's (1958) systems model of industrial relations to describe the employer, employee and state relationship within the system and their varying roles in the determination of workplace rules. Dunlop's systems model enables the researcher to identify a strong link between the industrial relations system and the social institutions of Samoan society that are structured around the fa'asamoa (Samoan customs and traditions) and the fa'amatai (chiefly) systems of social justice and traditional rule making. Dunlop's model (which suggests that the 'rule' is the fundamental goal of an industrial relations system) enables identification of the prevailing processes that employer, employee, state and their representing agencies use to determine the rules in the Samoan workplace. It suggests that while the worker (union) is considered to be one of the key actors' in the establishment of workplace rules, the nature and scope of union participation and influence on industrial relations decisions in Samoa do not reflect this: in the sense that unions play virtually no role in Samoa's industrial relations system. 
The thesis also attempts to uncover the 'shared ideology' that prescribes and defines the actors' roles, prestige, power and influence on the process of rule making in Samoa's IR system. In doing so it finds that Samoan government is the dominant player in industrial relations in the sense that the government can unilaterally make decisions and rules regarding employment relations both at the organisational and national level, without the involvement of employers and workers. While employee participation in employment decisions is clearly affected by economic, technological and market constraints, other factors relating to the culturally nuanced concepts of 'respect', 'loyalty' and 'trust' toward those who hold significant power and authority appear to be predominant influences in the determination of rules in all facets of Samoan society. This particular condition of the Samoan system of industrial relations is explained with reference to Dunlop's notion of 'shared ideology' and the 'locus and distribution of power' within wider society. 


\section{ACKNOWLEDGEMENT}

First and foremost I offer my sincerest gratitude to my supervisor, Dr Stephen Blumenfeld, who has supported me throughout my thesis with his guidance, patience and knowledge whilst allowing me the room to work in my own way. I am also very grateful to the staff at the School of Management at the Victoria University of Wellington: especially Sophie, Sue and Megan for their friendship and administrative support. I am indebted to New Zealand's International Aid and Development Agency (NZAID) for the fully-funded scholarship that was offered to me and which has enabled me to achieve this goal. Special thanks must go to all the participants who made this study possible through their willingness to share with me their invaluable contributions and unique experiences.

I would like to thank Mark Simpson for his important input into the final editing and proof reading of this thesis. Also, I would like to thank my best friend Sally GrevelLameko for her contribution to the proof reading of this thesis.

I cannot find words to express my gratitude to all our family and friends in Wellington who have in so many ways helped and supported me and my children during my study. I would particularly like to thank Tasesa and Anita Ulu, Maumalo and Tafaoga Tunupopo, Lolotai Tunupono, Stella and Roman Forrest, Fagafua Pelenato Viane, Okesene and Sausoli Aiono and Tauli and Moe Galuefa and their families for opening up their homes and hearts to us. I would also like to express my gratitude to Rev. Mataia Samuelu Nofoaiga and his wife Sulu of the Assembly of God Samoa in Royal Oak, Auckland for their words of encouragement and spiritual advice at times when this was most needed. I owe a great debt of gratitude to my parents Tulifuaina and Tagiilima 
Mataiasi and my mother-in-law Palepa Fruean for their endless support, love, prayers, numerous blessings and well wishes, which have kept me and the children all warm, healthy and safe in a foreign land. To all of my siblings and their families, and to my family in law, I thank you for your love and support. I would like to thank my cousin Olafaafouina Liufatu who travelled to Wellington from Samoa to help in taking care of the children in the final six months of writing up this thesis.

My sincere gratitude goes to the General Manager of the Electric Power Corporation (EPC), Muaausa Fiu Joseph Walter as well as the management of EPC for allowing me this rare opportunity to take on full-time study leave from work so that I can fulfill this dream. To my staff and colleagues at EPC, I thank you all for having to bear my work responsibilities during my leave of absence.

To those who have not been specifically mentioned, my gratitude is none the less.

Finally I dedicate this thesis to my loving husband, Papalii Lima Charlie Samson Fruean, with whom I share the credit of this work, and to our beautiful children Justina, Patrick, Derek, Tyren and Latoyanadira Fruean for their understanding, love and wholehearted support. At those times when I was most engrossed, my children served as a constant reminder of all that is most important in life. Having my children by my side through good times and tough times, while trying to complete this thesis on schedule, has made this journey a truly memorable and rewarding experience. 


\section{Table of Contents}

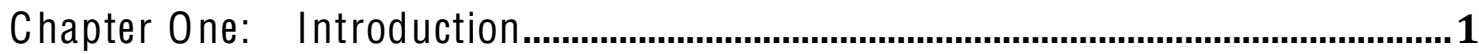

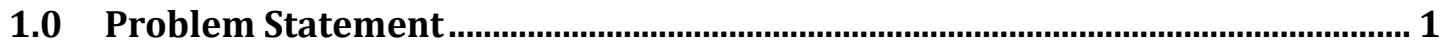

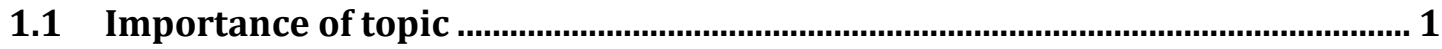

1.2 State of the field of IR in the context of Pacific Island Countries (PICs)............ 3

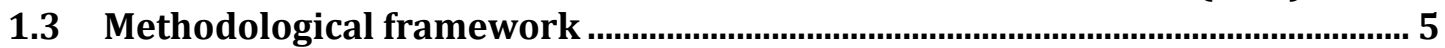

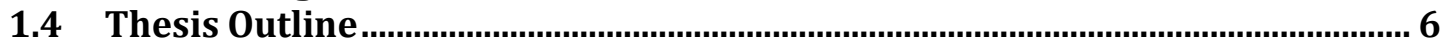

Chapter Two: Review of literature related to the study ....................................8

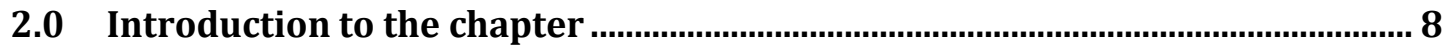

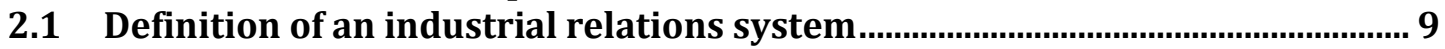

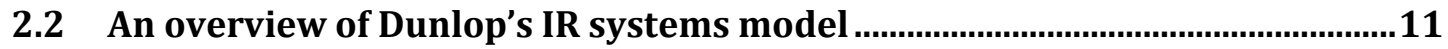

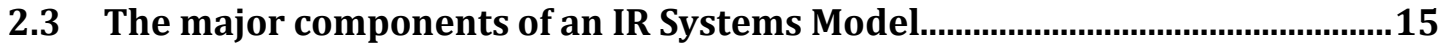

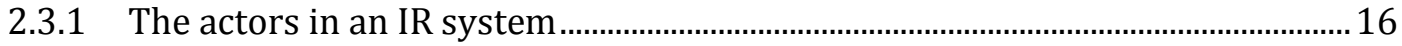

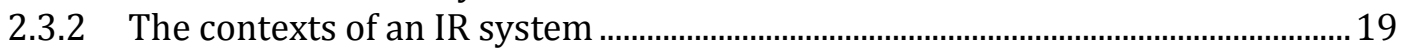

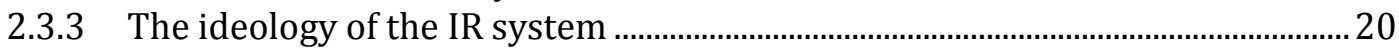

2.4 The conversion process: feedback loop .............................................................21

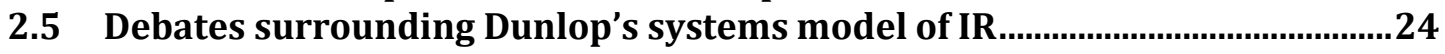

2.6 Review of literature on IR systems in South Pacific Island nations ..................35

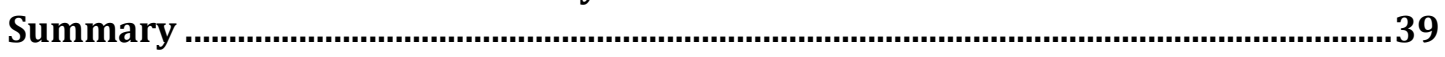

Chapter Three: Methodological framework....................................................... 41

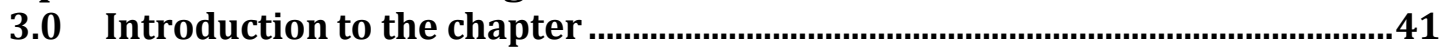

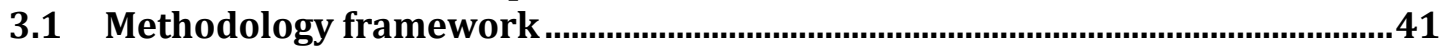

3.1.1 Methods for collecting the data ……….................................................................. 42

3.1.2 Methods for recruiting participants .......................................................................... 43

3.1.3 International Labour Organisation (ILO) Workshop................................................4 48

3.1.4 The interview process .................................................................................................... 51

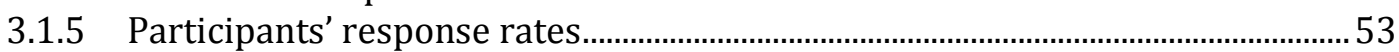

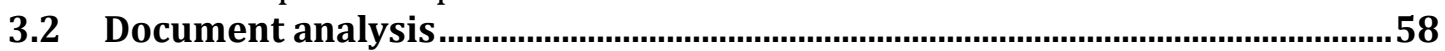

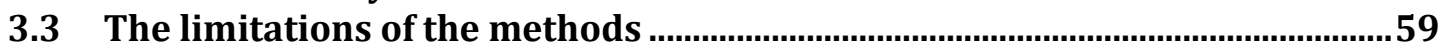

3.4 The analysis framework: Dunlop's systems model of IR ...............................61

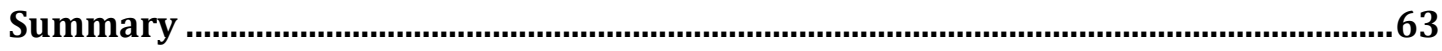

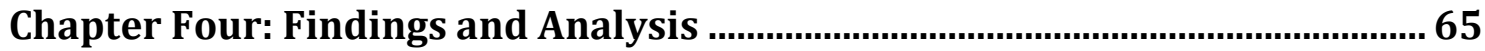

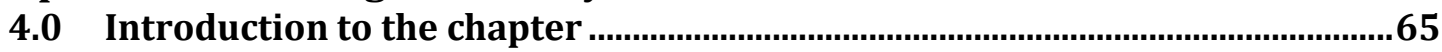

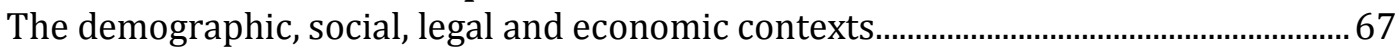

Employment and labour market characteristics ……….................................................... 70

4.1 The impact of the socio-political context on the IR system of Samoa...............71

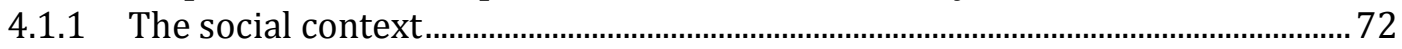

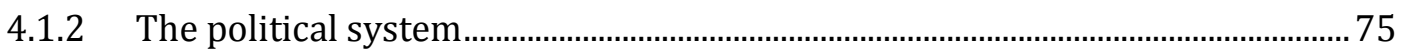

4.2 The impact of the economic context on the IR system of Samoa......................84

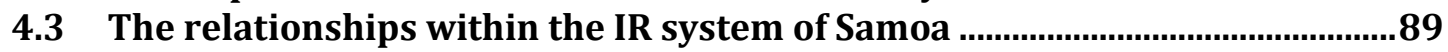

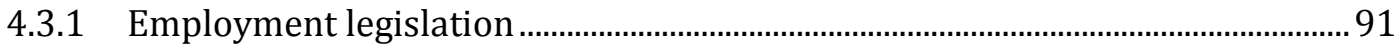

4.3.2 The role of government in Samoa's IR system ...................................................... 91

4.3.3 The role of the International Labour Organisation ................................................. 94

4.4 Employment in the public sector................................................................ 96

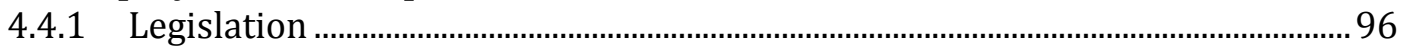

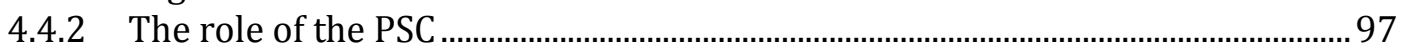

4.4.3 The process for establishing work rules in public sector employment............. 98

4.4.4 Procedure for wage setting in the Public Sector................................................... 101

4.4.5 Unionism in Samoa .............................................................................................. 102 


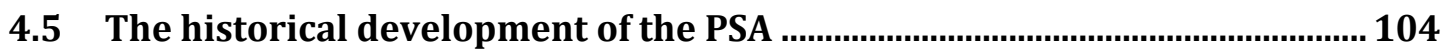

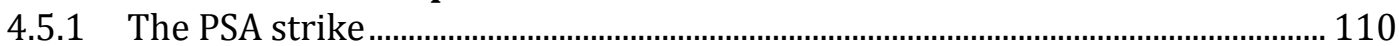

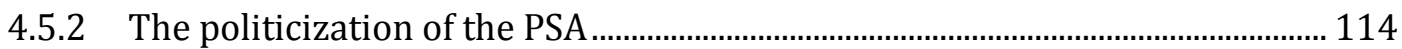

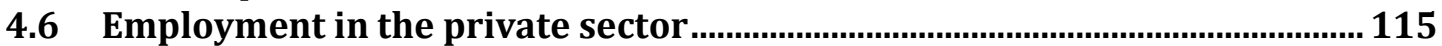

4.6.1 The environmental contexts of IR in the private sector .................................... 115

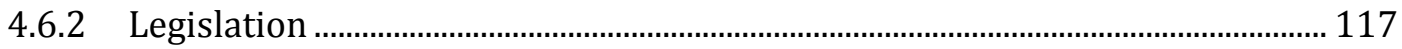

4.6.3 Procedure for settling disputes in the private sector ........................................... 119

4.6.4 Procedure for wage setting in the private sector .................................................. 120

4.6.5 Unionism and collective bargaining: historical overview................................... 121

4.6.6 The role of the Samoa Chamber of Commerce and Industry.............................. 127

4.7 Recent developments in IR in the private sector ............................................... 128

4.7.1 Review of the Labour and Employment Act of 1972 ......................................... 129

4.7.2 Maternity leave policy ......................................................................................... 131

4.7.3 Occupational Safety and Health regulation ............................................................ 133

4.7.4 Samoa's National Tripartite Forum …………...................................................... 133

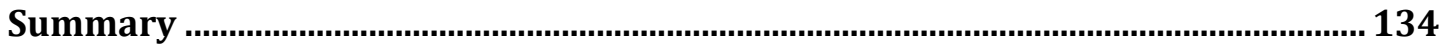

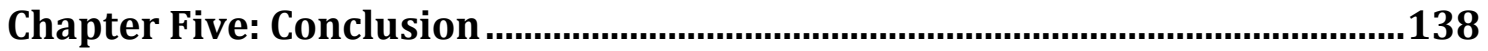

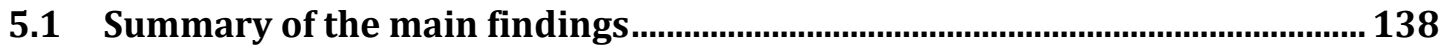

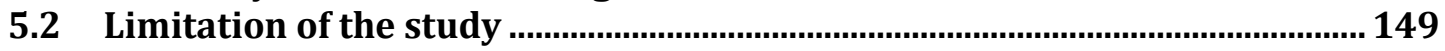

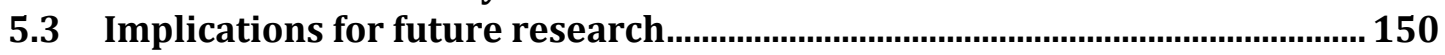

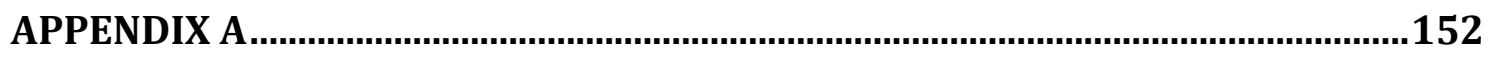

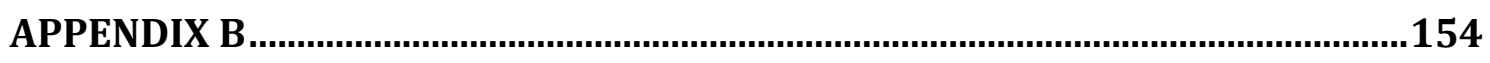

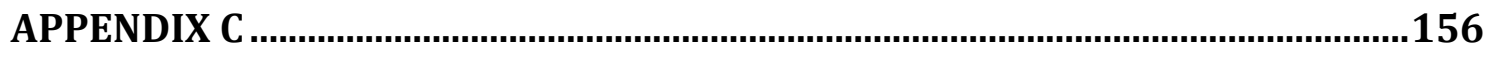

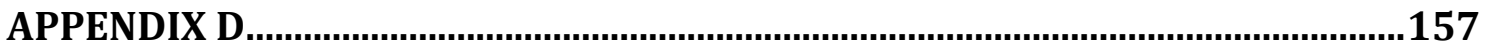

APPENDIX E

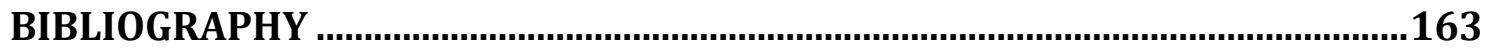

\section{Tables and Figures}

Figure 1: The relationships of an industrial relations system $\quad 12$

Figure 2: The relationships within the industrial relations system of Samoa $\quad 66$

Figure 3: Procedures for settling an industrial dispute in the private sector $\quad 120$

Table 1: Sample population, response rates and actual participation rate …..........................57 


\section{Chapter One: Introduction}

\subsection{Problem Statement}

The main objective of this research is to offer a broad description of the industrial relations (IR) system of Samoa with specific emphasis on the process of making rules that affect industrial democracy and employee participation and in decisions affecting their employment. The analysis involves mapping the Samoan IR system in accordance with John Dunlop's IR Systems approach established in 1958. This is accomplished through semi-structured and open-ended interviews with 13 participants: representative of the key sectors of Samoa's labour force.

The purpose of this study is first to obtain knowledge about the social, political, economic and legal contexts of Samoan society within which the IR system is embedded, as a subsystem of the wider community. Second, the research explores the nature and scope of employers, employees and state relationships within Samoa's IR system with regard to their roles and influences on the rule making aspect of Samoa's workforce.

\section{$1.1 \quad$ Importance of topic}

In mapping the IR system of Samoa, the research attempts to uncover the historical significance of the socio-political, economic and legal contexts of Samoan society and how these impact on the attributes of its IR system. The fundamental questions addressed in this research are: 
1. What are the technical, market and political 'contexts' or 'inputs' to the Samoan industrial relations system?

2. What role or roles does each 'actor' (i.e., government, employers or employer associations and employees or trade unions) play in that system?

3. What are the 'processes' used in that system for converting the 'inputs' into 'outputs' (e.g., government edict, collective bargaining, arbitration).

4. What are the 'outputs' or 'rules' that have derived from that system?

The specific objectives of the research are:

1. to understand the current IR system in Samoa and its historical and current development;

2. to identify, in the Samoan context, the degree of employee participation in decisions affecting their pay and conditions of employment (either through unionism or through other independent representation mechanisms);

3. to identify potential barriers to employee involvement (such as factors affecting employer recognition of trade unions as employee representatives) in industrial relations in Samoa;

4. to fill the gaps in the existing literature on IR systems (which has heretofore tended to ignore nuances in those systems in Pacific Island economies) by offering an accurate description of the Samoan system of IR.

The importance of this topic stems from its area of focus and purpose. While the research is intended to contribute to knowledge of the IR system of Samoa, it is also aimed toward encouraging further research in this area: in particular, research with the objective of improving industrial relations in Samoa. 


\subsection{State of the field of IR in the context of Pacific Island Countries (PICs)}

While there is a large body of research on IR in the literature found regarding Britain, the United States and other industrially developed economies (Ackers \& Wilkinson, 2003; Edwards, 2003), remarkably little attention has been devoted to study of IR and IR systems in small PICs. From the analysis of relevant literature in IR, it becomes clear that the vast majority of research has been heavily concentrated on IR systems in industrialised countries, which has the consequence that IR as a subject for research and practice is most relevant in larger economies and in the Western world.

Recent years have also seen scholars taking an interest in exploring industrial relations in developing nations: mainly in South East Asia and other parts of Europe. A variety of factors, such as the liberalisation of labour and product markets, heightened levels of market penetration as a result of the activities of rising transnational companies (TNCs), and other forces of globalization causing convergence in economic and labour regulations, may have prompted an interest among researchers to investigate employment situations in those countries. Samoa's experience is, however, different in some respects than most other small island economies, particularly in the respect of the large omission of unions as valid actors in the system. The history of unionism in Samoa points to the fa'asamoa (Samoan customs and traditions) as significantly influential on the potentiality of workers to form collective unions. Overall, this study, therefore, highlights the view that the contextual constraints brought about by the sociopolitical, economic and legal systems of Samoan society have invariably influenced various attributes of its IR system. In addition, the study highlights several international IR policies and practices that influence industrial relations in Samoa. For instance, the role the International Labour Organization (ILO) plays in the modernisation of labour 
laws in Pacific nations in order that they conform to International Labour Standards (ILS) demonstrates how global influences can impact not only on local government policies, but also on the national culture of the region.

With reference to related studies on industrial relations in PICs, the main piece of literature on employment relations and IR systems in Samoa and other PICs is found in the work of Prasad, Hince, \& Snell (2003). In their study, Prasad, et al. briefly highlight the roles of the state, trade unions and employers in the establishment of processes relating to the determination of working wages and conditions of employment as well as the settlement of disputes. It is not surprising that, in all of the seven island states included in the study, the government is considered to be the dominant player in the industrial relations arena: taking on the dual roles of employer and lawmaker. It is also noted that the government is seen as the single biggest employer mainly because the public sector comprises the largest proportion of the work community. The private sector is identified as having a less significant role when compared with the public sector. Employers associations are perceived as the minority, whereas trade unions and trade union activities are evaluated in terms of their historical, developmental and contemporary contexts.

Many PICs suffer from traditional and usually adversarial relationships between unions and governments, which makes it difficult for them to move ahead with labour market reforms (UN, 2008). Labour market legislation, in theory, should provide maximum protection for workers in PICs, but as it turns out, this provision is dependent on the degree to which employers choose to comply with the labour laws: as the Ministries of Labour in small island nations are typically understaffed or their staff members do not 
have the necessary skills and knowledge to advise workers on the appropriate course of action to take when dealing with complex issues and large employers. Furthermore, most workers operate in an informal sector, such as farming and agriculture, where they are not governed by any legislation (UN, 2008).

Though it is widely accepted that IR systems in the South Pacific nations remain as yet to be fully explored, their experiences may not be widely different from those of western and industrially developed nations. As Prasad, et al. (2003) have acknowledged, IR systems in Pacific island nations (Samoa included) have suffered from years of neglect due to the lack or absence of a body of research and thorough analysis of IR systems in PICs. In this regard, they provide a baseline study for future thematic research on IR in the Pacific islands. This present study can be viewed as an effort to bring Samoa's situation to surface, thus contributing to the overall knowledge of industrial relations in the context of small Pacific Island nations; but more than this, it can be considered relevant to the future improvement of public policies governing employment relations in Samoa.

\subsection{Methodological framework}

As briefly highlighted above, the focus of the research is on mapping the IR system of Samoa. In particular, it investigates the level of employee participation, either through a union or as individual workers, in influencing decisions and rules that affect workers' employment. In doing so, the research explores the various contexts of wider society within which the IR system exists in order to describe and understand the employers, employees and government sources of power and influence, as well as the 'shared ideology' that determines the rule-making processes of Samoa's working community. 
The analysis of the actor's behaviour, their perceived role and their level of influence on employment decisions has been to a large extent contextualised in the social, political, legal and economic systems of Samoan society, in order to determine the varying influences of these environmental factors on the attributes of Samoa's IR system.

The fieldwork, which included face-to-face, semi-structured and open-ended-question interviews with selected participants, took place in Samoa over a period of five weeks. There were thirteen interviews conducted with government leaders, heads of government ministries and statutory government corporations, leaders of unions (staff associations), individual employers in the private sector and other independent consultants. The researcher also attended a two-day ILO workshop to observe a tripartite panel discussion among employers, workers and government on the economic, social and political issues currently affecting employment in Samoa. The data obtained from the interviews and from the ILO workshop was invaluable: not only because this data fulfills the objectives of the present study, but also as it serves to establish the groundwork for future research. Given the descriptive nature of this study, the researcher obtained a lot of information that could help advance future studies in this area.

\subsection{Thesis Outline}

This thesis contains 5 chapters, as described below, as well as 5 appendices

The current chapter (1) outlines the background of this study and the format of the thesis as a whole. Chapter 2 presents reviews on literature relevant to industrial relations and the industrial relations system. In particular, the review is built around Dunlop's 
systems model of industrial relations, which is used in this study as part of the methodological framework undertaken to describe and analyse the industrial relations system of Samoa. This chapter also presents an overview of related study on IR systems in small PICs. Chapter 3 then presents the selected methodology that was used to obtain and analyse the data. Chapter 4 provides the key findings and analysis from face-to-face interviews with 13 participants, representing the employers, employees and state and their agencies in the IR system of Samoa, as well as the findings from data obtained through various publications on the topic. Discussions in Chapter 4 focus largely on the impacts of the socio-political, economic and legal systems pertaining to various attributes of the IR system, with particular emphasis on how these systems have facilitated and/or constrained the employers', employees' and the state's roles, goals, perceptions, values and relationships and have thereby influenced the processes that actors use to determine the workplace rules. Chapter 5 concludes the study through an articulation of the main findings, a brief description of the limitation in the criteria for selecting interviewees, an account of the implications of the findings and lastly a presentation of a set of proposed topics for future research. 


\section{Chapter Two: Review of literature related to the study}

\subsection{Introduction to the chapter}

This chapter brings into view the scope and nature of industrial relations, with specific emphasis on the 'Industrial Relations Systems' approach advanced by Professor John T. Dunlop in his book of the same name (1958). Dunlop's approach to the study of industrial relations (IR) remains to this day the dominant paradigm or conceptual framework for the study of industrial relations; therefore, his approach serves as the basis for the present study.

The chapter begins by defining the concept of an industrial relations system. Dunlop's methodology offers a means of describing, in general terms, how various 'inputs' from the environment - e.g., labour, capital, technology and management skill — are converted through a range of 'processes' into certain outcomes. An industrial relations system, as described by Dunlop, also is dependent upon the varying roles of the 'actors' in that system, recognizing the traditional industrial processes of collective bargaining and trade unionism as means of rule-making.

Both the study of industrial relations and application of the systems model focus on outcomes most closely associated with the interactions or 'relations' of employees and employers and the 'web of rules' concerning employment that they and their organisations, along with government, establish to govern employer-employee relations. For this reason, while productivity per se is a system outcome, it is not a principal focus of industrial relations. Similarly, industrial democracy and employee participation may be perceived as possible outcomes of the system, typically in the form of work rules, albeit they are not a primary goal of the systems model. 
Dunlop, in Industrial Relations Systems (1958) notes that an IR system can be thought of as being embedded in broader social contexts. In Collective Bargaining and Industrial Relations, Kochan (1980) observes that like any complex social context, IR systems are best understood by identifying and analyzing their various components and how these interact with one another to produce certain outcomes.

To this end, this chapter discusses the various debates for and against the relevance and limitations of Dunlop's model, by means of a review of the literature on IR systems. Given that Dunlop's intention (1958) was to develop a model — not a theory — that could be applied to any national context, what this chapter offers in this regard is a general critique of Dunlop's approach to the study of IR systems.

As part of this general critique of Dunlop's systems approach, chapter 2 also considers the difficulties associated with applying this approach to the study of industrial relations in small island economies. Specific emphasis is placed on seeking reasons why this approach has rarely been applied to the study of industrial relations in Pacific Island Countries (PICs). This discussion concludes with an overview of the literature on IR systems in PICs.

\subsection{Definition of an industrial relations system}

The term industrial relations (IR), or as some prefer: 'employment relations', came into common use in Great Britain and North America in the 1920s. Since the 1980s, in most industrially developed nations, the term IR has been joined by related terms: 'personnel management' (PM) and 'human resource management' (HRM) all three of which denote a practical activity (the management of people) and an area of academic enquiry 
(Edwards, 2003). The term 'industrial relations' can be used in two ways: in the more inclusive sense it refers to all relationships between managers and employees within the industry and in a community, whereas in a more restricted sense it refers only to collective relations between unions and employers (Parker, Brown, Child, \& Smith, 1967). In this way, IR may best be understood as 'all the areas of study and practice' that are concerned with employment functions in modern public and private enterprise; these functions involve workers, unions, managers, government and the various facets of the community at large. In short, the study of industrial relations is concerned with who makes the rules governing labour-management relations in the workplace, the nature of those rules, and how they are administered and regulated (Morley, Gunnigle, \& Collings, 2006). Furthermore, IR is also defined as a system of strategic choice; collective action by labour, business and governments; and the mutual relationships of conflicts, cooperation and power, affecting the content and regulation of employment relations (Boer, Benedictus, \& Meer, 2005).

While the search for a rigorous and analytical definition of the term 'industrial relations system' is noticeably difficult, the very fact it is so serves to heighten the importance of further study in the field of industrial relations. For Dunlop, the struggle to provide an exact definition takes account of two key factors: first, an understanding of what we mean by 'system', a term which in recent years received greater attention and explicit use in the literature to describe features characteristic of labour-management practices of one country as distinguished from others. Second, the use of the concept of industrial relations system is to facilitate analysis among different sectors within a country (e.g. private or public sector), or among different countries. 
In an attempt to conceptualize the term "system", Dunlop (1958) produces two relevant texts; the System of Industrial Relations in Great Britain and the American System of Industrial Relations, neither of which by any means intend to refer to a 'system' as 'planned order'; rather, Dunlop chooses to deal with the critical matters pertaining to the relationships between employers and employees that often emerge in an extremely involved and haphazard fashion. As noted in Dülfer (1996), it was the merit of the systems model produced by Dunlop that for the first time industrial relations between the relevant actors were convincingly grasped and presented. Dunlop's systems model, based on a more institutional approach, was primarily concerned with the fundamental relationships between actors and the actors' interactions with their environment, more so than with the processes by which these interactions are created and subsequently changed.

\section{$2.2 \quad$ An overview of Dunlop's IR systems model}

An IR system is an abstraction comprised of certain actors, certain contexts, an ideology that binds the system together, and a body of rules that regulate the actors in the workplace and in the work community (Dunlop, 1958). The 'web of rules' as identified by Dunlop is the dependent variable in this case, while the independent variables are the contexts (i.e. technology, markets and the distribution of power in the wider society) and the ideology of the system. The relationships of an IR system as discussed by Dunlop are illustrated in Figure 1. 


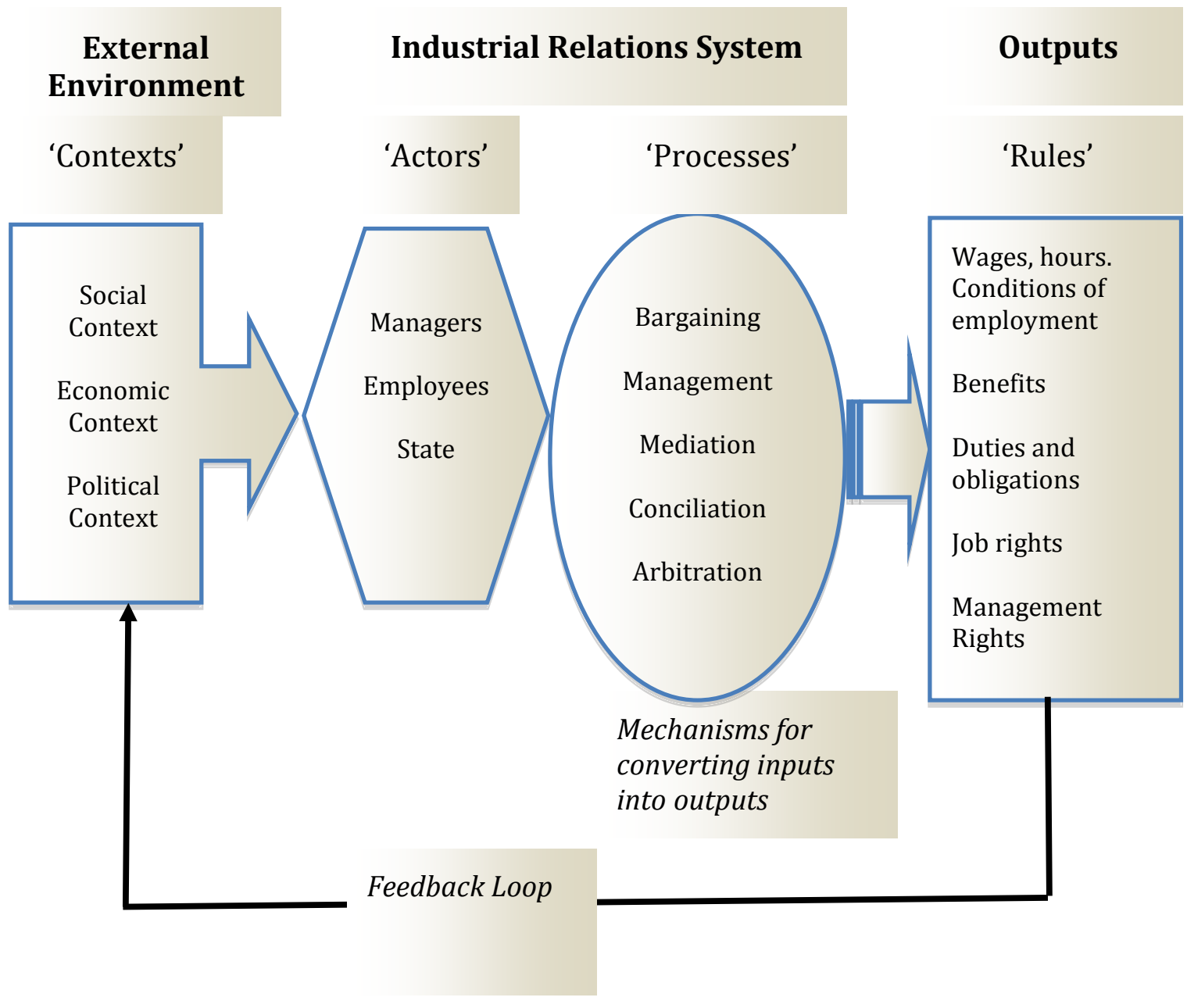

Figure 1: $\quad$ The relationships of an industrial relations system $^{1}$

A central task of an IR system is to provide a conceptual framework for organising knowledge about industrial relations and for describing why particular rules are established in particular industrial relations systems as well as how and why they change in response to factors affecting the system. In addition, an IR system may help to define why outcomes vary from one setting to another. For example, wage rates for a particular group of workers might be best understood as reflecting the interactions between unions and management (via collective bargaining) within the constraints of a particular, technological, market and community environment. In other words, an IR system is

1 Source: Rudman (2002) 
structured in such a way that it would provide a more encompassing framework for the analysis of environmental changes, which often demand the attention of the actors to review existing rules and/or to formulate new rules for the workplace. Therefore, any change or variation in work rules is a possible reflection of the interdependency of various constituents of an IR system on one another. For example, changes in rules governing minimum wage and conditions of employment may come about as a result of local governments responding to global market competition and other economic factors: albeit these influences are usually considered as external to the internal workings of an IR system. Thus, the notion of 'interdependency of the constituents' of an IR system on one another as discussed by Dunlop implies that the system could not act in an autonomous or independent fashion; instead, the system is shaped, at least to some extent, by its technological, market and political contexts.

In general, Dunlop views an IR system as a subsystem on its own rather than as part of a wider economic context: though it will partially overlap with the economic and political contexts (Leat, 2007). This view suggests that while the wider society is seen as providing certain external constraints and influences, which may help shape the industrial relations system, it does not completely dominate the employment relationship. Dunlop also identifies three separate analytical problems that need to be distinguished in the industrial relations framework. The first of these is concerned with the relation of an IR system to the society as a whole; the second refers to the relation of an IR system to the economic context; and the third concerns the inner structure and characteristics of an IR system itself. 
The relation of an IR system to the society as a whole considers the overall sociopolitical and legal context of a nation. This implies that everyone within the society, whether employed or not, will be affected by and have influence on, the structure of the IR system in some way. The economic subsystem is also vital as it helps to determine the outcome of wage negotiations between employers and workers (or their unions). It allows the state to intervene whenever necessary to ensure that the economic interests or concerns of each party are within reason and without excessive demands from either party to the effect of adversely impacting the nation's overall economic status. The inner structure and characteristics of an IR system focus on the rule-making aspects of the workplace and work community, which may be direct outcomes of societal influences, other environmental factors, or negotiations between employers and unions through mechanisms such as collective bargaining, joint consultations or tripartism. These mechanisms, as discussed by Dunlop, can help form the IR system, but they do not necessarily amount to any specific or predetermined outcome, mainly because an IR system will be constrained by its environment. For instance, utilizing a joint determination process for creating workplace rules does not necessarily assume an equal participation from management and workers in the rule-making process. Collective bargaining, though it portrays, or at least can be perceived as, the principal process for setting employment terms and disputes, is not inherent in an IR systems model. It is the rules that will always be the basic element of an IR system (Dunlop, 1987).

In view of the rule-making process, one might argue that if these processes are to be adopted from advanced and industrialized economies for use in smaller and developing nations, their effectiveness will largely be dependent upon the leaders and rule-making authorities of that particular industry or nation. In addition, the actors' relationships 
within the system will invariably be constrained by various environmental factors that may often lead them to make rules that are not necessarily in the best interests of all parties. These constraints and environmental contexts may also vary from one country to another.

\subsection{The major components of an IR Systems Model}

Dunlop identifies the major components of an industrial relations system as:

1. The actors (workers and their organisations, management, and government).

2. Contextual or environmental factors (labour and product markets, technology, and community or "the locus and distribution of power in the larger society" [from Dunlop's Industrial Relations Systems]).

3. Processes for determining the terms and conditions of employment (collective bargaining, legislation, judicial processes, and unilateral management decisions, among others).

4. Ideology, or a minimal set of shared beliefs which enhance system stability, such as the actors' mutual acceptance of the legitimacy of other actors and their roles.

5. Outcomes, including wages and benefits, rules about work relations (e.g., standards for disciplinary action against workers), job satisfaction, employment security, productive efficiency, industrial peace and conflict, and industrial democracy.

The precise nature of the relationships among the various components of the systems model may vary significantly with the level of analysis and from one system to another. 
For example, at an enterprise level, the rules may be best understood as an environmental ('contextual') constraint upon the immediate parties to the employment relationship (workers, management, and possibly unions). This suggests that the rules are the outcomes that, in turn, influence the inputs (albeit in a later period) through their effect on the environment ('context'). At the national level, IR system or systems legislation can be viewed as a process by which the relevant parties (via the state) establish terms and conditions of employment, or the rules that workers and management must abide by in establishing those terms and conditions. Thus, when comparing IR systems at any given level of analysis, the roles of the various actors may differ (Encyclopedia of Business, 2009). For example, unions may play a critical role in one system and virtually no role in another. The extent to which the actors' roles in influencing employment decisions may also vary across industries within a nation perhaps is best illustrated by public sector employment, where the government is also the employer.

As an open system, the IR systems model has proven useful and endured in that it can be extended and modified to include other critical environmental factors: such as the prevailing national culture, the actors' leadership styles, and the strategic choices that leaders make in sustaining that system. One example of how an IR systems model can be extended is noted in Meltz (1991) with his inclusion of the role of cultural values in his distinction of environmental factors.

\subsubsection{The actors in an IR system}

Dunlop identifies the actors as (1) a hierarchy of managers and their representatives in supervision, (2) a hierarchy of workers (non-managerial) and their representatives that 
exist in the form of unions, work councils and other forms of representation, (3) specialized government agencies (and specialized private agencies created by managers and workers) concerned with workers, enterprises, and their relationships.

The first two actors as described by Dunlop are directly related to each other in the sense that managers are responsible for giving instructions and for the day-to-day management of the workforce, and workers are employed to serve the means of the management by following managerial instructions in the performance of their prescribed duties. Although workers may be said to be 'unorganised' at some earlier stage in the employment relationship, they will eventually develop certain norms, conduct, culture and attitudes toward managers that will, in turn, cause them to be an 'organised' group. In other words, the values and norms that workers themselves develop at an earlier stage of the employment relationship, often through informal and social networking with their like-minded peers, will later define who they are and what their roles might be in the employment relationship. As Dunlop (1958) puts it, '...workers in a continuing enterprise are never unorganised. The formal hierarchy of workers may be organised into several competing or complementary organisations, such as work councils, unions, and parties' (p. 8).

The hierarchy of managers, as Dunlop explains, need not necessarily be defined by their ownership of capital or business, as managers may be employed in the public or private sector, or perhaps through a combination of the two. Managers' roles and authority in the rule-making process within an IR system may also vary significantly among various sectors of industry. Dunlop describes the specialized government agencies as performing various and distinct functions within the system, depending on the scope of 
their responsibilities. In some IR systems, the specialized government agencies may have broad and decisive functions to override the hierarchy of managers and workers. As an example, the state may pass laws regarding a minimum wage and other conditions of employment without engaging in any form of confrontation with employers and worker representatives. If that is the case, the decision-making capacity of managers and employees concerning these employment matters may be minimal. In other IR systems, the role of specialized government agencies, at least for many purposes, may be as minor and restricted as to allow managers and workers to directly deal with their relationships without reference to government agencies. In other systems, the hierarchy of managers or workers may be assigned a relatively narrow role (Dunlop, 1958).

The distinctions and variations among national IR systems may be attributed to various factors such as the differences in management (and union) ideologies, national cultures, strategic choices and the underlying principles that define the actors' roles in the system. For instance, Flanders (1970, p. 93) observes that the origins of differences in national systems are to be found in "certain underlying principles, expressing value judgments, which are broadly accepted throughout the nations". These underlying values, as defined by Flanders (in Britain they were economic freedom and peace), have institutional consequences.

By establishing processes that allow workers' emancipation in order to express a legitimate voice and that allow differences to emerge, managers will be able to channel such differences into more productive outcomes for employers and employees. As Gollan, Markey \& Ross (2007) observe, new forms of institutions: such as work 
councils, joint management, empowerment and quality circles, serve as recognition that value creation is an essentially social process and that organisational sustainability depends on legitimate social governance.

\subsubsection{The contexts of an IR system}

Dunlop identifies the actors and their organisations as located within an environment: defined in terms of technology, labour and product markets, as well as the distribution of power in wider society as it impacts upon individuals and the workplace. While these features of the environment are determined by the wider society and its subsystems (for example, economic, political), they are not explained within an IR system (Dunlop, 1958).

The first environmental context as explained by Dunlop is the technological characteristics of the workplace. These have far reaching consequences, as they can influence the form of management and employee organisation, the problems posed for supervision, many of the features of the required labour forces (including the skill level and the education required of the workers), and the potentialities of public regulations (for example, occupational safety and health regulations, business conduct and ethics laws, etc). Further, the technological characteristics of the workplace often determine a range of other factors including the size of the workforce, the product and services to be provided and their essentiality to the health and safety or the economic development of the community as a whole, the location of the business, the stability and duration of employment and so on. 
Dunlop's second environmental context is the market and budgetary constraints facing the organisation. While these constraints are usually a direct concern of the managerial hierarchy, they will necessarily condition all others in the system in the sense that workplace rules and decisions affecting employment relationships are susceptible to market conditions. In modern society, the highly competitive global market puts considerable pressure on organisations, especially those operating in small economies, and on nations to compete, thus affecting national decisions on the type of IR systems to implement. Budgetary constraints may also pose enormous challenges on the ability of the enterprise or the nation to produce sophisticated and high quality products, which in turn can affect the employment prospects for workers with regards to secure and longterm employment and reasonable wages.

The third context is the locus and distribution of power throughout the wider society, within which a particular IR system exists as a subsystem. Dunlop describes the distribution of power among the actors in society as reflected within the IR system; each actor's prestige, position and access to the legitimate authority within the wider society serves to shape and constrain an IR system. For Dunlop, "the concern is not with the distribution of power within the industrial-relations system, the relative bargaining powers among the actors, or their controls over the processes of interaction or rule setting. Rather the reference is to the distribution of power outside the industrialrelations system, which is given to that system" (Dunlop, 1958, pp. 11-12).

\subsubsection{The ideology of the IR system}

The ideology, or set of ideas and beliefs commonly held by the actors, helps to integrate the system into wider society. The ideology, or in Kerr's (1983) term 'shared 
understandings', is a body of common ideas, created by the system, that defines the role of each actor and defines the ideas that each actor holds toward the place and function of the others. The concept of the system ideology is expanded on by Kerr (1983), with the idea that each of the actors in an IR system may have their own individual ideology. However, 'an IR system requires that these ideologies may be sufficiently compatible and consistent as to permit a common set of ideas which recognize an acceptable role for each actor' (Dunlop, 1958, p. 8). For instance, in Great Britain, the philosophy of 'voluntarism' can be generally regarded as the common and accepted set of ideas that defines the roles of the actors within a particular system (see Flanders, 1965; Flanders \& Clegg, 1954). The voluntarism ideology is essentially that managers and employees and their representative institutions should be left to resolve problems, difficulties and conflicts on their own without the intervention of government and, in particular, without the intervention of the law (Leat, 2007, p. 28).

\subsection{The conversion process: feedback loop}

In the IR system, as with any system, the inputs are converted into outputs: such as the rules governing work and work relationships, wage rates and industrial democracy to name a few. This conversion occurs through the application of various processes, including collective bargaining, joint determination and the unilateral rule-making authority of management. At the time of Dunlop's writing, the most dominant process in the USA, the UK and other industrially developed countries was collective bargaining: a process through which the parties involved, namely the employers and trade unions, seek to resolve industrial disputes and jointly establish work rules, both substantive and procedural (Leat, 2007). Other processes include the unilateral determination of rules and dispute resolutions by either party, through the process of 
conciliation or arbitration. The state may also intervene in the settlement of disputes and in determining rules through the mechanism of state legislation.

Within the IR environment, actors interact with each other, negotiate and use economic and political power in determining the rules that are the output of an IR system. Dunlop classifies these rules as substantive and procedural rules. Substantive rules are outcomes, such as the rate of pay and hours of work that are determined by the procedural rules. Procedural rules comprise both the rules governing the determination of the rate of pay (substantive) and they have the function of setting procedures and processes that govern the behaviour and interaction between the participating parties in order that they may reach decisions or make rules. Flanders (1965) provides a useful description of substantive and procedural rules in the clauses of a collective agreement. On the one hand, the procedural clauses regulate the behaviour of the parties (i.e. trade unions and employers or their associations) to the collective agreement as they deal with the methods to be used and the stages to be followed in the settlement of disputes. The substantive clauses on the other hand are concerned in particular with the rates of pay and other conditions of work, the segments covered by the collective agreement. As Leat $(2007$, p. 7$)$ states, 'while the rules are the outcomes of the system, they are also the product of a range of inputs and utilization of particular processes for the determination of the rules and for the resolution of conflicts'. In addition, the processes through which the rules of the work community are determined may vary considerably from one country to another as to the precise nature of the environmental context in which the IR system exists (Locke, Kochan, \& Piore, 1995). 
Some writers have criticized Dunlop's emphasis on the 'rules' as essential in any IR context. For instance, Roche's (1986) criticism of the systems model is that it is geared literally to the study of rules alone, and overlooks the relevance of other social processes in an organisation, such as the balance of power between the unions and management, the notion of control in the workplace, and the level of trust between the parties. Indeed, one of the main criticisms of Dunlop's systems model, in particular, the emphasis on procedural rules, is that it is more concerned with a descriptive approach in explaining how unions and management work within given rules and institutions than with seeking to explain why employment relations develop as they do (Briges \& Villemez, 1994; Margerison, 1969). Such descriptive approach, notes Marsh (1969, p. 261), is now 'not the most highly praised academic technique, though it was that used by the Webbs (Webb and Webb 1897) whose Industrial Democracy became such a landmark in the industrial relations field'.

It is argued that any change in the rules governing the performance of work inevitably raises issues of the relative power of the actors to achieve an alteration of the rules that is advantageous to them. The sources of power held by each actor enabling them to influence work rules may arise from the environment, for example the strategic position of certain groups of workers in relation to the technology of a plant, whereas some belong to the actors themselves, such as the capacity of management to close a plant or the workers' capacity to strike (Dunlop, 1958). The 'power of the actors' in the larger society (as Dunlop puts it), especially the links between the actors and political parties and power-groupings in the community, are also critical as these links can have significant effects on the rule setting process. Kirkaldy (1947) argues that industrial relations in any given country is intimately connected with the forms of its political 
government; and the objective of an industrial organisation may vary from purely economic to purely political ends.

Although the power held by each party can influence rule and decision-making, it is essential to note that an IR system does not presume an equality of power of influence among the actors in that 'even if the workers were devoid of any voice or organisation, an IR system would still set the rules of the workplaces with the involvement of the employers and government' (Markley, 1993, p. 2). The rules that govern behaviour in the workplace and work community could be expressed in a variety of forms. For example, they could be regulations produced by its managerial hierarchy, the rules laid down by any worker (or union) hierarchy, the order of governmental agencies, collective agreements and the customs and traditions of the work community (Jackson, 1991). As Flanders (1965) points out, the procedural and substantive rules regulate different sets of relationships. Relations that are usually regulated by procedural rules have sometimes been called collective relations since they involve representative organisations, but they are not confined to trade unions and employers' associations. The state, society, management and work groups can also participate in collective relations.

\subsection{Debates surrounding Dunlop's systems model of IR}

The literature on IR has provided some useful insights into IR systems: in particular, the debates that have contributed to our general understanding of IR systems and more importantly, the endless efforts of critics to identify the limited applications of Dunlop's IR systems model. For the most part (Schienstock, 1981; Shalev, 1980; Singh, 1976; Walker, 1977), the systems model has been criticized for its lack of theoretical content 
in spite of Dunlop's appeal, from the outset of his inquiry, that he did not intend to devise a theory of IR. In a similar vein, Adam (1991) criticizes the model for its inability to stimulate hypothesis-testing research, but as Meltz (1991) observes, this is due to a lack of interest among industrial relations scholars in testing hypotheses. Further, some criticisms of the IR systems model include judgments such as the claim that it is too static and thereby fails to specify how changes occur in IR (e.g. declines in unionism); that its view of ideology is too simplistic; or that it is too deterministic or does not encourage sufficient appreciation for strategic choices made by the actors (Howard \& Palmer, 1993).

While a number of people have argued that there is considerable merit in Dunlop's work (see Craig, 1970; Dülfer, 1996; Flanders, 1965; Kerr, 1983; Kochan, Katz, \& McKersie, 1986), some have noted that the systems model is deficient in certain respects and that modifications are essential. Dunlop's systems model has gained the support of some British writers: such as Flanders, who defines IR and systems of IR as a study of institutions of job regulation. He argues that the core of an IR systems model involves the study of certain regulated or institutional relationships in the industry and that not all relationships associated with the organisation within an industry are relevant. The systems model does not include, for example, the cartel agreements among firms or their trade associations, or the relationships which they have with their customers and with the community at large. Further, he notes that an IR systems model is only concerned with matters that are directly associated with the employment functions; the relations between the business enterprise and its employees and among employees themselves. The relationship between employers and employees is to be placed in the legal setting, usually in the form of contracts of employment, which represent, in 
common speech, jobs. He argues that an industrial relations system is best viewed as one of the rules that appears in different guises: in legislation and statutory rules, in trade unions legislation, collective agreements and arbitration awards.

An IR systems model, as described by Dunlop (1958) and in a similar vein by Flanders (1965), is criticized by Bain \& Clegg (1974) who suggest that there are two central defects in the systems approach. First, an IR system should be regarded as a model, within which facts about employment relationships may be organised, and must not be misunderstood as having predictive values in itself. For instance, Dunlop's view of ideology, or the set of ideas that binds the system together, might be taken to imply that an IR systems model is 'actually' stable and integrative and 'necessarily' strives to perpetuate itself. They argue that Dunlop's emphasis on 'ideology' suggests that sources of conflict and cooperation, order and instability in an IR system are being ignored, when they may in fact be of equal relevance to the problem. A similar view is expressed by Hyman (1975) who argues that stability and instability must be treated as of equal significance as system outcomes. Second, the systems model largely omits behavioural variables (e.g. human motivations, perceptions and attitudes) that are essential to the full realization of the actors' values, beliefs and goals. While it would present an enormous challenge for researchers to include all variables, because of the extent to which the analysis may vary among sectors or among nations, to ignore the aims and interpretations of the actors would seem to hinder significantly an understanding of job regulations. Thus, if IR operate as a system at all, it is a much more open system than in Dunlop's model. 
Blain \& Gernard (1970) generally accept the systems model as useful, but also point out that:

The focus is on the structure of an IR system and ignores the 'processes' which are the behavioural dynamics of the system. In the model, the actors are viewed in the structural rather than a dynamic sense. Although they are the 'doers or reagents' they are presented as formal or informal organisational hierarchies, rather than behavioural mechanisms that are themselves in a continuous state of change. Because the actors in any industrial relations system are seen mainly as organisational phenomena, the model does not explain how they determine the processes of the system (p. 390).

Similarly, Hyman \& Brough's (1975) critique of the systems model also identifies the dynamic nature of social relationships and the need for an historical dimension. They argue that IR systems are far from being compatible, integrated and stable, but rather are full of contractions that could be exploited by the conscious organisation of workers in the face of change. To describe industrial relations as the study of a system of rules (Dunlop, 1958) or as a study of the 'institutions of job regulation' (Flanders, 1965) is to 'focus on how conflict is contained and controlled, rather than on the processes through which disagreements and disputes are generated' (p. 11).

Somers (1969) criticizes Dunlop's IR systems model for its simplicity, hence its failure to identify the complexities of the processes by which, according to Somers, certain inputs should produce certain outputs. Somers has argued that,

Although Dunlop may be able to show a relationship between certain types of environmental context and certain rules and decisions at the workplace, his system does not trace any sophisticated process by which the inputs must result in the outputs. He can do this only in the most rudimentary fashion because rules and 
decisions are products of the minds and emotions of men, and they result from the environmental changes only as these changes are registered in the minds and emotions (p. 20).

The critique of the systems model due to its simplicity has influenced the work of others: for example, Craig's (1970) construction of an input-output model. Craig was confronted with a question of how the environmental forces (cultural, legal, economic, etc.,) interacting with the actors' goals, values and capacities through certain processes (collective bargaining, unilateral action by management or labour) result in the rules which are the output of the system. When Gill \& Golding (1980) put Dunlop's systems model in a 'test' as a training intervention in management education, they criticized the model for its lack of attention to 'history', either as an 'external' or 'internal' environmental influence. In response to this criticism, Walker (1981) points out that Dunlop's systems model (and alternatively, Craig's input-output approach) is inherently historical in nature. For example, the output of the system feeds back on the system, possibly producing change, and in any case, there is no reason why any element in the system should not change over time. "History is in the actors, not only in the environment, in the form of attitudes they absorbed during their lifetime, and perhaps in the form of historically hallowed objectives or values" (Walker, 1981, p. 25). He argues that Dunlop's idea of power distribution, within and outside an IR system, reflects the goals and values of the actors and the degree to which these are sufficiently compatible to permit an IR system's continued existence. This suggests that if the goals and values of some actors reject the possibility of any role at all for one or more of the other actors, there will be no IR system, only a political one. For example, where unions are seen as "transmission belts" for the ruling party, as in Communist countries and corporate 
states, the state ensures that industrial relations are part of the apparatus of the state (p.25).

Leat (2007) views the systems model as a mechanism for securing the objectives of the parties involved: whether this constitutes, for example, the resolution of conflicts between immediate parties and their representatives; the participation and involvement of workers in decision making or control of the labour process; the handling of grievances and the management of discipline; or the pursuit and achievement of equal opportunities. Wood, et al., (1975) share a similar view of an IR system as a rulemaking 'action' system and not as a system of rules per se.

The question of whether the systems model can be applied in any national context and whether it can facilitate the analysis of distinct national cultures serve to highlight the processes of convergence and divergence as well as the strategic choices made by the actors. Dunlop, in association with Kerr, Dunlop, Harbison, \& Myers (1960), notes that technology and other homogenizing forces resulting from industrialization would generate convergence in IR systems, although various offsetting forces would lead to continuing diversity. Doeringer (1981) argues that there is convergence in a broad sense, as countries develop alternative solutions to problems common to all industrial relations systems. Differences observed among IR systems are not simply random, but are rooted in the responses of individual countries to the pressure of industrial evolution. Williamson (1981) presents a view of market pressures as the driving forces behind institutional convergence, as nations and organisations seek for the most effective and efficient means of utilizing labour. For Dunlop, the international differences in IR systems reflect the vast differences between nations in the locus of 
power and the distribution of rule-making authority among managers, the state and workers' organisations (unions).

Kerr, et al. (1960) observe that this diversity will be reflected in the rules derived from the policies and ideologies of industrializing elites. In their view, the two most influential forces for continuing diversity in industrialization are a clear ideology held by the ruling class and a persistent, recognized series of national traits developed in earlier times. However, they also argue that the forces causing uniformity among different nations become stronger than those enabling diversity; ideological differences tend to fade as the various cultural patterns existing in the world interact and merge. Pluralistic industrial society will be one in which the struggle between uniformity and diversity continues, but which 'develops a common cultural consensus' (Kerr, et al., 1960, p. 249). This observation may explain Dunlop's lack of attention to the role national cultures play in IR systems, as he makes no mention of culture. It may also explain his emphasis on the distribution of power in wider society as the key to understanding cross-national differences, particularly in the prescribed status of the actors. Thus, it has been argued that it is the locus and distribution of power in wider society, which structures an IR system itself and defines the status of the actors, that is likely to be the most important of Dunlop's contexts in influencing the characteristics of distinctive national cultures. National cultures play a negligible role in industrial relations systems.

For Poole (1993), variations in IR systems and practices across countries have their roots in the strategic choices of the parties. The strategic choice theory advanced by Kochan, McKersie, \& Cappelli (1984) was developed at a time when industrial relations 
in the U.S. were changing rapidly. For Kochan, et al. (1984) a major problem with Dunlop's systems model lies in its view that a shared ideology provides stability to the system: in the sense that, the rule making process creates experts on both sides whose common experiences and interactions inevitably lead to shared understandings. They also point out that an IR systems model tends to focus more on the events at the bargaining level (i.e. national or industrial level), and therefore fails to recognize that important decisions are made at other levels (enterprise or managerial levels). The traditional IR systems models (Dunlop's included) treat unions as a permanent participant in the worker's employment relationship and view management as simply reacting to union demands, pressures, and initiatives (Kochan, et al., 1984).

Although the strategic choice theory may have been successful in providing an alternative means of theorizing, it can be viewed primarily as an extension of the IR systems model; therefore it is not inconsistent with the traditional theories of IR or Dunlop's systems model. The IR processes and outcomes are said to be determined by a continuously evolving interaction of contextual pressures and organisational responses, and the relative importance of either the context or the parties' responses can vary over time (Kochan, et al., 1984). For example, Lewin (1987) notes that the majority of managerial decisions that have been referred to as strategic choices can easily be viewed as managerial responses to relevant forces in the external environment. He argues that pressures from domestic and foreign competition may induce management to make adjustments in their competitive business strategies by improving the quality of their products and services offered, and by reducing costs (labour or otherwise). These pressures can be seen as strongly influencing employers' to avoid negotiation with unions. Labour or product market changes do not have independent effects, nor do they 
operate in a unique or deterministic fashion. This is also true of the choice and discretion on the part of the labour force, management, and government because they condition all other elements of an IR system.

Similarly, other theorists (see for example, Clark, McLoughlin, Rose, \& King, 1988; Marchington \& Parker, 1990) refer to the strategic choice approach as valuable in highlighting variations amongst employers and across national systems of industrial relations. They point out that parties are essentially 'social actors' who shape the institutional arrangements in which they operate. Their choices are inevitably influenced by culture and political ideology, as well as by economic and public policies. They are limited in their formulations of policies, implementation of rules and formation into groups by economic, political and social structures; by organisational and institutional forces; and by the distribution of power (Poole, 1986).

As with Kochan, et al.,(1984) strategic choice concept, Leat (2007) points out that the relationships among actors within an IR system occur in three different layers of contexts; the international, national and organisational contexts. He considers the interactions between various layers of contexts to operate as two-way processes: as such,

'...the international context exerts influence upon the national context and thereby upon the organisational context and the employment relationship itself, yet the interactions within the employment relationship produce outcomes which become a part of the national context' (p.30).

He suggests that within an organisation, the values and beliefs held by managers and workers influence each party's expectations and perceptions of their interests and nature 
of their relationship. These are likely to also determine management styles and approach: for example, the managers' attitude towards unionism, whether they are prepared to share power and control with workers, and whether they are willing to employ mechanisms for the joint determination of work issues and resolution of conflicts. For workers, their interest may exist in the form of collective organisations with the expectation that they will be provided with the right to participate in decisions affecting their employment and the right to be treated fairly, with dignity and respect.

(Turner, 1991), in support of the systems model, argues that there are two factors essential in discussing the variations in the stability and extent of the representation of workers' interest in response to contemporary change. First of these factors is the extent to which unions are integrated into processes of managerial decision-making, as opposed to being engaged in adversarial, arm's-length unionism. The second factor is the presence or absence of laws or enterprise bargaining arrangements in encouraging and regulating firm-level union participation from outside the firm. For Turner, it is the way that unions influence decisions that is institutionalized in an IR system, not the employer's strategies or values.

Clegg (1976) challenges the Dunlop-Flanders tradition of job regulations to analyze the behaviour of trade unions in determining the interests of workers in the labourmanagement relationship: in particular, the nature and scope of trade union activity. For Clegg, collective bargaining is limited in application as it is identified as the foremost determinant factor for analyzing union behavior: at least in those countries in which job regulation is the dominant approach. 
For Dunlop, employers and unions are more than capable of resolving their own conflicts without the need for assistance from the state (or state agencies). Thus, a basic theme implicit in Dunlop's activities over more than four decades, and frequently expressed in his speeches and papers, is the value of resolving disputes by a consensus developed through effective negotiations. In this respect, employers and unions are seen as possessing the legitimate power and expertise as well as in-depth knowledge and information about a range of issues and problems within the employment relationship, as opposed to an industry outsider, who does not possess any of these attributes. This suggests that the majority of conflicts between employers and unions are often complicated, requiring more time, effort and resources and that it is unlikely either one would accept totally losing out to the other. Yet, since both parties are constrained by their environments, they will eventually arrive at a consensus where both can maximize their interests within their own means. In his presidential address on National and Consensus Labour Policy in 1960, Dunlop notes:

In a democratic and pluralistic society the government is seeking to impose on parties to collective bargaining by statute and administrative rulings a set of standards and conduct which in many respects is highly unrealistic. To remove the parties from any significant responsibility for the formation and administration of policy is destructive of the character of our society, leads to impractical and unreal policies and to mass evasion and disrespect. Such is the state of government labour policy.

Furthermore, the actors in Dunlop's model are supposed to behave as homogeneous groups with regards to their interests and their bargaining power. This assumption is rejected by Dülfer (1996) who argues that it does not correspond with the realm of the work relationship, in which remarkable differences in interests and even conflict positions can occur within individual groups of actors. In view of the debates hitherto, 
whilst collective bargaining may be viewed as an ideal process for determining the rules of the work community in many societies, its usefulness and implications are notably varied among different cultural and political environments. As Wood (1978) has noted, rather than to view an IR system as problematic and something that needs to be achieved, that system should embrace the generation, construction and solution of the real issues of the world as its driving force and thus move beyond a confined focus on rule-making and collective bargaining.

\subsection{Review of literature on IR systems in South Pacific Island nations}

Little has been written about IR systems in PICs, and to a remarkable extent there is a limited application of Dunlop's IR systems model in analyzing employment relationships in small island nations. In a study of employment and IR in the South Pacific by Prasad, Hince, \& Snell (2003), a number of common themes (as well as some distinct ones) have emerged that may be best understood and analyzed using Dunlop's systems model. Besides the fact that Prasad, et al.'s (2003) study is so far the only relevant piece of literature on employment relations and IR systems in small island nations, the study has been very useful in providing a general overview of IR in the context of PICs. Prasad, et al.'s study is comprised of a descriptive analysis of the industrial relations systems in Samoa, Tonga, the Cook Islands, Kiribati, Solomon Islands, Vanuatu and Fiji Islands.

Prasad, et al. (2003) have directed their effort to the assessment of significant factors that are shaping the employer, government and worker relationship in enterprises, industries and across labour markets. In doing so, they highlight issues: such as 'transformation of employment relations through public sector and enterprise and 
diversification in the types of employment contracts', to be of particular interest for comparative analysis (p.1). These issues tend to form part of their research framework, alongside others such as the notably slow rate of development in small island nations of labour legislation and labour institutions (e.g. unions).

Prasad, et al. include in their methodology illustrative case studies and historical inquiries into traumatic events, such as strikes and other industrial disputes, in order to gain a better understanding of the actors' roles with regards to how employers and unions respond to or are affected by changes in government legislation or by the shift in economic policy among other things. In this way, they identify employers and trade unions as having played a wide range of roles in industrial relations systems, a fact that makes it more difficult to interpret and understand the choices actors make with regards to the rules of the workplace. The lack of worker participation in the establishment of workplace rules in several PICs may have an implication on the limited use of Dunlop's systems model for analyzing national industrial relations systems: in particular in small island nations where union activities are deemed to be considerably weaker.

Several PICs (Samoa included) currently operate under outdated and weak labour legislation, much of which dates from colonial times and fails to align with International Labour Standards (ILS). As well as promoting good governance, modernizing legal infrastructure in the area of employment is vital to the Pacific region's achievement of balanced economic, social and political development, which emphasizes both economic efficiency, and the wellbeing of the population as a whole. Central to this process of legal modernization will be the development of labour legislation that protects labour rights while providing a favourable environment for private sector development and 
facilitating the generation of new employment and income earning opportunities, particularly for youth. Such measures will be essential to poverty reduction strategies in PICs (Pacific Island Forum Secretariat, October 2007).

Globalization has brought major challenges to PICs in reforming labour legislation. With the passing of time and global development, labour legislation requires substantive change and updating (McDonald, 1997). This view has implications for convergence in industrial relations systems at the national level, particularly in PICs where there is a notably gradual movement towards the adaptation of worldwide labour laws and practices. The International Labour Organisation (ILO) convention, for example, may be viewed as one way of institutionalizing uniformity among national systems of industrial relations.

In many PICs, unions may be seen as insignificant for various reasons. First, there is ongoing concern about the lack of jobs relative to growing populations in PICs due to their limited resources, as well as the limited capacities of local governments and employers to create and sustain jobs (International Labour Organisation, 2001). Another emerging trend in industrial relations in PICs is the negative effects of liberalization policies (e.g. job losses) and the desire by governments and employers to reduce labour costs and improve flexibility as a basis for improving international competitiveness (McDonald, 1997).

Most PICs are characterized by large informal and subsistence sectors. In view of the high population growth rates in small island nations and low employment growth in the formal sector, the informal sector will continue to provide income opportunities for 
many Pacific Islanders. However, productive employment growth in the informal sector is currently affected by lack of commercialization of economic activities: in particular, lack of secure individual land tenure, resulting in difficulty for accessing commercial bank loans, lack of entrepreneurial skills and lack of innovating business ideas (Duncan \& Voigt-Graf, June 2008). As PICs represent small economies, compared with larger economies, these Pacific island nations have a greater reliance on overseas aid for development and external markets for provision of goods and services: this position of reliance, in addition to the limited base of production experienced by most PICs, puts them in a vulnerable position (International Labour Organisation, 2001). Such obstacles may be overcome by targeted political and regulatory changes, as well as a focus on training for the informal sector.

Formal employment in most of the PICs carries a very small proportion of the labour force and is largely concentrated in the public sector. Public sector concentration, particularly in the many government run Corporations, bears some responsibility for the poor economic performance of PICs, in part because public sector wages may be set at levels that are not justified by worker productivity. The monopoly position granted to government corporations and their comparatively high wages have 'crowding out' effects on the private sector by raising private sector wages (Asia Development Bank, 2007). Thus suggests that public sector wages should be based on private sector wages and not the other way around.

Drawing from these discussions, it can be argued that the nature of IR systems in PICs may in various respects differ considerably to those of industrially developed nations. This difference in large part is due to the lack in many PICs of necessary resources and 
financial means afforded by their governments and due also to a lack of sufficient levels of domestic demand or skilled workers to establish large domestic industries as a "springboard" to transform PICs into market-driven export economies.

\section{Summary}

The last few years have seen theorists merely trying to broaden the scope of industrial relations and thus present based on their perceptions and preferences, a history of the subject; study of this history shows that it has developed theoretically following the lead of Dunlop. An IR systems model has led theorists in industrial relations to concentrate on a specific aspect(s) of industrial relations to the extent that it opens up opportunities to explore a wide range of interpretations and viewpoints about the role each of the actors play in the system.

On the one hand, some may argue that the systems model represents a broadening and not a narrowing approach in that it recognizes the interdependencies between the industrial relations system and other elements of wider society. This has implications for a wider application of Dunlop's industrial relations systems model in any national setting. In another respect, because writers and critics of the systems model work with different methods and usages of the model, it is hard to claim that Dunlop's work will lead to an integrated industrial relations theory that could obtain wider consensus (Wood, 1978).

The preceding literature review has presented several interpretations as well as criticisms of Dunlop's systems model by industrial relations specialists. Firstly, the viewpoint put forward by Flanders recognizes the system of industrial relations as a 
system of rules and job regulations. Secondly, Bain \& Clegg, (1974) argue that rules are just one component of the IR system, which also consists of certain actors, certain contexts and ideology. The third viewpoint attempts to conceptualize the contexts (technological, market and political) as being the environment of an IR system, thus external to the internal workings of the system itself. These viewpoints do not entirely suggest anything different from what Dunlop devised in 1958; rather they tend to expand on Dunlop's IR model.

It is clear that Dunlop's systems model is not intended to be taken for granted or as a prescribed model. Rather, its usefulness is evident in the work of those who have taken on the challenge of either expanding on the systems model, in order to account for the variations among national industrial relations systems, or using it as the basis for historical inquiry into a particular industrial relations system. The fundamental principles such as the range of inputs, outputs and processes within the IR subsystem have remained relatively similar and/or unchallenged over the past decades. It is with the long-term consistency of its principles in mind that Dunlop's systems model could be considered useful in describing the IR system in Samoa. 


\section{Chapter Three: Methodological framework}

\subsection{Introduction to the chapter}

This chapter aims to provide an overview of the methodological approaches and research design selected for this study, in order to provide a broad description of the IR system of Samoa with specific emphasis on the process of making rules to affect industrial democracy and employee participation in decisions related to employment. The chapter begins by outlining the detailed step-by-step process that was undertaken to collect and analyse the data. This is followed by a brief overview of Dunlop's industrial relations systems model as the core framework for organizing facts and knowledge about the scope and nature of industrial relations in Samoa. Dunlop's systems model is used to describe, in general terms, the IR system in Samoa with regards to the role of the state, employers and employees, and their interrelationships within that system. Furthermore, the systems model is utilized to identify the key features of Samoa's IR system and consideration is given to the reasons why this system is rarely applied to the study of industrial relations and/or to understanding industrial relations systems in small Pacific Island Countries (PICs).

\subsection{Methodology framework}

The research is significantly descriptive in nature as its primary goal is to explore the purpose and scope of the IR system in Samoa with specific emphasis on the perceptions, values and expectations of the state, employer and employees about their roles in IR. A descriptive approach is relevant to the extent that it enables the analysis of mainly historical data related to the actors' behaviours, customs and practices, and to the actors' interactions with their socio-political and economic contexts. This 
methodology attempts to discover how the employers, employees and the state are influenced by, or have influence on, the type of IR system that is implemented. This approach may also help to uncover the reasons behind certain characteristics of the industrial relations system of Samoa that would distinguish it from other systems.

Cavana, Delahaye, \& Sekaran (2001) note that a descriptive study is undertaken in order to discover and be able to describe the characteristics of the variables that are of interest to the researcher in a given situation. Furthermore, they suggest that descriptive studies are conducted to gain an understanding of the characteristics of organisations that follow certain common practices. For example, the researcher might aim to identify and describe the characteristic features of the industrial relations systems that support union participation in the making of rules governing employment.

The following sub-sections detail the steps taken in order to obtain the data.

\subsubsection{Methods for collecting the data}

The construction of the research instrument took place over a period of less than two months from April through May 2009. There are two main methods employed for the data collection. The primary data are drawn first from face-to-face interviews with representatives from various government ministries and agencies, employer organisations and staff associations or unions, second from the International Labour Organisation (ILO) Workshop that took place in Samoa on 27 - 28 April 2009. The ILO workshop included a Tripatite panel discussion among the government and its agencies, 
employers' associations and employees towards formalizing a Tripartite Forum as part of the Decent Work Country Programme (DWCP) for Samoa. ${ }^{2}$

The secondary data was obtained through the analysis of a range of government legislation, books and articles (both published and unpublished) on employment issues in Samoa and PICs. In addition, various ILO progress reports on the recent developments in labour law and the institutionalization of various ILO conventions within member countries in the South Pacific were also sought for this study. These materials were considerably helpful in gaining an insight into the nature and scope of industrial relations systems within the context of small PICs.

\subsubsection{Methods for recruiting participants}

This research focuses on the views, perceptions and expectations of the three main actors in the industrial relations system of Samoa. Given the significant roles of the state, central trade union bodies and key employers in this system, it was essential for representatives of these organisations to participate in the study. In addition, representatives of several government ministries and state corporations, managing directors of both large and medium-sized businesses operating in Samoa as well as, in some cases, overseas, and leaders of trade unions representing various segments of the country's labour force were also invited to participate in this study. The inclusion of both government ministries and corporations was intentional. Although the two groups are legitimately government owned; their employment relation matters are governed under two separate legislation. The ministries are regulated under the Public Service Act

2 DWCPs have two basic objectives. They promote decent work as a key component of national development strategies. At the same time they organise ILO knowledge, instruments, advocacy and cooperation at the service of tripartite constituents in a results-based framework to advance the Decent Work Agenda within the fields of comparative advantage of the Organisation. 
of 2004, administered by the Public Service Commission (PSC), whereas for corporations, along with other privately owned companies, their employment matters are legislated under the Labour and Employment Act of 1972, which is administered by the Ministry of Commerce, Industry and Labour (MCIL). The participation of these two groups was critical in assessing the ministries' key roles in the establishment and implementation of labour laws in the public sector, as well as discerning their levels of influence on government legislation and their capacities to represent the workers more effectively, with the government in the role of both employer and regulator. Individuals representing those key actors in the system were invited to participate in the study based on conditions such as their familiarity with the socio-political structure of Samoan society, their access to privileged information about the workings of industrial relations in Samoa, or any previous or current participation in that system. Furthermore, those interviewed were likely to have been directly involved in IR, to have extensive knowledge of and insight into the IR system in Samoa, or a consequent combination of both.

Union participation was considered to be a key focus requiring that it was essential to obtain a valid sample in this respect for the interview. The selection of union participants specifically targeted those from unions with at least 50 or more active members. This presented a serious limitation on the sample selection, mainly because unions are a minority group in Samoa, thus having a very small proportion of the sample population to choose from. In the end, there were potentially 5 unions discovered to have 50+ members and were all invited to participate though not all of the 
five unions responded, for various distinct reasons. ${ }^{3}$ Those who were invited to participate in this study included; Yazaki Samoa Staff Association (YSSA), Samoa Medical Staff Association, Samoa Nursing Staff Association, National University of Samoa Academic Staff Association (NUSAS) and the Public Service Association (PSA).

With specific reference to business leaders who were invited to participate, on the basis that they were expected to have dealt with more complicated and challenging employment issues, the selection of those to interview was limited to organizations employing at least 100 employees. Some of these organizations were unionized, and others were non-unionized organizations and were suspected to have practiced a strategy of union avoidance.

Gaining access to potential participants was incredibly helpful for obtaining background information about the events and decisions considered in this study. Since the research was based in Samoa, the majority of the interviews took place there: with the exception of one, which was conducted in Wellington, New Zealand. The interview in Wellington, with a New Zealand Member of Parliament (MP), was organised through the secretary of his Wellington office. This interview took place on 17 March 2010, which was considerably later than the completion of all other interviews in Samoa. Due to the time constraints for these interviews, related to the required travel, it was absolutely

\footnotetext{
3 'Trade union' is used in this study to refer to staff associations. The term itself has been rarely accepted in the context of Samoan society, which may explain the lapse in any record of union (staff associations) registration. It was also difficult to define 'trade union' in Samoa due to the lack of explicitness in the level of union activity that staff associations may or may not pursue. Those who were invited to be interviewed were selected on the basis of membership, their status in the community, and most of all on the ground that they had some form of direct involvement in IR. For instance, some associations (e.g., PSA, Yazaki, Samoa, Medical Staff) have made a mark in history through their engagement in strikes, therefore they stood out as relevant participants.
} 
necessary to liaise with a senior government employee bearing easy access to the heads of government departments and to basic information for a range of managing directors. Finding a government liaison who would provide access information for potential participants was achieved immediately through a close relative in Samoa. The information required included the participants' names, and their matai (chiefly) titles, if applicable, their contact details (email was the preferred mode of communication but telephone numbers were also sought), their career positions and the organisations that they currently work for. It may be worthwhile noting that in the Samoan way ('fa'asamoa') it was very important to acknowledge the participants, in particular the heads of government departments, by their matai titles. This practice is seen as a gesture of respect ('va fealoai' or 'faa'aloalo') for those who are in higher authority. Doing so would provide an advantage to the extent of almost immediately ensuring their participation in the study. Indeed, it was quite fortunate on my part to have a close relative in Samoa that I could rely on to assist with the provision of this firsthand information. Thus, access to potential participants was organised through numerous phone calls, emails and skype communications made possible by the availability of this important family connection in Samoa.

Formal invitations for participation were forwarded to selected heads of various Government ministries and agencies, as well as to business and union leaders. These communications requested that the recipient either participate directly in the research or assign an appropriate spokesperson to represent their organisation (or group). The letter explained the research topic, the reason for undertaking the research, and how the information gathered from the interviews would be used (see APPENDIX B). The participants were also advised that a high level of confidentiality would be maintained 
at all times during and after the research. Name suppression would receive the utmost attention, including, if necessary, that a participant would only be identified as a representative of government or of their agency, employer or union. These terms were not relevant to the other participants who had been identified as independent consultants. A consent form (see APPENDIX C) also accompanied the letter of invitation in order to gain the participants' trust by providing them with all the information necessary for them to make their decisions about participating in the study.

For the formal interviews, 20 participants were selected and each received a complete 'participant information pack' comprised of the participation information sheet (or letter of invitation), consent form and the interview schedule (see APPENDIX A) for the interviewee's review and comment. The intended participants were asked to schedule their interviews as soon as was reasonably possible within the time frame specified in the letter: 23 April through to 14 May 2009, which was the entire duration of my visit in Samoa. Given the time constraints within which to complete at least 14 to 20 interviews, all the necessary arrangements (including scheduling interviews and accessing the participants' background and basic information) took place remotely from Wellington and through correspondence with a close relative before my departure to Samoa. Communicating with someone trustworthy who would effectively carry out these tasks in Samoa was one of my strongest priorities.

To ensure that the participants received their invitations to participate in the study, all of the information packs were hand delivered to the participants' offices, where they were then asked to sign for the release of their respective packs. All of the information packs reached the relevant offices within three working days, during the second week of April 
from the $9^{\text {th }}$ to the $13^{\text {th }}$. To confirm that interview appointments were organised accordingly, regular email communication with the participants was critical throughout the scheduling period. This was followed by phone calls from 19 April 2009 onwards, after I had arrived in Samoa. Personal visits to some of the employers' offices were attended later to finalise and secure their appointments, especially for those whom I had been unable to reach via the phone or email contacts provided for this purpose before my visit. Besides those instances, the majority of interviews were scheduled and confirmed within a matter of days following the participants' receipt of their information packs. The others who did not respond initially to the invitations before the interviews began were contacted twice or three times during the interviewing weeks. Follow-up phone calls to reconfirm the times and places for interviews were usually made a day before the interviews took place.

\subsubsection{International Labour Organisation (ILO) Workshop}

An unexpected opportunity emerged that allowed me to observe a two-day (27-28 April 2009) ILO workshop: hosted by MCIL. I was very fortunate to receive an invitation from the MCIL shortly after my arrival in Samoa at which time they heard about my research. At that time I had completed two interviews out of the intended 20. The first part of the workshop, which took place on 27 April, involved the government, employers' associations and employees' representatives in a Tripartite Panel discussion on social justice and globalisation. Attending the MCIL/ILO workshop had presented me with the opportunity to meet in person with two of my interviewees, who were then able to confirm their interview schedules. I was also very fortunate to be introduced to and engaged in casual conversation about my research topic with two prime government 
representatives and the Director of the ILO for the South Pacific Region, who offered to assist with the data collection if needed.

One of the highlights of the workshop was when I discovered that there was a formal body representing all employers (both public and private sector organisations) in Samoa, especially as I had just been informed otherwise by my first two interviewees. Due to my lack of knowledge and information about this employer-representative organisation, its members were consequently not on my list of participants, but upon learning of its existence I extended an invitation to the chairperson of the employers' association to participate in this study. Initially, I was politely turned down, but the chairperson eventually agreed for me to audio-record her presentation, a concession which I was quite happy with considering the circumstances that had led to our meeting. My confusion and lack of knowledge about the existence of an employers association in Samoa was partly influenced by the nature of my first two interviews: one with a government representative and the other with an independent consultant who opposed the idea of the employers association being passed as the appropriate representative for employers in the industrial relations arena. Both were prominent figures in society, so there was a tendency for me personally to rely on the information provided by them to be true. It was a side effect of the circumstances under which the association was established originally that most people assumed its role to be of a purely economic nature; this view indicated in particular that any discussions of employment matters (e.g., wages, working conditions, benefits. etc.) were the least of the association's concerns. It was argued that the association was more inclined towards exploitation of the economic avenues available to the country in order to increase local business capacities with the aim of expanding on their product markets overseas. However, it 
would be seen as unprecedented not to take note of the core values and objectives of the association as relevant to the study because it was perceived as playing a significant role in the economic sub-system, although it had virtually no role in the industrial relations system. Indeed, the workshop provided me the opportunity to draw my own assessment of the role the employers association was playing in the industrial relations system in Samoa, whilst also taking into account the concerns of the PSA and government as well as their views about the economic factors that had affected the industrial relations system of Samoa.

On the night of 27 April 2009, I was invited to a function that was held in celebration of the ILO's $90^{\text {th }}$ anniversary of working for social justice. This included the launching of commemorative stamps to mark the event. The function was attended by various prominent figures in Samoa. Among the attendees were cabinet ministers, government officials, heads of various government ministries and corporations as well as ILO representatives. The Prime Minister delivered the keynote address of the night, which was to my advantage as he spoke about the nature of the industrial relations system in Samoa and why it would always be a unique system compared with that of other PICs. The Director of the ILO for the South Pacific Region also gave a brief overview of industrial relations issues faced by Pacific island nations which was found to be very useful.

Following the tripartite panel discussion on social justice and globalisation on 27 April, the second phase of the workshop, which took place on 28 April, involved various industries and sectors of the work community in an Occupational Safety and Health (OSH) programme. This programme was also hosted by the MCIL. The OSH 
programme was intended to raise awareness about the OSH Act of 2002. This was followed by the signing of the "Samoa Decent Work Country Programme (Samoa DWCP)', by the tripartite constituents (i.e. State, Employer and Employee) that also took place on 28 April. The signing was a core part of the ILO $90^{\text {th }}$ celebrations in Samoa. Besides the official recognition of the tripartite arrangement under the Samoa DWCP, the adaptation of OSH legislation was also seen as a key recent development in industrial relations in Samoa. The workshop had been both an intriguing and a fruitful experience to the extent of becoming one of my main sources for gathering relevant and factual information about my topic.

\subsubsection{The interview process}

The participants were given at least two weeks to review the interview schedules prior to their interviews. The interview schedule consisted of 10 predetermined questions. Although it was prepared to ensure that basically the same information was obtained from each person, there were no predetermined responses. With the use of open-ended and semi-structured interviews I was free to probe and explore within those predetermined inquiry areas. Interview schedules ensured good use of limited interview time; they made interviewing multiple subjects more systematic and comprehensive; and they also helped to keep my interactions with the interviewees focused. Submitting the interview schedules to the participants for their comments prior to the interviews attracted both positive and negative responses: for example, some complained that the wording of the questions was difficult to follow. This response is both positive and negative because it highlights a flaw in the questions, but also enables me to fix the problem by simplifying the questions during the interviews. 
In the letter of invitation, the participants were asked to review the questions and email me any concerns they may have had with the interview questions. However, most comments about the questions were made only on the day of the participant's interview. For most participants, being provided with the interview schedule beforehand gave them the opportunity to properly prepare themselves; some still improvised their responses while others had gone as far as writing down their answers for each of the ten questions. Some of the participants found the interview schedules to be helpful as they not only gave them the feeling of being in control of their interview, in their view it also facilitated their ability to research and prepare on the topic so as to reduce or avoid the likelihood of giving vague or meaningless responses.

Two people found the wording of the questions to be technically difficult and they felt that they would not be the right people to be interviewed for the study. Another candidate, a union spokesperson felt that the questions had prompted a lot of negative feelings towards management, thus he was concerned about revealing intimate details about the employer that could potentially adversely affected his employment, particularly at a time when major economic recession had threatened the security of jobs.

The feedback I received from the interview participants was invaluable and for those experiencing difficulties with the questions I immediately addressed any issues individually via email. Those who found the questions to be too complex were reassured that the questions would be rephrased and simplified during their interviews so they could get a good grasp of the intended meanings. A reinforcement of the participants' rights to confidentiality and name suppression was once again 
communicated to all participants, with particular emphasis for the participant concerned about losing his job if he revealed too much information about management. Despite this effort, this participant chose to avoid talking about the role the association plays in the IR system in general, or the establishment of rules in his place of work. I had the impression, from his tendency in the interview to speak only of praise for management and owners and of how Samoan people should be appreciative of the fact that the company provides employment for many people, that his answers were not entirely genuine.

It was also discovered that by giving the interview schedules to participants before their interviews, most would be encouraged to cover three or four questions all at once without having to wait for me to ask each question in turn. This practice apparently reduced the actual number of questions I was required to ask as most participants would talk more openly and confidently about the topic; yet at the same time it also put me in an awkward position as I often had to quickly scan the questions in order to avoid asking those that had already been answered in this way. Very rarely would I interrupt the interviewees unless it was absolutely necessary, as when the interviewees began to drift too far off the subject matter.

In keeping with the flexible nature of qualitative research design selected for this study, the interview schedule was marginally modified over time to focus attention on areas of particular importance and to exclude some questions, which were considered to be unproductive for the goals of the research. 


\subsubsection{Participants' response rates}

A total of 13 formal interviews (twelve in Samoa and one in NZ) took place at locations and times nominated by the interviewees. The majority of interviews took place at the participants' offices in central Apia (the capital city of Samoa), where most of the government ministries' offices are located. In fact, most of these offices are housed within the same building. This fact made my job easier and on one occasion I managed to carry out three interviews in one day. Each interview lasted between 50 and 60 minutes. This time frame coincided with the initial proposal, with the exception of two interviews that lasted 90 minutes. The 90-minute interviews were intentionally extended, as some follow-up questions, which were not included in the interview schedule, were needed, in order to gain a better understanding about the workings of the industrial relations system of Samoa. Furthermore, those particular interviews were important because of the distinct roles these interviewees' had played in the establishment of the IR system in Samoa, with the first interviewee representing a state agency and a labour law making authority for the private sector industries, and the second interviewee was a former executive member of the PSA and a union activist who spearheaded the labour movement that led to the establishment of the Samoa National Union of Workers (SNUW) in 1995. In their prior roles and level of participation in IR in Samoa, the interviewees have gained an extensive wealth of knowledge about the workings of the current system and this knowledge made their contribution significant for the study.

The face-to-face interview method not only allowed me to adapt questions whenever necessary, it also helped to clarify any doubts and to ensure that the interviewees properly understood the questions as I could either repeat or rephrase them as needed. It 
also permitted, where appropriate, for more complex questions to be asked compared with other methods of data collection. The use of open-ended and semi-structured interviews encouraged the participants to discuss more openly their experiences with, and perceptions of, Samoa's IR system, while at the same time enabling me to observe, listen, record and later extract details about that system from the participants' responses. All interviews were audio-taped and subsequently transcribed in full.

As illustrated in Table 1, the participants were grouped into three main categories: employers (both in the public and private sectors), trade union members and the state; a fourth group was also considered, formed by the independent consultants (or those classified to fall outside of the strict definition of actors in IR: employee, employer \& state). The independent consultants were included on the basis that they were likely to be unbiased about their views and that they would be providing an 'outsider perspective', which could enrich the data. All of the independent consultants have had wide-ranging work experiences in Samoa as well as overseas. Two of the independent consultants had worked as ambassadors overseas before returning to work as consultants in Samoa. The other consultant had worked in Samoa for a number of years as an educational officer for the Public Service Association (PSA) and later became the Secretary General of the SNUW. He is currently a Member of Parliament in NZ. Given their present statuses in the community and the wealth of experience gained throughout their careers, both abroad and in Samoa, their interviews contributed significantly to this study.

With 20 invitations to partake in the study sent out to the potential participants, it was observed that the employers and representatives of trade unions (or employee 
associations) had the lowest response rates on average. The three organisations whose representatives did not respond to their invitation letters and did not return any of my phone calls were ruled out as uninterested after two failed attempts to set up appointments with their secretaries. The reasons for non participation from those organisations were not clearly stated and any speculation about their lack of interest in participating was not supported with evidence. For instance, there existed a rumour that employers, especially those in the private sector and those known for avoiding unions, were most likely to oppose any enquiries relating to employees: in particular, any discussion of unions would be seen as intimating and insulting. Similarly, there was some speculation among several of my interview subjects that employers would become very suspicious that any enquiries of the nature of the questions in this study were intended to check in on them to see if they were in compliance with the labour laws.

Out of 20 individuals requested to be interviewed, only 13 actually participated. This represents a response rate of $65 \%$ which is considered to be sufficient as the study is quite limited in scope and descriptive in nature: therefore it does not require hypothesis testing via empirical evidence. Completing all of the interviews in time was an intense process due to which the follow-up calls, particularly to those who did not respond to their letters of invitation or arranged appointments, were limited to three phone calls during the interview weeks. ${ }^{4}$ Even when interviews had been scheduled, the immediacy of the interviewees' work demands frequently required interviews to be postponed or re-scheduled at short notice. Two of the interviews that were scheduled and confirmed did not eventuate.

${ }^{4}$ Not all the interviews were scheduled and confirmed before the interviews began on 23 April 2009. The
confirmed interviews prior to the interviewing period constituted $75 \%$, which was very good. 
Table 1: Sample population, response rates and actual participation rate

\begin{tabular}{|l|c|c|c|c|c|c|}
\cline { 2 - 7 } & \multicolumn{2}{|c|}{$\begin{array}{l}\text { Number of Invited } \\
\text { or Potential } \\
\text { Participants } \\
\text { (a) }\end{array}$} & $\begin{array}{l}\text { Total Responses } \\
\text { received }\end{array}$ & $\begin{array}{l}\text { Scheduled } \\
\text { (nterviews }\end{array}$ & $\begin{array}{l}\text { Achieved } \\
\text { interviews } \\
\text { (c) }\end{array}$ & $\begin{array}{l}\text { Actual } \\
\text { Participation } \\
\text { Rate (\%) } \\
\text { (e) }\end{array}$ \\
\hline $\begin{array}{l}\text { State (state } \\
\text { agencies }\end{array}$ & 3 & .15 & 3 & 2 & 2 & .10 \\
\hline $\begin{array}{l}\text { Employer } \\
\text { (association) }\end{array}$ & 8 & .40 & 6 & 6 & 5 & .25 \\
\hline $\begin{array}{l}\text { Employee } \\
\text { (unions \& } \\
\text { staff } \\
\text { associations.) }\end{array}$ & 5 & .25 & 4 & 3 & 2 & .10 \\
\hline $\begin{array}{l}\text { Independent } \\
\text { consultants }\end{array}$ & 4 & .20 & 4 & 4 & 4 & .20 \\
\hline TOTAL & $\mathbf{2 0}$ & 1.0 & 17 & 15 & 13 & .65 \\
\hline
\end{tabular}

\section{Calculating the response rate}

$\frac{a}{d} \times \frac{\%}{1.0}=e$

As noted above, the independent consultants achieved the highest rate of actual participation, at full participation, based on the number selected for the interview. One of the possible explanations for the full participation of independent consultants could be that the study did not involve them directly in the sense of reflecting on their current career position. Another reason could simply be that the times scheduled for their interviews were appropriate. On the other hand, from what I gathered during the interviews, the independent consultants were in a position where they could comfortably and safely critique the current system, in particular the roles of state, employer and employee in industrial relations. They were also observed to be less biased towards any particular group, which made their contributions particularly valuable for this study. 


\subsection{Document analysis}

The document analysis was considered invaluable for a study of this nature, especially as there was a significant lack of information, study or previous knowledge about the industrial relations system of Samoa for literature review. More specifically analysis was essential due to the limited application of the systems model to previous study of industrial relations and industrial relations systems in Samoa, and to a similar extent in other PICs.

The secondary data were obtained through the analysis of various publications available, in particular, the study of employment relations and IR systems in South Pacific island nations by Prasad, Hince, \& Snell (2003). Their study could be seen as the only conclusive piece of literature regarding the Pacific island nations, which made it one of the core materials for my analysis. This study provided preliminary background insights into the industrial relations system in Samoa.

The availability of various national legislations (e.g. the Labour Act of 1972, the Public Service Act of 2004, the Occupational Health \& Safety Act of 2002 and the Incorporate Societies Regulations of 1952) not only set the legal scene within which the industrial relations system operates, they also offered support in the analysis of the actors' behaviour and their relationships within the system, in particular, their limited capacities in certain aspects of the employment relationship. For instance, strikes were considered illegal because they were not legislated for in any of the labour laws.

Country reports and other publications, such as newsletters and brochures by the ILO and the United Nation's offices in the South Pacific, albeit frequently piecemeal, were 
helpful in the discussion of certain historical and causal events that resulted in some of the recent developments noted in the IR system of Samoa today. A brief history of the Samoa Public Service Association (PSA) by Hince \& McFarland (1997) was considerably helpful given the lack of interest and empathy from the association to take part in the study. For the most part, those materials were seen as supplementing the data collected through interviews.

\subsection{The limitations of the methods}

As with any research methodology, limitations are inevitable. Firstly, the selection of participants was observed to be significantly concentrated on the public sector, while the private sector was somewhat neglected. Secondly, the participation rate could have been enhanced if I had not restricted my sample population to companies with 100 or more workers: it should be noted that the largest percentage $(80 \%)$ of the employer community in Samoa is comprised of small family-owned businesses employing fewer than 20 workers. ${ }^{5}$ However, this selection does not necessarily bias the analysis and conclusion because the participation of a collective body known as the Chamber of Commerce and Industry (herein referred to as "the chamber") as the employers' representative for local businesses in the private sector, is seen as sufficient representation of small business for the purposes of this study.

Thirdly, in the selection of union participants, concentration was again directed at the federated trade union of Samoa or the PSA, which represents the vast majority of government workers. As the largest union of workers and a core group for this study, it was unfortunate that they did not wish to be interviewed, though some basic

${ }^{5}$ Estimated at $75 \%$ of the employers having fewer than 10 employees. 
information about the union was obtained through the workshop, through document analysis and mostly through the interviews with former PSA members representing various segments (e.g., government agencies and ministries as well as independent consultants) of the labour force. ${ }^{6}$ The recruitment of union participants took into consideration their reputations and historical positions within the work community. They were considered to be active participants to the extent that some had been engaged in strikes and other forms of industrial disputes in recent years with their employers, meaning in most cases 'the government'. As discovered during the data collection, limiting the selection of union participants to those who were considered to be active and organised in the employment relationship possibly overlooked the smaller associations of workers who were not seen as unions per se but nonetheless are organised within own organisations. Similar to this is the situation with the employers' representative body: the PSA represents the view of smaller associations/unions in Samoa at the ILO workshop, a representation that is also considered sufficient for the purposes of this study.

The sample population for the main groups (employer, employee and state) could have been improved and extended to include more participants from the private sector. Due to the low number of large private businesses operating in Samoa, the people holding such positions relevant to this study were employed predominantly in the public sector. Nonetheless, the complex nature of the study evidently influenced the selection process to the point that it was reasonably expected that only those employed in high-level

\footnotetext{
6 The majority of my interview subjects had been involved or had had close connections with the federated union as members. At the time of the study, many of the participants who also became heads of various government ministries and corporations still considered themselves as members and they still paid their subsidiary fees. This was in spite of the union becoming extremely disorganised and inactive over the last five years. They all spoke openly about union activity, the variation in their roles within the IR system and the extent of their membership, which I felt would be sufficient for my purposes.
} 
positions such as managing directors and business leaders were likely to have had access to the relevant information needed for the study. In addition, the participants' prestige and positions in those organisations required them to have made decisions affecting employment outcomes. Therefore, they would be expected to have relevant knowledge of the subject matter.

\subsection{The analysis framework: Dunlop's systems model of IR}

As the objective of the study is to explore the views, perceptions and values of the key actors in order to describe the IR system in Samoa, some strong personal and emotional contradictions emerged during the data collection. Dunlop's systems model of industrial relations as depicted in chapter 2 (Figure 1) was used as the core framework for the analysis of the actors' roles, values and expectations and the actors' relationships with each other within Samoa's industrial relations system. Utilizing the systems model as a guideline ultimately gave me control over the use of data in that I became aware of the subtleties in the meaning of qualitative data gathered from interviews. It enabled me to give meaning to the data, to make sense of the issues that emerged during the analysis and to separate points that were pertinent from those that were not. Adapting Dunlop systems model also enabled me to concentrate on the core aspects of the research, whilst it reduced the possibility for judgment errors to an acceptable degree. It allowed for the research to identify and discuss the fundamental components, namely the actors and the processes or mechanisms (e.g., collective bargaining, arbitration, etc.), used to convert inputs into outputs or rules (substantive and procedural). These components of an IR system as discussed by Dunlop are considered to be of significant value to the discussion of the IR system in Samoa. With strong emphasis placed on Dunlop's view that the distribution of power in wider society affects the actors' behaviours, decisions 
and choices as well as their level of influence on the outcomes of the system, a closer look at the types of social institutions existing in Samoan society, rules and regulations governing employment relations in Samoa was also necessary. In short, Dunlop's framework ultimately drew attention to the impacts of the external environments, including the socio-political, economic and legal contexts that tend to shape and influence the decisions made by key players in the system.

Dunlop's systems model was seen as not only describing the features and characteristics of an IR system, but more importantly, helping to acquire new understanding about the nature and scope of industrial relations and the IR system of Samoa that was not discovered in previous studies. As a methodological framework, the systems model guided the construction of the research questions and the development of data collection methods and research design. It also helped to maintain the focus of research throughout the data collection phase. Furthermore, the systems model helped to determine whether sufficient data existed in order to support the purpose of the study, as well as aiding in the identification of any conclusions made as a result of the investigation.

Dunlop's systems model also brought into perspective the significance of causal events discovered from the interviews, the literature review and the analysis of secondary data, to increase understanding of certain characteristics of these events in relation to the inner workings of the IR system in Samoa. In addition, descriptive details of the extant IR system itself, and any other ramifications that were evident during the study, were identified and explored using the systems model. Though the systems model did not trace any sophisticated process by which certain inputs result in certain rules affecting industrial democracy and employee participation in decisions on worker employment, it 
did prove to serve the purposes of this study in describing the industrial relations system of Samoa in the most rudimentary and practicable manner.

\section{Summary}

The use of a range of data collection tools, such as the semi-structured interviews, workshop observations and document analysis, to collect data has provided a wide range of useful information which is necessary to the study in order to give an accurate description of the industrial relations system of Samoa. Given the lack of information and prior research in the field of industrial relations in Samoa, utilizing open-ended and semi-structured interviews as the primary tool has enabled the researcher to uncover information that would not have otherwise been possible with an exclusive focus on other data collection methods. The chosen methods allowed the researcher to ask follow-up questions and to probe individuals for elaboration on specific issues that were seen to be of particular relevance to the research.

Secondary data have enabled the researcher to bridge any gaps in information identified during interviews as well as those discovered during the preliminary stage of the research, particularly during the review of literature on Samoa's IR system and that of other PICs. Most of the information gathered through previous research, including for example, Prasad, et al. (2003), and other types of materials such as Samoa country reports, national policies and regulations, were seen primarily as supplementing the views and perceptions of the respondents, but they also helped the researcher to verify data collected through interviews for the purpose of reducing the influence of subjectivity in the analysis. 
Finally, the use of Dunlop's model as part of the methodological framework aided the preliminary preparation of the research as it provided the researcher with a clear sense of direction about the types of interview questions to ask in order to achieve the research objectives. The systems model also helped define the characteristics of individuals to be included in the study, as well as the factors and areas of Samoa's IR system that would require utmost attention throughout the research. 


\section{Chapter Four: Findings and Analysis}

\subsection{Introduction to the chapter}

This chapter first provides a brief overview of Samoa's background to highlight the demographic, social, economic and legal contexts as well as to provide some key information on the employment and labour market characteristics of Samoa. This is followed by a detailed analysis of data gathered from 13 semi-structured and openended interviews and from key presentations of the employers' association, workers' representatives and state representatives at the International Labour Organisation (ILO) Workshop. The analysis also includes a review of several documents to supplement the views and expressions of the participants in this study. The data are organised and analyzed using Dunlop's (1958) systems model of IR (as depicted in Figure 2). ${ }^{7}$ The application of Dunlop's systems model in this context, whilst it provides a coherent and descriptive analysis of the IR system of Samoa, also goes to demonstrate that Dunlop's framework can be widely applicable when it is used to aid an understanding of the interconnectedness among various components of the employment relationship that are common to all IR systems.

\footnotetext{
${ }^{7}$ Figure 2 represents an adapted and modified version of Dunlop's system model of IR (and alternatively Craig's (1970) input-output model) which has been used in this context to illustrate how the Systems Model is relevant in highlighting several attributes of Samoa's IR systems with reference to how the environmental forces interacting with the actors' goals, values and capacities through certain processes in the rules of Samoan workplace.
} 


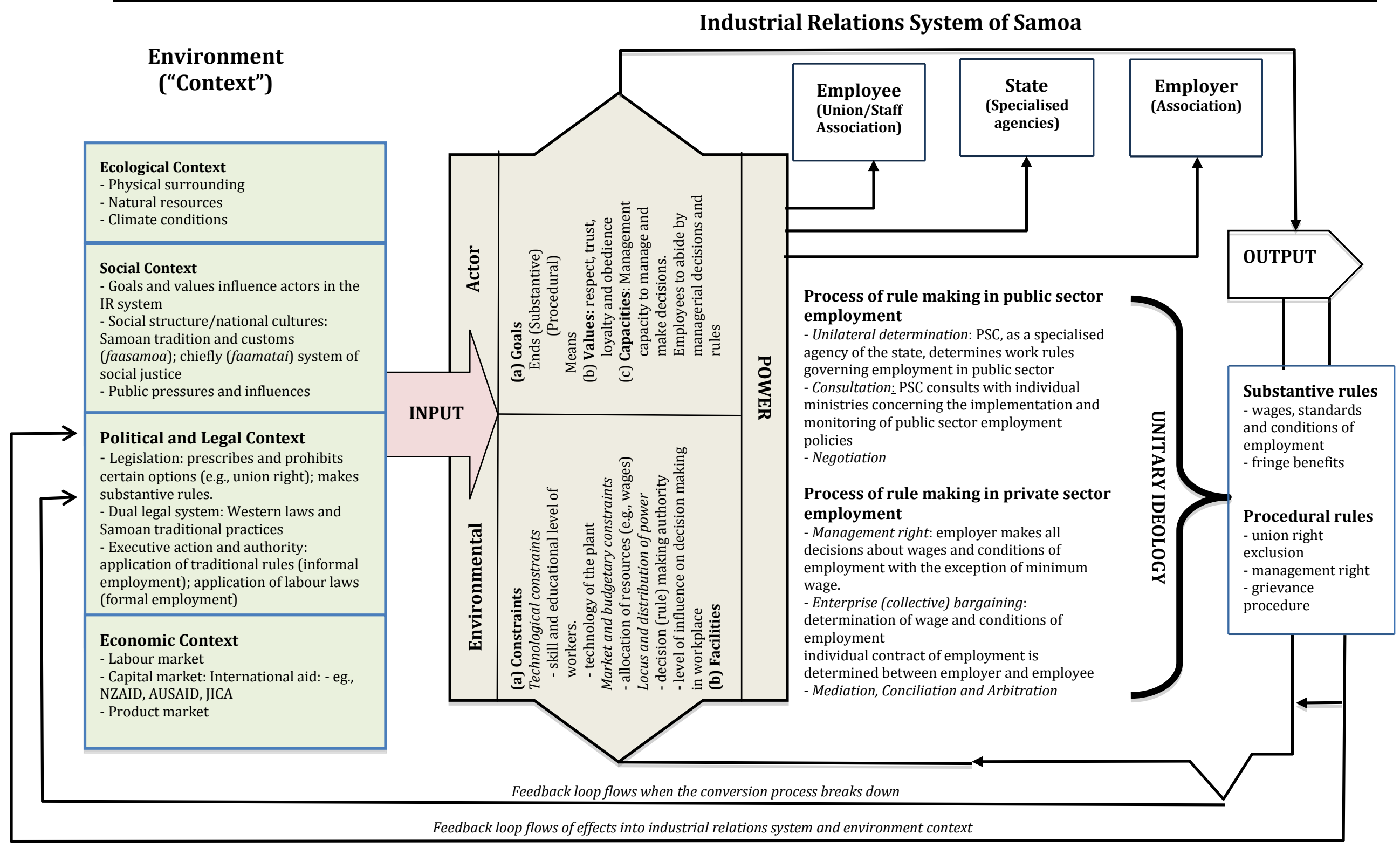

Figure 2: The relationships within the industrial relations system of Samoa

Mapping the Industrial Relations System of Samoa: An assessment of industrial democracy and employee participation in employment relations decisions in a Pacific Island Nation. 


\section{COUNTRY CONTEXT}

\section{The demographic, social, legal and economic contexts}

Samoa (previously known as 'Western Samoa') is a sovereign state, as it has been since 1962 after becoming the first Polynesian nation to reestablish independence. Prior to that, New Zealand occupied the German protectorate of Samoa at the outbreak of World War I in 1914 and it continued to administer the nation until 1962.

Samoa consists of two main islands, Upolu and Savai'i, and seven small islets. It is located about halfway between Hawaii and New Zealand in the Polynesian region of the South Pacific. The main island of Upolu is home to nearly three-quarters of Samoa's population and is the location of its capital city of Apia (U.S Department of State Affairs, 2009). Likewise, employment is highly concentrated in the capital city: where most of the government offices and privately owned businesses are located.

Samoa's current total population is 179,186 in accordance with the most recent census in 2006 (Samoa Bureau of Statistics, 2010). ${ }^{8}$ In 2006, the population was comprised of 92,961 males $(52 \%)$ and 86,225 females $(48 \%)$. The median age in Samoa was then only 19.7 years, which together with a continuing high birth rate, means that Samoa will continue to have a very youthful population. The estimated annual population growth rate between 2006 and 2015 is $0.8 \%$ which, due in large measure to considerable expected emigration, is lower than in most other Pacific Island Countries (PICs).

\footnotetext{
8 (Samoa Bureau of Statistics, 2010). The 2006 Census was the most recently published and conclusive information available during the data collection and it was therefore considered to provide accurate and updated information on Samoa's demographic context.
} 
Samoa is a constitutional parliamentary democracy that incorporates traditional practices into its governmental system. Executive authority is vested in Head of State Tui Atua Tupua Tamasese Efi, elected by Parliament in 2007. From the establishment of Samoa's independent democratic parliament in 1962, public policy remained relatively consistent for several decades. The unicameral Parliament, elected through universal suffrage, is composed primarily of the heads of extended families (matai). The ruling Human Rights Protection Party (HRPP) has maintained its majority and continues to be the only officially recognized party in Parliament. The structure of the national government is in various aspects a reflection of the type of communal arrangements that exist in the nation's villages. A Fono a Alii ma Faipule (Village Council) is present in each village and is headed by a Sa'o (Paramount Chief) who exercises authority over the extended family and lower ranking chiefs. 9 This traditional system of rule making, which is organised around collective rather than individual efforts, continues to play an integral role in bringing Samoan society together. The emphasis on collective rule making is a reflection of the fa'amatai, a 'political philosophy' largely associated with notions such as 'compliance' and the 'obligation' to abide by decisions made by higher authorities. These elements of the socio-political context have influence over the IR system in Samoa.

To this day, Samoa continues to strive in maintaining a good balance between the fa'asamoa (Samoan customs and traditions) and Western legal systems, which still

\footnotetext{
${ }^{9}$ Fono a Alii ma Faipule (a.k.a Fono) means a council or meeting and it applies to national assemblies and legislatures as well as local village councils. For the purpose of this study, the Fono is also used in this analysis to refer to the traditional rule-making authority that runs in conjunction with the judiciary system. The Fono's primary focus is on maintaining law and order in the villages. It usually comprises of all the matais that are seen as the representatives of their extended families to village meetings. It can be seen as a medium for voice to discuss issues that are pertaining to the welfare of the people within that community.
} 
dominate a lot of practices. Yet, as will be discussed in later parts of this chapter, most participants in this study have agreed that, although Western rules may appear to be dominant in shaping Samoa's institutions and laws as well as IR and IR systems, this appearance is only at the surface; the goals, values, behaviours and relationships among the government, employers and employees in Samoa are predominantly influenced by the fa' 'asamoa.

The economy of Samoa has traditionally been dependent on development aid, family remittances from overseas, agriculture, and fisheries. Samoa's economy is vulnerable due to remoteness, income volatility, and susceptibility to tropical cyclones, as well as limited economic diversification, environmental damage and limited institutional capacity. Agriculture employs two-thirds of the labour force and furnishes $90 \%$ of exports: featuring coconut cream, coconut oil, and copra. The manufacturing sector is mainly concerned with the processing of agricultural products (Heritage Foundation, 2010b). Tourism has notably become one of the fastest growing industries, but like many businesses in Samoa, tourism operations are typically small family-owned operations, usually employing between 5 and 10 people at the most. In Samoa, the single largest employer is Yazaki EDS Ltd, a Japanese-owned vehicle (wire harnessing) manufacturing company currently employing over 1000 local workers: most of whom are women. Though the size of the Yazaki workforce has been reduced significantly from 4000 workers since its establishment in 1991, it still remains the single most significant business development and the biggest company operating in Samoa. 


\section{Employment and labour market characteristics}

Samoa's workforce is divided into two main sectors - the formal (workers in regular paid employment) and informal (workers in subsistence, or in service to a matai, who may still be classified as economically active but are not earning regular wages). In 2006, Samoa's total employment population was recorded at 53,928 of which 36,478 were males $(67 \%)$ and 17,450 were females $(33 \%) .{ }^{10}$ Although there is no record of how the workforce was allocated, the Ministry of Commerce, Industry and Labour (MCIL) identified that in 2006 the formal sector comprised approximately 28,000 workers and the informal sector around 25,000. Prior to that, formal sector employment had always been outnumbered by employment in the informal sector; this shift was considered an improvement given Samoa's vulnerability to limited resources and lack of institutional capacity to create and sustain formal employment.

The increase in formal sector employment may be attributed to factors, such as the expansion of the infrastructure (e.g., government buildings, roads and other major projects) carried out by both local and overseas companies. This expansion opened up some opportunity for manual employment to cater for the large unskilled and lowskilled segments of the labour force in Samoa. An increase in entrepreneurship activities via community-based projects with sponsorship from overseas agents such as NZAID, AusAID, Japanese International Corporation Agency (JICA) and others, as well as the growth in the tourism and hospitality industry, may have also contributed to the increase in formal sector employment.

\footnotetext{
${ }^{10}$ Employment - refers to the number of working age population (in the case of Samoa it is 15 - 64 yrs) declaring themselves as 'employed' (work with pay, full-time, part-time) or working without pay during the reference period in 2004 Census.
} 
The MCIL provides valuable data comprising a recent and brief overview of Samoa's employment situation. ${ }^{11}$ In 2004, a total of 15,854 employees, comprising of 9,533 males $(60 \%)$ and 6,321 females $(40 \%)$ was recorded, within which $46 \%$ of the overall private sector workforce was under 30 years of age. Forty nine percent of working women were under 30 years of age compared with $44 \%$ of working men. The number of permanent public servants in 2004 was 3,761 including 2,083 males (55\%) and 1,674 females (45\%). Thirty nine percent of public service employees were under the age of 30 , compared with $42 \%$ of employees in the private sector.

\section{STRUCTURE OF THE FINDINGS AND ANALYSIS}

Following Dunlop's model in mapping the IR system of Samoa from the point of view of the participants of this study, who were identified as playing key roles in the establishment of employment rules, the findings will be presented and analyzed under the following four major subsections.

- The impact of the socio-political context on the IR system of Samoa

- The impact of the economic context on the IR system of Samoa

- The relationships within the IR system itself

- The recent developments in Samoa's IR system

\subsection{The impact of the socio-political context on the IR system of Samoa}

Samoa's early socio-political context followed a hierarchical pattern, a pattern which is generally taken to be characteristic of traditional Polynesian island states, particularly

\footnotetext{
11 MCIL carried out three labour market surveys in the years 2000, 2002 and 2004. The surveys were of the formal private sector employees (2000 and 2004) and the semi-formal sector (2001), the latter referring to those who work for themselves or unpaid workers in family own ventures.
} 
with the institutionalization of authority and social justice structured around chiefly title-bearers. In addition, the homogeneity of cultural practices and languages within Samoa, and the network of kinship groupings and allegiances that extend throughout Samoan society, are not only typical of Polynesian island groups (Lawson, 1996), they also help to maintain a robust cultural foundation which causes Samoa to be very slow in responding to changes or influences from Western cultures and industrially developed nations. The socio-political structure of Samoan society has, therefore, been noted by the participants in this study as one of the most influential factors on the development of Samoa's IR system.

\subsubsection{The social context}

It remains evident to this day that the system of unique cultural values, beliefs and norms commonly identified as the fa' asamoa (the Samoan way) not only helps maintain stability, law and order throughout Samoan society, as it has since the beginning of time, it is also an important feature of Samoa's IR system. The fa' asamoa refers to the overall traditional system of behaviour and responsibility that prescribes the relationships between individuals within the community and particularly with those persons that hold positions of authority (Aiono, 1986). More specifically, the concept of fa'asamoa is construed in terms that imply a unitary cultural entity encompassing the whole of Samoan people (Lawson, 1996). Fundamental to the institutionalization of Samoan society is the fa' amatai (or the matai traditional system) of social organisation and social justice. In addition to prescribed familial relationships, which extend to one's entire extended family (the aiga or suli (heirs)) with its familial chief (the matai), one also owes respect to other persons in positions of authority within the same village 
(Aiono, 1986), and to a long-standing customary web of traditional rules that deem to hold the community together.

Due to the significant value of traditional rules to Samoan society, any breach of these rules has far reaching consequences. For example, most Samoan villages enforce a period of prayer in the early evening: signified by the ringing of a bell or the blowing of a conch shell. During this period (the $s a$ ), one should not stop in the village if passing through, and there may be appointed guardians standing by the road to ensure that travelers do not stop there. In some extreme breaches of certain taboos, the village authorities, through a consensus decision made by the Fono may order the offending family (usually the offending family's matai and his extended family) to be banned from the village. The law does not always provide protection for people who may be severely punished through the matai traditional rule-making system, especially when there is a strong unity among the village authorities that would impose upon the court to acknowledge a village decision or rule to be final and binding. This practical application of traditional authority is made possible because much of Samoa's land is held in the communal trust of the local matai, and the people's livelihood depends on this land.

Central to the fa'asamoa, and in particular the fa'amatai is the notion of tautua. The tautua, literally meaning "service" is derived from the Samoan proverb "O le ala i le pule o le tautua" (the pathway to authority is through service). This means that everyone within the extended family, or a part of that particular kinship, is expected to be in some form of service to their Paramount Chief, and each family member has a chance to be bestowed a chiefly title in reward of their service. In various respect, the concept of tautua and its practicable application to the Samoan culture resembles that of 
the Chinese concept 'guanxi' which implies to refer to familial and social obligation, shared status and reciprocal favour. Quanxi relationships are used in order to secure personal, business and political advantages, and are important in all aspects of business life in the Chinese world (Mead \& Andrews, 2009).

In an organisational setting, the concept of tautua is also interpreted by most participants in this study as a way of proving one's trustworthiness to a particular employer in exchange for a promotion, or some other means of reward. For instance, the longer a person is in service to a certain employer, the more likely they will be to advance to a higher-level position, regardless of whether they have the most worthy qualification or not. As one of the participants in this study noted, "loyalty in most of Samoa workplaces is manifested through long service, which is enough in itself in most organisations to secure one's employment for life". Another participant explained that because of the significant value that Samoan society has placed on the concept of tautua, which can be said to be also measured by 'seniority' (or length of service to a particular employer), it causes Samoa's IR system to closely mirror that of the Japanese model of IR - this has been good for employment due to some cultural recognition between Samoan workers and the significant corporate investment (i.e. Yazaki EDS Ltd) in Samoa. Other participants shared a view that the term tautua is onerous because in its strictest sense, it implies 'compliance' and that any person in a position of service to a matai will naturally not be in a position to question the integrity of the rule-making authority as this would be seen as flouting Samoan custom, a practice that very likely would bring about severe consequences. According to these participants, Samoan culture and the nature of hierarchical relationships in various communities and institutions in Samoa does not support wider participation from the various facets of the 
public. Likewise, with IR in Samoa, unionism is often perceived as a 'Western prototype' with the primary objective of countering local authority. Based on several interviews with union representatives, this perception of 'unionism' portrays the very concept as uncharacteristic of Samoan society, as it is stood in stark contrast to Samoa's beliefs and cultural values.

\subsubsection{The political system}

Since Samoa's declaration of independence in 1962, and prior to universal suffrage in 1990 which allows individuals of 21 years and above to vote, only the matai were allowed to vote into Parliament a selection of candidates who would represent their respective constituencies around the country. In spite of the advent of universal suffrage, which was introduced in an effort to democratize the electoral system of matai-only vote, eligibility for candidature to date remains confined to the matai for forty-seven members of Parliament, with the exception of two (2) non-matai candidates representing the individual voters (i.e., Samoan citizens descended from nonSamoans). ${ }^{12}$ This brings the number of members to a total of forty-nine in the Legislative Assembly (Parliament). Forty-seven of these members are matai, elected in six two-seat and thirty-five single-seat constituencies. The restriction of matai-only candidature for Parliament reinforces the dynamics of the matai system, based on the social division between leaders and followers. For Lawson (1996), the measure of democratization through universal suffrage was only partial and it was not driven so much by a support for democratic values per se, but by a desire to preserve important aspects of Samoan tradition in a climate of foreign cultural influence.

\footnotetext{
12 Those descended from Germans, English, Chinese, Melanesians who were brought over to Samoa as indentured labourers during the German administration.
} 
Theoretically, and in the context of Samoan tradition, democracy has supposedly been given to non-matai titleholders through some degree of participation in village councils and through the right to vote. In practice, however, the electoral system is far from being democratic because the village council ultimately decides on the candidate who will be voted into Parliament prior to election. Once a ruling is made, the village council will then enforce this decision upon everyone within that village or district, and whoever decides to go against the council's ruling will incur a fine from the village authorities. A newspaper article by Jasmine Netzler-Iose (2010) as referenced in APPENDIX D serves to demonstrate this undeniable authority of village councils over whom the district people should vote for during parliamentary election. In the Western world, this custom may be seen as a violation of a person's right to freely vote for a candidate of his or her choosing, but for many Samoans the practice is merely a reflection of unity and collectivity and mainly serves to protect the dignity of the Fono. Some of the participants in this study argued that this practice could be troublesome mainly due to the nature of village councils and concerns surrounding the legitimacy of traditional decision-making. This suggests that, while the nature of traditional decisionmaking has been historically represented by 'unanimity', which implies that a degree of consensus is achieved, in Samoan society consensus refers also to an obligation to abide by a decision once it has been reached. As Lawson (1996, p. 143) notes, "Unanimity was therefore a public goal and its public expression was essential for the purpose of making the decision binding”.

Issues regarding political legitimacy of Samoa's parliament as largely related to the dynamics of the matai system, and the autocratic nature of that system has been noted by most participants in this study to be continually influencing the goals, values and 
expectations of the actors within Samoa's IR system to the extent that there must always be a clear distinction between the leaders and their followers. Some of the participants in this study suggested that certain aspects of the hierarchical nature of the sociopolitical context can be likened to a master-servant relationship; this perception can also be directed at the concept of tautua (service) that is central to the matai system and traditional Samoan work relationships. Both conscious and unconscious perceptions of a master-servant archetype in employer-employee and matai-public relationships exert significant influence on Samoa's IR system. According to Dunlop, the actors (i.e., employers, workers and government) interact and negotiate with each other within the influence of a common environment (i.e., social, political and economic contexts), and in the process (i.e., bargaining, mediation and arbitration) determine the rules that are the outcomes (i.e., pay, employment conditions and job rights) of the IR system. Through emphasizing the significance of a common environment for actors in the system, some of the union representatives in this study argue that managers are very likely to mimic the behaviour of national leaders by mandating policies and practices that support dictatorial leadership in their structuring process. For instance, almost all the participants in this study referred to the notion of faaáloalo or va fealoai (respect) as the fundamental principle rooted in every relationship in Samoa, and yet various interpretations were placed on what the concept really meant and the extent to which it is considered relevant in the employment relationship. The notion of 'respect', which is espoused in rendering of one's service either to the paramount chief in the village community or to the boss in the workplace, is also taken to mean 'obedience' or 'compliance' with the community or work rules. The workers who were interviewed, on the one hand, identify faaáloalo as a way of reinforcing the master-servant relationship between the employers and workers, as in the words of one of the independent 
consultants; the employers who were interviewed, on the other hand, have noted that it is a mutual element of a good working relationship and an essential principle upon which tripartism can be built as a useful medium for promoting the interests of employers and workers alike.

To me personally, because of the fa'a-Samoa especially: this general understanding and expectation that as a worker you must show the "utmost respect" for your boss, in the sense that you are basically there to follow the rules and be a trustworthy person, it reinforces this relationship that the workers are in fact servants and the boss is really the master [Independent consultant 1].

In the context of our Samoan culture, mutual respect, le faaáloálo and ava' fatafata, we believe should be applied in our relationships with our workers and if we do that, then tripartism works and social dialogue works and whatever issues that may arise particularly as we move forward with labour reform and other developments. We believe, based on mutual respect instill into our culture, we can work together [Employer representative].

Contrary to the employers' representative's viewpoints, a union respondent argued that employers tend to use the concepts of faaáloálo and ava'fatafata (or va fealoal) to manipulate the employment relationship to their advantage and to avoid the result of workers forming into unions. From another perspective: one that was commonly shared among the independent consultants, is that the fa'asamoa is often one-sided and exploitative in the sense that the cultural aspects of faaálo'alo or va fealoai are almost exclusively reserved for those who are in authority and ones that hold power in the work community or in society at large. This suggests that while the fa'asamoa is seen as the cornerstone of many relationships in Samoa: both within and outside the employment arena, it is used primarily to the advantage of the national government for the purpose of demanding cooperation from the people. 
In view of the perception of $f a^{\prime}$ 'asamoa as one-sided, the data reveals that there will be a continuing reliance from Samoan people on the responsibility of state to do the right thing. This implies that Samoans very frequently trust their government to possess a high level of knowledge and expertise in the ethics of decision-making and trust them to make sound decisions for the benefit of all the people in the community. Likewise, in the IR system, employees also hold a view that their employers 'know best'; thus, they rely on employers to be capable of making decisions that are also advantageous to the employees. As one of the independent consultants pointed out:

Governance in Samoa in the traditional sense is supposed to be good and based on some human nature and on people looking after their own kin. And when it comes to governance in the form of central government, let's face it, with all this talk of democracy, the people being governed have not got the foggiest idea about what the government is doing. They don't understand it, they don't want to think for themselves, they haven't got the time to understand, they just expect their leaders to do the best thing for them. They entrust to them with their welfare and their future and whatever. They expect good governance from the leaders who are expected to act in their interests [Independent consultant 2].

From this viewpoint, the government's main source of power, which places them in full control of the political system, derives from the social context. The suggestion of this view is that the carefree nature of many Samoans has made them complacent towards playing any role in influencing national policies to a point where people are only too happy to accept the status quo of Samoan society. Several interviewees pointed out that, because of the fa'asamoa and the certain ways in which every Samoan has been brought up to think and behave within their village communities, any expression of an opinion that would seem to question the integrity of the decision-making authority can be taken as disrespectful. Additionally, as the individuals have become accustomed to how things have 'always been' in the past, they would naturally accept the fa'asamoa to be 
the only 'real and objective world' they know. From the interviewees' point of view, the social implications that Samoan culture extends on IR are far reaching: mainly because the government is the dominant player in making employment rules. Powerful leaders, as it is now, no less socially construct the socio-political context than the people themselves. As one of the interviewees pointed out, Samoan people are so constrained by their own cultural surroundings that they would willingly accept every decision (in spite of how unreasonable a decision may be) for the mere purpose of being accepted as respectful and obedient servants. This relates to Dunlop's discussion of the actors' sources of power that are derived from the contexts of the IR system; in Dunlop's discussion the concern is not so much to do with what goes on within an IR system itself, but with the distribution of power in wider society which is attributed to the system, thus affecting the relationships among the actors, their positions, and ultimately the outcome of the system.

When the participants in this study were asked about whether or not unions should have a place in Samoa's politics, most expressed the belief that unions should certainly play a significant role in IR, but also noted that it would be impossible to see unions taking an active role unless it is done so in the political arena. As one of the participants reported:

I think that as a small country and a small environment it requires a political world: and a political world is not forthcoming. You will need people who will support the purpose of unions in such a way that it would promote equity and get discussions and debates going [Independent consultant 1].

While the majority of interviewees agreed that, in order for workers to have an effective voice in IR, union participation must take place in the political arena or in Parliament, they were also particularly mindful about the way the electoral system works in Samoa. 
It would be very difficult for union representatives to win votes based solely on some great ideas that union delegates might have on the development of the country, because they would also need to have a lot of money to secure votes. What this means is that if a candidate decides to run for Parliament, he or she will first need to take what is commonly known in Samoa as an $o^{\prime} o$ (gift giving) to the Fono in his or her constituency and if the Paramount Chiefs are satisfied with the gift given they will then enforce upon every voter within that constituency the obligation to vote for that particular candidate. Thus, every candidate representing a particular constituency will be competing for votes based on the respective $o$ 'o that they offer to the local Fono: who will then decide the fate of each candidate based almost entirely on how much money and food each has given to the village. This practice had the Supreme Court deal with several petitions from losing candidates against winning candidates that raised bribery charges, and these petitions eventually led to the government's enactment of an Electoral Bill in 2005, which legalized gift-giving as in accordance with fa'asamoa. Under this Statute, the $o$ 'o must be presented within an approved time frame beginning 180 days before the end of the Parliamentary term and culminating 90 days from the date of election. Some of the participants in this study argued that because of the way Samoa's electoral system works, representatives win election not based on the possession of relevant knowledge of how to run the nation, but because they were able to satisfy the Fono with gifts of money and food, and this practice has always been a problem in Samoa. As this practice permeates throughout the socio-political context, it has greatly affected the quality of decision-making in all aspects of Samoan society: including IR. The majority of participants agreed that most of Samoa's citizens do not seem to see beyond the impact of political status establish through the giving of $o$ 'o. With the government legalizing gift giving as fa' asamoa and, therefore, not officially a 
form of bribery, this legislation reinforces the dynamics of the social (fa'amatai) system. It signifies the importance of social values in the political system: values that have also clearly impacted on the way employment rules are made, ultimately affecting the relationships between actors in the IR system. For other respondents, legal affirmation of political gift-giving simply highlights the difficulty faced in Samoan culture and legal systems when trying to distinguish between a bona-fide gift given in accordance with Samoan customs and traditions on one hand, and outright bribery on the other.

An emphasis on the quality of a 'benevolent society' also emerged as one of the principal characteristics of Samoan society and its IR systems. This is manifest in the Prime Minister's keynote address during an ILO function on 27 April 2009. In that address, the Prime Minister refers to Samoa as a benevolent society. His speech indicated that the extent of benevolence in Samoan society distinguishes it from other Pacific Island Nations. From the Prime Minister's point of view, because Samoans have been raised and taught to respect their elders and their leaders, it is highly unlikely for Samoa to experience strikes and any other form of severe political unrest to the extent that these actions have occurred in Fiji and Tonga.

The emphasis on Samoa being a 'benevolent society' also emerged from interviews with several of participants in this study. For some participants, the term 'benevolent society' has been used as a constant reminder to people that Samoa today enjoys the character of a God-founded, peaceful and loving society. For others, the concept of a 'benevolent society' is entrenched in the history of Samoan society, and that it has in 
modern times been used to the advantage of powerful leaders to demand respect and loyalty and, most of all, to keep the people quiet.

As one respondent in this study declared:

We don't want to admit that our government is not benevolent because we always assume it to be, because we always want it to be and expect it to be, but there will come a time when people will say "no - it's not benevolent." People in government, if anything, they think they are benevolent by doing what they can to keep people quiet. They know how to keep the people quiet, the people need to be quiet: quiet so there is no fuss, and when some people make a fuss, they are assessed very harshly [Independent Consultant 2].

Some of the key union representatives in this study shared a belief that there is a strong connection between the nature of 'benevolence' in Samoa and the government implementing strategies, which support union suppression. The context in which the phrase 'benevolent society' has been interpreted in these instances suggests that 'unions' are alien to Samoan society and IR due to the nature of most union activities. Because this view is commonly shared by union participants, it thus suggests that Samoan unions see their role in perhaps a similar light to enterprise unions in Japan, and hence much of the rest of East Asia. While the supporters of enterprise unionism argue that it leads to a cooperative relationship between employer and union, critics claim that the dependence of the union on the individual employer leads to quiescence and ineffective representation (Encyclopedia of Management, 2010).

The majority of participants in this study referred to inter-personal, both within and outside the work environment, as usually founded on 'trust' and 'loyalty': in which both concepts are construed to encourage one 'to trust your leaders' and 'to be loyal to your 
leaders'. In the context of the workplace, these forms of trust and loyalty are seen as the bases upon which good IR are founded and where the unilateral action of employers and management is accepted as the common ideology that binds the system together. The unitary ideology, as discussed in (Dobson, 1982), comprises a belief that hierarchical structure of organisations should be accepted, with a natural division between the leaders and the led.

For most of the union interviewees, the concepts of fa' aaloalo and va fealoai are seen to have silenced the voice of the worker, putting them in a more vulnerable and weaker position in the employment relationship. As one of the government representatives noted, the fa'asamoa tends to settle a lot of issues within the individual organisation without the need to resort to strikes and other severe industrial actions, and without the need to bring matters to the attention of the Labour Department. People will only come to the Labour Department to seek assistance in areas of the law that are not really clear to them, or basically to ask about their rights under the legislation: especially when they feel that their employers have lapsed payment of certain mandatory entitlements such as superannuation and accident compensation. "Therefore, things have been working out so much better that way and there is no real need to be pressuring workers or encouraging them to become organised for the purpose of stirring things up in their relationship with their employers".

\subsection{The impact of the economic context on the IR system of Samoa}

Although Samoa's economy has been reported as generally positive for a small island nation, with an economic freedom score of 60.4 placing it as $13^{\text {th }}$ out of 41 countries in the Asia-Pacific region (Heritage Foundation, 2010a), its economy has been 
substantially affected by the global recession, particularly in terms of a fall in manufacturing, exports and remittances (Australia Government Agency, 2009). ${ }^{13}$ For instance, when the global financial crisis affected the production and export of automotive wire harnesses to Australia by Yazaki Samoa in late 2008, Yazaki was forced to reduce both its workforce and its operational hours in order to cut costs (Central Bank of Samoa, 2009). These reductions inevitably impacted on the employeremployee relationship in that company.

As discovered during an interview with a Yazaki union representative, the most severe impact of the recession was that it gave Yazaki management full control of the employment relationship and the power to lay off half of the workforce immediately as well as delaying payment of benefits (e.g., untaken annual leave) without consulting the worker's union or Yazaki Staff Association. While the respondent noted that this outcome was fair given the situation at the time, what arose from the interview offered an explanation of the process that Yazaki uses to determine workplace rules, that is, the 'management's right' to unilaterally make decisions in the workplace. As was also discovered during the interview, the senior executives of the Yazaki Staff Association were also members of the company's management; thus the Staff Association was seen as an apparatus by which management could gain the cooperation of the workers. The impression that results from this relationship between management and staff representation is that any effort to organise workers is usually in practice geared towards efficiency and productivity and not industrial relations.

\footnotetext{
13 While the term "economic freedom" allows various interpretations, it is used in this context to refer to Samoa's freedom to produce, trade and consume any goods and services acquired without the application of force, fraud or theft.
} 
With the majority of local businesses operating on a relatively small scale, an increase in the cost of doing business forces employers to cut jobs. A report from Samoa Chamber of Commerce and Industry ("the chamber") notes that the vast majority of employers are finding it difficult to keep up with required minimum wages and the payment of other benefits such as maternity leave. These factors are identified in the chamber's report to be impinging on employment relationships in Samoa, and in turn hinder significantly the overall ability of the nation to create and sustain formal employment especially in the private sector, which stands as evidence of the significance of the informal employment sector. Because of the inability of many small family businesses to strictly adhere to conditions governing payment of wages and other benefits during recession, there is a general preference held by employers for a selfregulated and decentralized system of IR. In their view, a decentralized system of industrial relations is more suited to Samoa's business environment, as it would give employers the autonomy and flexibility to make necessary adjustments during times of hardship. Flexibility better suits employers, as well as the government, as one of the union representatives noted that decentralized, fragmented systems favour the powerful, on the principle of 'divide and rule', thus adding to the diminishing relevance of unions. Such is the current state of the Public Service Association (PSA) or the national union of workers in Samoa.

An analysis of Samoa's economic context also reveals that the impact on employment of increased business costs is particularly evident in private sector employment. Rising costs have contributed to the employee's hesitance to pursue negotiation with their employer over better wages and other forms of compensation comparable to public sector employees due to the fear of losing their current job. In the private sector, it is 
relatively easy to fire people because there is little protection available to workers under the current Labour and Employment Law of 1972. In most cases, the only requirement is for one party to give at least one-week's notice to the other to make known one's intention to terminate the employment relationship.

Besides a shortfall in formal employment accompanied by recent increases in youth unemployment (Australia Government Agency, 2009), the vast majority of the workforce in Samoa, especially in the private sector, is employed in low-skilled positions. This has put workers in a much weaker and more vulnerable economic position because in the resulting labour climate they could easily be replaced upon leaving. Unemployment has also greatly reduced the incidence of workers organising into unions in the private sector, and in turn has minimized the potential for workers to participate in employment decisions at any level.

The lack of (or access to) quality education is identified by some of the participants in this study to be one of the main reasons most workers are finding themselves in weak and vulnerable bargaining positions. General lack of education in the workforce has notably affected employment, particularly in the informal sector: firstly by determining a low minimum wage for informal sector workers and secondly by influencing the extension of the labour law to also include subsistence, informal workers (those in service to the community or to a matai).

As one of the key participants points out:

When the labour laws were drafted, they allowed for a certain degree of 'dualism'. They introduce the Western model but make sufficient allowance for the fact that we 
also have our traditional system (cultural values) that may come into conflict with the western model in some ways [Government Representative 1].

While the Labour and Employment Act of 1972 establishes the basic standards and conditions of employment for the private sector, its application is limited to those in formal employment. This is viewed by some of the participants in this study as sufficient, merely because the Act recognizes certain elements of the fa'asamoa that cannot be fully comprehended by Western law. Such elements include a matai right to create rules and to reward a person who has provided a service to the matai and village community in whatever way or means that the matai considers appropriate. For instance, a paramount matai may bestow upon an individual that has been supportive an important chiefly title, or give the individual the exclusive right to use and develop a portion of communal land in order to earn a living for his family. In Samoa, most families do not have freehold lands, and with a significant number of people, especially those living in the villages and engaging in subsistence, informal work, the people rely on the generosity and support of local matai to attain the basic necessities of life such as food and income from farming activities. The provision of exclusive rights to and by matai is a key example of the attributes of Samoa's IR system that Western labour law cannot accommodate, and in which cases the traditional customs and rules prevail. For example, the act does not impose a minimum wage or employment standards on the informal sector, particularly pertaining to familial relationships, as these rules would affect the livelihood of the individuals within the community. To enforce Western labour law on employment relations in the informal sector would threaten to disturb the peaceful nature of Samoan society and therefore impinge on the system of social justice and authority structured around matai. 
According to some of the respondents, the chief success of Samoa's IR system is that while formal employment is governed by Western rules in conjunction with informal customs and practices derived from the fa'asamoa, informal employment is guided primarily by Samoa's traditional (fa'amatal) system: without the intervention of the Western laws.

\subsection{The relationships within the IR system of Samoa}

Samoa's IR system is quite stable, though some improvements are necessary in certain areas of the legislation to allow for 'union' recognition and to encourage workers' (via unions) participation in employment decisions. According to several interviewees, the law makes no reference to trade unions with regards to union activities in general: for example, regulations for membership, registration and more importantly dispute resolution procedures. In addition, they contend that there are no statutory procedures governing the negotiation of either individual or collective contracts of employment.

The lack of precise procedures to deal with unions and industrial disputes largely springs from the social institution of Samoan society. While there is a law that allows the formation of free trade unions in Samoa, the fa'asamoa, in particular the notion of the 'benevolent society', which is typified by values of respect, trust and loyalty towards the elders and leaders, hinders significantly the development of unions as formal and strategic organisations possessing valid roles and purposes in the determination of workplace rules. The data also reveal that, while employers are generally supportive of workers forming unions, they show very little interest in creating an integrated IR system for public and private sector employment, and are particularly averse to any suggestion for employers and workers associations to organise 
as collective bargaining partners. Interviews with union representatives otherwise reveal that trade unions would have benefitted from nationally integrated IR institutions among which their unity provide strength. An excerpt expressing this viewpoint is referenced in Appendix E: Para. I.

The current trend facing employment in Samoa, however, is towards recognition of freedom of association of all workers, including those in the public sector. Employees are free to join trade unions and staff associations to protect and represent their interests at work. There have been conflicts between government and unions or staff associations over issues related to pay that have resulted in strikes. In 2005, strike action was taken by the Samoa Medical Association, which prompted the government to appoint a committee to review the salary structure for doctors. The government also took a bold step to restructure the public health sector, which resulted in the establishment of a National Health Service (NHS) in 2007 as a separate entity from the Ministry of Health $(\mathrm{MOH})$. According to one of the interviewees, these changes are largely attributed to pressure from the Samoa Medical Association in collaboration with other international agencies such as the World Health Organisation (WHO) and the Australian Government Agency. What arose from this interview reflects positively on Leat's (2007) discussion on how the international context can exert influence on the national context, and eventually on the organisational context and the IR system itself. This literature, among others such as Kochan, McKersie, \& Cappelli's (1984) strategic choice theory, extend Dunlop's discussion of the technological, product market and budgetary contexts and the locus of power distribution in a larger society where these factors are seen as affecting the actors' relationships within the IR system. Such is the state of various 
public sector structural reforms in Samoa that the combination of traditional and Western leadership in the IR system is under threat.

\subsubsection{Employment legis/ation}

There are two distinct pieces of legislation governing IR in Samoa. The Public Service Act of 2004 (a modernized act replacing the Public Service Act of 1977) applies to public service employment (or government workers) and the Labour and Employment Act of 1972 regulates private sector employment as well as the majority of government statutory corporations (e.g., Electric Power Corporation, Samoa Water Authority, etc.). This legislation is administered under two separate government departments, the Public Service Commission (PSC) and the Ministry of Commerce, Industry and Labour (MCIL), under the general direction of the Commissioner of Labour. Despite an effort to bring both the public and private sectors under one constitution, through the introduction of an IR bill to Cabinet in 1992, the bill fell short in various aspects. In particular, the fact that unions were not even mentioned in the bill, in which the term "workers" was used to express the collective approach, did not settle well with the nation's unionists (see Prasad, et al., 2003).

\subsubsection{The role of government in Samoa's IR system}

The Samoan government remains the most significant and dominant employer in the public sector and in IR in general. While most participants in this study were highly critical of the national government's role in IR, as discussed previously, recent years have seen the government relaxing its authoritative stance and taking a more proactive and holistic approach to IR by focusing on human capability and human resource development (HRD) in certain areas and professions. However, these changes in the 
government's mood and approach did not occur independently and not without pressure from unions and staff associations and overseas donor agency such as AusAID and its involvements in departmental reforms. For instance, discussion with representatives from the two main medical staff associations in Samoa highlighted the positive impacts that HRD policy has had on employment relations: particularly with improvements in working conditions and incentives for medical personnel, which were reviewed during the doctors' strike in September 2005. The impact of the doctors' strike led to a government acknowledgement of the need to retain doctors and to attract overseas doctors to cover local skills shortages. The HRD framework also opened up opportunities for undergraduate and postgraduate training for other professionals in the health system: such as nurses, radiologists, lab technicians, pharmacists, radiographers, dentists, etc. Upgrading the skill level of nurses, which make up the largest health workforce at the National University of Samoa (NUS) Faculty of Nursing and Health Science (Australia Government Agency, 2009), has had a significant impact on the nurses' salary and conditions of employment according to one of the union respondents. This move also upgraded the standard of practice in nursing as well as the nurse's reputation. These developments have affected various attributes of the extant IR system of Samoa, as was apparent from an interview with one of the union representatives. See Appendix E: Part. II.

The introduction of postgraduate nurse training, in specialist areas including midwifery, mental health and pediatric nursing, also owed much of its success to the collective efforts of the Samoa Nurses Association. ${ }^{14}$ Based on the medical profession's situation at present, and in retrospect of the role the Samoa Medical Staff Association and Nurses

\footnotetext{
14 The emphasis on the Nurses and Medical staff (doctors) Associations in this discussion is due to their participation as union representatives in this study
} 
Association played in influencing employment policies in the public health sector, unions can and indeed will have some effect on IR outcomes, rules and regulations, provided that a certain element of acknowledgement of each party's role exists between the government and employees.

The representatives from the medical associations and government agencies reflected very positively on the newly established framework of the public health sector for various reasons. Since 2007, the Ministry of Health has been divided into two main sections, with clearly defined and distinct roles. The Ministry of Health (MOH) is assigned the role of administering public health policies and the role of regulator of these policies. The National Health Service (NHS), established in 2007 under the National Health Service Act of 2006 has the primary role of providing a wide range of clinical and general health services to the public; hence the majority of doctors, nurses and other clinical staff, such as radiologists, are incorporated within the NHS. The $\mathrm{MOH}$ remains under the jurisdiction of the PSC, while the NHS has its own Board of Directors and this board is comprised mainly of medical personnel. Based on interviews with union representatives in the health sector, the most promising attribute of the restructuring is that it would give medical staff the opportunity to exercise strategic control of budgetary as well as personnel issues. This suggests that the NHS division will be able to deal directly with substantive issues of pay, benefits, terms and working conditions for medical professions because the NHS will have its own budget: autonomous of the $\mathrm{MOH}$. However, what also came across quite strongly from the participants is the view that the NHS and MOH interests very often overlap and interrelate to an extent that the role of one organisation would often be compromised for the gain of the other. Given also the MOH's role as a specialized government agency 
responsible for public sector health policies, it is likely that this agency would make rules that are advantageous to the Ministry or would define these rules based on whatever the Central government dictates. Put simply, one of the representatives for the Samoa Medical Association reported that for as long as the government continues to overrule the budget requirements of the NHS, which would include funds for specialized training for medical staff, salary increments and a range of incentives to retain doctors in the public sector, there remains a possibility for the public health sector to revert back to "the way things were for the doctors" under the MOH. As long as a dominant player exists in Samoa's IR system, there will always be a "non-zero sum" i.e. everybody depends on everybody else: win or lose - together.

\subsubsection{The role of the International Labour Organisation}

Industrial relations regimes are relatively new and evolving in Samoa. The International Labour Organisation (ILO) has advisors working with Samoan national government to strengthen its IR system, legislative frameworks and collective bargaining and dispute resolution on the basis of ILO conventions. As discovered from the ILO workshop, reasonable progress has been noted to have taken place in Samoa's IR system. This includes the ILO's creation of a tripartite forum to discuss matters relating to employment in general, and to help design a unified dispute resolution system for both public and private sector employment.

Following the systems model, this tripartite relationship is located in an environment (or from the point of view of the systems approach: in a supra-system), which Dunlop reduced to three kinds of factors: market conditions and budget constraints, the stage or level of technological development, and the distribution of power in the larger society. 
Dunlop is of the opinion that the actors' relationships within an IR system are valid at all levels, i.e. in the workshop, in the enterprise, in the economic branch, in the economy as a whole and internationally. Therefore, the tripartite relations must be viewed as a pure formal pattern when applying to all hierarchical levels, because the factual quality of relations and processes at these levels can be very different, even contradictory (Dunlop, 1958).

Samoa's IR system highlights a number of important issues to be considered in the implementation of a Tripartite Forum. First, the tripartite relations are seemingly valid only for larger organisations such as Yazaki Samoa, thus ignoring the existence of smaller and less significant employers and staff associations. Second, the tripartite relations primarily take place at the national level, yet if the majority of employers and employees are operating at a small business level that is also largely untapped in terms of representation, the effectiveness of a tripartite arrangement on the organisational level is questionable. The output of the system, however, affects both workers and employers, mainly in the private sector, in that small businesses basically rely on the dialogue between the government, the chamber and the Public Service Association to produce rules advantageous to them. From the respondents' points of view, this implies that there is a greater reliance from employers and employees on the 'benevolent government' to exercise its discretion on industrial relations and economic factors that are beyond the immediate parties' ability to control. Such discretion may include the government subsidizing for workforce training and short-term skill development, reducing product import tax rates and subsidizing the payment of leave (e.g. maternity leave) in the private sector. 


\subsection{Employment in the public sector}

\subsubsection{Legis/ation}

As briefly highlighted earlier, IR in the public sector is regulated by the Public Service Act of 2004, which is administered by the Public Service Commission (PSC) and applies to all government workers. The act was intended to modernize the legal framework for the Samoa Public Service (SPS) from the original Public Service Act of 1977. Since 2004, the act has had two amendments, one in 2007 and the other in 2009 , to reflect the various public sector structural reforms taking place over the past decade. Though the legislation has undergone several revisions since its original form in 1977, it still lacks a formal dispute resolution process that deals with unions: an omission that has also been noted by Prasad, et al. (2003) to have had a noticeable impact at times when negotiations between the government and the PSA collapsed. This indicates that, albeit a formal process to deal with employee grievances is clearly present, there is still no mention of unions. More precisely, any other change in regards to employee grievances and disciplinary procedures (e.g., Public Service Amendment Act 2002) has been minimal and incremental with merely an individual as oppose to a collective (union) focus. The Public Service Act of 2004, however, seeks to promote employee participation in decision-making through workplace forums, employee consultation and joint decision-making on certain employment issues. It provides for simple procedures for the resolution of labour disputes mainly through independent dispute resolution processes, which apply to both individual grievances and group or workers' association disputes. 


\subsubsection{The role of the PSC}

The PSC was established under the Constitution of Samoa as the principal employer for all of the SPS, but the Public Service Act of 2004 in reference to the Public Service Act of 1977 outlines the methods and conditions of the PSC as well as the Commission's powers of investigation and enquiry. Under the current legislation (i.e. the Public Service Act of 2004), and as in the original act (i.e. the Public Service Act 1977), the Public Services Commission, or officers of the Commission, may use the same powers as the Commission of Inquiry to summon witnesses and to receive evidence. ${ }^{15}$ The establishment of the act in 2004, in order to better reflect structural reforms in the public sector that had taken place in 2003, also coincides with changes in the Commission's duties. Several HR functions that had previously been undertaken by the PSC have all been devolved to the individual line ministries for implementation: these include recruitment and selection, ${ }^{16}$ promotion, transfer, disciplinary actions and termination of public servants, including for example termination by retirement and by redundancy. Thus, since the public sector structural reforms the Commission has concentrated on its strategic HR functions of a policy (rule) making authority for public sector employment. These functions can be broadly described in terms of policy planning, development and promotion, policy monitoring and evaluation, as well as advising and assisting ministries on all HR related matters. Based on several interviews, participants feel that the current practices in public sector employment, including a concentration on individual contracts, are likely connected to the decline in PSA activity in recent years, and the unions' diminishing efforts to establish a centralized bargaining structure with government. The data also reveal that, while there is evidence of legislation established

\footnotetext{
15 All employer powers exercised by the Commission or by a CEO under the Act are exercised on behalf on the government which also makes clear that the employer is the government.

${ }^{16}$ Limited authority of a CEO: A CEO of a government ministry is given the authority to recruit employees starting from a clerical to a principal level position with the exception of contract positions (e.g. Assistance $\mathrm{CEO})$ which must be done by the Commission.
} 
for the protection of the workers (individual rights), the government also seeks to control social conflict. These two intentions have deepened with time in that there is now sufficient protection for individual employees, with concessions to standards of employment and work benefits, and yet the lapse in legislation recognizing union rights is perceived by several participants as the government's practice to control and limit groups or collective actions. This allows the government ample discretion in decision making over the legalization of unions and the admissions of workers demands and strike regulations, particularly in public sector employment.

\subsubsection{The process for establishing work rules in public sector employment.}

Although the Commission is primarily responsible for setting the terms and conditions of employment for all government workers, as stated in the act, any changes to an existing policy are to be made in consultation with the Human Resources Coordinators (HRCs) and Assistant CEOs of all the government ministries. The ministries are encouraged by employment policies to share work-related information with employees in order to minimize conflicts and to facilitate discussion between the ministries' representatives and the Commission when reviewing policies. Indeed, one of the government representatives reported that the relationship between the Commission and the individual ministries has generally improved over the past decade: mainly due to the decentralization of HR operational functions to line ministries, and the Commission's adaptation toward a consultative rather than a dictatorial process in the establishment of work rules.

The consultation process appears to be the prevailing mechanism in determining IR outcomes in the public sector. Based on several interviews, it was found that the 
establishment of a consultative framework to involve line ministries is partly due to the Samoan government responding to pressures from overseas agents (e.g., Asian Development Bank, Australia Agency) urging Samoa to control government spending, and partly relates to the enhancement of public sector services, through processes such as training, education and up skilling that support employees' professional development needs. These changes indicate, at least to some extent, that the consultation process is primarily guided by an economic as opposed to a purely industrial relations focus.

While the consultation process has allowed some degree of participation from the government ministries, it is clear from the interviewees' viewpoints that they would much prefer a 'co-determination process' by which they may take a more active role in the establishment of mostly procedural rules: for example, taking part in the design or review of the salary structure. From that perspective, the majority of interviewees pointed to what they see as the "true nature" of the 'consultation process', in the sense that the Commission is concerned more about demanding support and compliance from the ministries, than it is about encouraging participation in decision-making. This is also characteristic of Samoa's social context and traditional rule making, in the sense that neither of the two processes is intended to presume an equality of power between the PSC and individual ministries or the staff of organisations/associations. Generally, this analysis of the processes corresponds with the systems model, as it is fundamentally concerned with the determination of rules governing the performance of work, noting that such rules vary in their degree of explicitness on a scale running from laws at one end (e.g., the Labour and Employment Act of 1972) to informal customs and traditions at the other. What Dunlop offers in this regard proves to be of relevance to Samoa's IR system, in that certain processes do not necessarily result in certain (or predetermined) 
outcomes. In addition, applying Dunlop's model in this context helps remove the relevant parties from any unrealistic assumption that a co-determination process will give workers equal power of influence over workplace rule. This applicability is also true of the view expressed by Markley (1993), that even if the workers play no part in the establishment of workplace rules, an IR system would still set the rules: in the case of public sector employment with just the sole involvement of the government.

Industrial relations in the public sector appears as though the government through the PSC unilaterally sets the rules, a practice that seems also to be contributing to the lack of clarity as to the role that the CEO of a ministry is supposed to be playing in the system. As one of the government representatives reported, a CEO has a limited role in policy making, though he or she may be perceived to be a representative of the employer and as such a member of the rule-making authority. In addition, any clear process that the Commission must follow in determining the salaries and conditions of employment remains yet to be seen, as stipulation on this matter was not included in the modernization of the Public Service Act. The Act does not explicitly recognize a role for unions in the consultation (or negotiation) process for the determination of salaries and conditions of employment. Prasad, et al. (2003) raised the same concern and most participants discussed the various deficiencies of salary structures in the public sector and argued that these generally relate to the hierarchical positioning of salaries across professions and occupational groups. For example, all CEOs across the government ministries and statutory corporations receive the same remuneration package regardless of the individual scope and nature of their responsibilities. The next level down from the CEO which is the Assistant CEO position, is also assigned a salary range that applies to all ministries and corporations. This pattern of salary structuring trickles down to the 
lowest-ranked occupations where the wage rates of public servants consisting mainly clerical work are determined at a point in time by an internal job evaluation system carried out the PSC.

\subsubsection{Procedure for wage setting in the Public Sector}

The government's position of opting for a standardized pay system across all the government ministries is geared towards consistency and to avoid having to deal with issues of pay differentials. However, some union representatives noted that the standardization of the pay system appears to be neither a realistic nor a sustainable option, because it undermines certain values, qualities, qualifications and other professional attainments that are required of some professions and not of others. For instance, one of the union representatives argued that a newly graduated doctor should be on a higher salary grade than someone with a Bachelor of Science (BSc) for example, and that a senior consultant should not be paid a lower salary than his CEO simply because the pay structure dictates that no one should be paid more than a CEO in the public sector.

According to one union representative:

Salaries should not be standardized across the ministries. You get paid for the work you do. It does not matter whether you are a CEO or somebody lower down the ladder: the energies and all the work that you do, if you can weigh it out, and if it is worth a lot more than the work of a CEO, then you deserve to be paid a pay comparable to what you're doing that the CEO is not doing or cannot do [Union Representative 1].

Several interviewees suggested that it would be difficult to assume that participation from the ministries (or staff associations) will necessarily result in improved wages and 
conditions of employment for certain occupational groups, in part because of budget constraints and largely because wage setting in the public sector is not justified by worker productivity. The contexts of budget constraints, technology and locus of power, as discussed by Dunlop affect the actors' goals, bargaining positions and level of interactions within the IR system. Provided that unions become involved in wage setting in the public sector, wages are likely to increase: thereby in turn affecting private sector wages. This result would occur because any alteration in one part of the IR system can be expected to impact on other parts, and to feed back into the system. Fundamental to Dunlop's discussion, however, is the view that even if the balance in a system is somewhat displaced due to changes in the environment, it would become reestablished given the condition that no major alterations would occur in the actors, contexts and shared ideology. Samoa's IR system can thus be interpreted in light of Dunlop's view in that in order to preserve various aspects of Samoan traditions, which basically give the government the power and authority to unilaterally make decisions pertaining to industrial relations, the government makes sure that unions remain relatively marginalized in the processes of industrial relations.

\subsubsection{Unionism in Samoa}

An analysis of Samoa's IR system requires knowledge of the role unions' play in industrial relations: in particular of their involvement and influences on the rule making aspects of the employment relationship. In Samoa, the term 'trade union' is rarely accepted, and in most cases it is not used to refer to an organisation of workers as the term is seen as a Western concept that does not quite fit with the cultural values and norms expected of Samoans. To some, the term 'trade union' connotes the necessity of an existing "oppression" to be opposed - a form of insubordination that contradicts the 
longstanding tradition of respect for those in higher authority, or for those who have been chosen as leaders. Others simply see 'trade unions' as an unfit concept mainly because there is not sufficient trade in Samoa to justify the need for trade unions. In fact, a more common and culturally accepted term for a workers' organisation is 'staff association', which implies equal reference to any workers' organisation within the workplace. The organisations that 'staff association' may apply to include other professional organisations of workers such as doctors, accountants, teachers, lawyers, etc. The majority of these staff associations are located within the public sector, but they are non-government organisations (NGOs) in the sense that their activities are not governed under any statute. Their main objective is to safeguard the interests of their members, which are not always purely related to IR. Being formally organised groups of workers, they would naturally expand their roles to pursue collective bargaining and negotiation with the employers in regards to wages and conditions of employment, but most do not in actuality feel that they are acting as unions. Another interesting perspective expressed in the interviews was that because of the way in which Samoa's economy is organised, most Samoan people do not really feel the urge to join or to become formally organised as unions, because the survival of the individual is not always dependent upon formal employment, as it tends to be in New Zealand and Australia, for example. This worldview thus suggests that for most people, it really is not greatly significant if they have a job the next day, or the following week because they will always have a community to fall back on for support. An excerpt expressing this view is included in Appendix E: Para. III.

For the most part, however, the lack of union activities and the marginalized role of unions in Samoa's IR system carries the implication that Samoa is predominantly a non- 
unionized nation, to the extent that unions will continue to be marginalized in Samoan society for the foreseeable future.

As one of the participants in this study noted:

I think Samoa is generally an environment that is alien to unionism; or rather Samoa and its IR system would be viewed by trade unionism and IR experts as alien. The basic ingredients that reflect the makings of unions or call for the organisation of workers are not there, or not quite there yet [Independent Consultant 3].

In addition, Samoa, like many PICs, has no organised institutional relationship between trade unions as representatives of workers and employers' organisations, in the sense of collective bargaining partnerships, as are common in industrialized economies.

\subsection{The historical development of the PSA}

Expatriates first established the PSA (formerly known as the Western Samoa PSA) in the 1920s as part of the New Zealand Public Service Association, and the union became localized after Samoa gained its independence in 1962 (Prasad, et al., 2003). The PSA was first incorporated in 1964 and it has since struggled to represent the interests of permanent workers in the public, including teachers, doctors, dentists, nurses and post office workers. The primary objective of the union at the time was to maintain salary levels in parity with changes in the cost of living. It also assisted members with appeals regarding promotion, re-grading and disciplinary action. Several of the participants in this study considered the PSA as the closest entity to a 'union' in the context of Samoa.

Other associations, such as the Nurses Association, Teachers Association, and Samoa Medical Staff Association, emerged alongside the PSA to focus on professional issues: 
including for example, specialized and professional development training. As noted earlier, these associations would occasionally pursue 'industrial' matters, or they would pursue matters where the industrial/professional division was less clear, for example, providing training for midwifery nurses. Nonetheless, individual public employees generally maintained dual membership of their professional association and the PSA, albeit there was no affiliated or formal link between the associations (Prasad, et al., 2003). Having dual membership seems appropriate in this context: for example, the Nurses Association has other international affiliations that members could approach about matters such as specialist training and professional development, but locally situated issues related to pay and other conditions of employment require the support of the PSA.

Other than 'pay', one of the interviewees explained that, exclusive member services such as the PSA Loan Scheme and the PSA Bar \& Pool House motivate workers to remain a part of the union, despite several criticisms that the Association does not behave in the capacity expected from a union. From 1984 until the late 1990s, the PSA operated as a Credit Union, by using members' subsidies to fund a loan scheme to members at a discounted interest rate that was agreed upon by the executive members. At the same time, the PSA operated a Bar and Pool House, selling Vailima (local beer) to members, also at a discounted price. From the respondents' point of view, these factors affected the union's status in Samoa's IR system because the PSA emerged as a social club and not a trade union.

During the early years of independence, the PSA faced a number of difficulties, which eventually led to its failure to remain as an incorporated society in 1978. It was reported 
that the union faced difficulties in attracting and organising members. Membership continued to drop, with only a minority of the permanent public servants remaining. The absence of a precise procedure for settling disputes between the PSA and the PSC made it difficult for the Association to represent a 'united' voice regarding wages and conditions of employment.

The PSA, however, developed a reasonable working relationship with the PSC on dayto-day matters that included an agreement for direct deductions of union subscriptions from the payroll and permission for workers to leave work early (about $3 \mathrm{pm}$ ) to attend the Annual General Meeting (AGM) of the Association. But the settlement of collective disputes about salaries and other terms of employment was a different matter. The PSC, individual ministers, Cabinet and the Prime Minister would become involved in trying to resolve industrial issues with the Association but this caused more delays and problems throughout the 1960s. This situation was not addressed when the Public Service Act of 1977 was established and it eventually surfaced as a significant issue leading up to the PSA strike of 1981 (Prasad, et al., 2003).

As explained by the participants in this study, conditions for the PSA generally worsened in around the early 1970s, and by 1978 the union became deregistered after failing to submit annual returns as required under the Incorporated Societies Ordinance of 1952. While interviewees noted that some activity that occurred in the early 1970s evidently resulted in a partial upgrade of salaries in July 1975, over the years this activity was spasmodic and diminishing. In that regard, it may be worthwhile to note that one of the participants in this study played a key role in the initiation of a salary review that resulted in a salary upgrade for a specific class of teachers in 1975. This 
participant, from the perspective of direct personal involvement, offered an explanation as to the reason why such an initiative was somewhat short-lived:

I made an argument that the teachers of Samoa College were a special lot. The PSC was able to upgrade the teachers' salary based on that argument. Since precedence was set with the Samoa College teachers' salary, other public sector employees approached us to negotiate on their behalf and it really became a major concern for the government, as a general wage increase would also drive up the price of labour in other sectors. The fact that the government was not able to satisfy everyone in this situation in this way prompted the PSA strike action [Independent Consultant 3].

The above interviewee also confirmed that the Samoa Teachers Association was the only real active association at the time, but was not a participant in IR matters. It was an active organisation of workers in the sense that it was a body of light-minded individuals who were there to serve the whim of government. For example, if the government wanted a cultural dance group to perform during independence celebrations, or when entertaining visitors from abroad, the Samoa Teachers Association was the best group to carry out these requirements.

Although other professional associations, such as those attended by nurses, doctors and lawyers, slowly came in under the PSA after it was revived in 1979, most did not fully understand 'industrial relations'. Those who knew something about the concept thought that they could carry the PSA to a point where it would become a formally recognized union representing all public servants, but they too had other personal motivations and agendas. Some would campaign for election to executive positions both as public servants and as PSA members. As explained by one of the interviewees, the vast majority of public servants, like the teachers at the time were seen as individuals who could easily be controlled and influenced by cultural practices. For other public 
servants, they basically saw the reestablishment of the PSA as an opportunity to stand out as 'educated young men' with great ideas, which they believed would give them the advantage of being recognized as a minority and an elite group of people who were fortunate to have been educated abroad.

The reestablishment of the PSA in 1979 emerged as one of the focal points of discussion with those interviewees who had taken part in the revival of the Association because the event links directly to the PSA strike in 1981. As highlighted above, one of the factors that seems to stand out from the research discussions is that, the very few PSA leaders who have had education abroad were lauded by the impression of possessing certain qualities that would distinguish them as an emerging generation of future professionals in Samoa. In addition, this elite group of individuals genuinely believed that they had an advantage to attract more members and that they could easily influence employment policies in the public sector. Like the government, the PSA also sought to gain unilateral control of employment decisions in the public sector by exerting pressure on government to make policies that are advantageous to the union. That pressure apparently became the main source of power for those individuals seeking high positions in the PSA, and therefore, the strike encompassed a political rather than an IR focus. This discussion relates to Dunlop's view of power-distribution within and outside the IR as it reflects the goals and values of the actors and the degree to which they are sufficiently compatible with permitting an IR system's continued existence. It suggests that if the goals and values of the actors reject the possibility of any role at all for one or more of the other actors, there will be no IR system, only a political one.

In its earlier years of reestablishment, the PSA's determination to play an active role in trying to bring Samoa's IR system to a reasonable level-playing field for the 
government and workers had not been significantly affected by the lapse in regulations governing union activities, as was evident in the PSA strike. When the interviewees were asked about the current role of the PSA, and how it has evolved since the strike, there was a consensus among former members that the union had only been active in IR from the 1980s into the early 1990s. In addition, however, some were particularly apprehensive about the PSA posing as a union representative for the private sector; others were frustrated with the fact that the PSA is not doing what it is supposed to be doing, which is to keep debates going with the government. The latter view is based on some interviewees' belief that situations would eventually improve for the union, provided that it continues to play a hands-on role in public sector employment. As one of the interviewees noted, there will come a time when unions can and will challenge decisions that are unilaterally made by employers or government if they can keep on building momentum as a union, and if they can continue working towards attracting more members so that the voice of the workers can become stronger. At present, almost all interviewees shared the view that the PSA's role and energy has been diminishing over the past decade to the point where the union is seen as a disorganised and an inoperative organisation. Excerpts expressing this concern are referenced in Appendix E: Para. IV.

While the majority of participants agreed that the PSA has not been a fully functional organisation of workers over the past six or more years, some emphasized causes of the PSA's present situation. For instance, one of the government representatives argued that the reason for the PSA's lack of action over the past years might possibly be linked to overall improvements in employment relationships, especially in the public sector in which workers do not necessarily see any relevance in joining the union. This is due to 
wages and working conditions being generally improved in the public sector, even without any pressure from the PSA. Others, such as the independent consultants, shared a view that leaders of the PSA do not really know what its role is, nor do they understand the extent to which its participation in formulating national policies impacts on workplace rules, especially when the PSC has not really allowed the union to perform any role at all. One of the participants added that the mere existence of a law allowing the formation of unions in Samoa does not necessarily mean that unions are expected to behave in the way that unions do in other countries or become fully functional organisations of workers, because that type of association would not fit in well with the cultural aspects of Samoan society. Therefore, it is not the choice of the unions to be passive; it is a condition being imposed upon them by society and social norms.

\subsubsection{The PSA strike}

The PSA strike emerged as one of the main points of discussion with the vast majority of interviewees who had had some form of direct involvement with the government during the strike: some had slightly more profound experiences than others. Interviews with former PSA members reveal that some of them still maintain their memberships with the PSA regardless of their respective employment statuses, for example as heads of government departments. Two of the participants in this study noted that they had to withdraw their membership with the PSA because of the conflicting objectives of their current roles as representatives of government agencies responsible for employment, and as PSA members. Those who remain with the PSA only do so in the sense of continuing payments of their fortnightly subsidies to the union, but they have not 
participated in union meetings and other activities for several years, and they do not have any intention or interest to be actively participating in these activities in the future. Based on discussions with the then PSA members who were centrally involved in the PSA dispute, the thirteen-week strike by some 4000 public servants was undoubtedly the most drastic and memorable experience for most. What also arose from those conversations was the view that since the strike is considered to be the first ever event of such magnitude to take place in Samoa, it basically became a 'test of faith' on the part of the PSA, which was aimed to establish the union's position in not only the IR arena, but also in the socio-political context of Samoa as a whole. Several interviews indicated that the PSA was motivated by the intention to see how far workers could go to influence employment relationships in the public sector and/or to create a new cultural work environment in the knowledge that the strike would also impact on the fa'asamoa.

In general, the PSA's strike was considered to be uncharacteristic of Samoan society. From an IR perspective, there were two significant issues that emerged very clearly from the PSA strike. The first issue of concern for the PSA relates to whom the employer was with the power to negotiate, and reach a settlement. For instance, the unclear division between the PSC as the employer and the government's role as legislator was explained by one of the interviewees as one of the contributing factors to the dysfunctional reporting relationship and an unclear line of communication between the union and the government officials. An excerpt expressing this view is referenced in Appendix E: Para. V. 
The second issue raised was concerned with the procedures to be followed when a dispute arises. As highlighted earlier, there were no defined procedures to handle either the substantive issues (wages) or the issue(s) of principles: for example, is a strike a valid reason for a public servant to be absent from work? Some of the interviewees argued that, given the lack of procedural rules governing union activity, there was nothing in the legislation defining whether a strike was legal or not. The lapse in regulations governing industrial disputes also allowed for flexible arrangements between the government and the PSA, in the sense that either party could do as much as they deemed necessary, or they could do as little as possible, to influence IR outcomes. However, with the power and authority vested in government, it is inevitable that the government would have the final 'say' in every employment decision in the public sector.

The PSA strike in 1981 has had notable impact on industrial relations and the IR system of Samoa. First, the strike undoubtedly attracted international attention in that the existence of the PSA as a union in dispute became part of the consciousness of international trade unionism. Expressions of solidarity and funds (a burst of international assistance surfaced during the strike) and were a base for extended and increased assistance in the ensuing years (Hince \& McFarland, 1997). In addition, the strike being the first of its kind in Samoa was an intense learning experience for all parties concerned: an experience which most participants in this study noted to have caused divisiveness and social disparity in Samoan society, because it contradicted the beliefs and values espoused in the fa'asamoa and the true nature of interpersonal relationships within the society at large (see also Snell, 1992; Wendt, 1981). Generally, there was also a realization that the strike had confirmed a deep-seated perception that 
unionism is a practice that is alien to Samoan culture. But from a political perspective, the strike clearly demonstrated the power of 'unity' and 'solidarity', in that the PSA not only had become more feasible as an institution, but it (and its members) had demonstrated the capacity to act as a union. Furthermore, the PSA clearly emerged as a political force. Some prior evidence of this potentiality could have been adduced by the impact of the treatment of the earlier PSA by Prime Minister Mata'afa in the late 1960s, with the public servants reaction leading to (possibly) the fall of Mata'afa's government at the 1970 elections (Hince \& McFarland, 1997). Likewise with the consequence of the 1981 strike, it was evident from interviews with some of the former PSA members, that the PSA's political influence led to the defeat of Tupuola Efi's government in the 1982 election.

That strike brought a lot of changes and historical events that impacted on the IR system. We knew that we had a very unfriendly employer, which was the government, so we wanted to change the government. Therefore, we took on a political agenda, and voted in the candidates from the districts who then went in and voted Tupua out and he never became Prime Minister again [Independent Consultant 4].

After the events of 1981, the PSA did revert to a cooperative, if not submissive, role of consultation and discussion (usually informal) with the PSC concerning day-to-day matters, which were largely related to wages and basic conditions of employment. While some marginal improvement to workers' situations was noted (which was not necessarily a result of the union pressure), the PSA began to move away from playing any real role in the IR system, particularly in the public sector. One of the participants offered an explanation about the diminishing relevance of the PSA in Samoa's IR system. 
[The diminishing relevance of the PSA] may not be [the PSA executives'] fault, things have changed since the strike of 1981. At that time, the PSA showed itself for being a truly functional organisation of workers and was active as such. Since then, maybe the scenario has changed and they no longer act in that way or maybe they cannot act anymore because the people who make up the PSA do not have the loyalty to the PSA that they were able to demand or call upon at that time. They were truly independent, I mean, they were all public servants, but when it came to the issues of the PSA, they were independent and saw themselves as employees that have issues and could act together as employees. And of course, since that time, the ranks of the public servants within the PSA had been drawn from the senior officers even up to the CEO level. Now those people are all contract workers to the government and they are no longer interested in the PSA [Independent Consultant 2]

\subsubsection{The politicization of the PSA}

In several interviews with former PSA members, it was found that an interesting development took place when HRPP came into power in 1982. The then Prime Minister, Tofilau Eti Alesana, announced his portfolio in which PSA was to become a ministerial portfolio. During that time, most people suspected that the politicization of the union was intended to ensure that the union became and remained a part of the apparatus of government and to bring the PSA under the control of the government so that there would be no recurrence of the 1981 strike. Some of the participants noted that this speculation became a reality when the Yazaki workers went on strike in 1993 and the PSA refrained from playing any active role in representing the workers, which eventually led to the fate of many employees to lose their jobs. This is despite the PSA posing as a formal national union for every worker, including private sector employees. The PSA's decision not to partake in the Yazaki workers' strike is seen as having been political, in that some of the participants share the view that the PSA executives at that time were torn between their responsibility to members and their obligations to the government as public servants. As most were high-ranked government officials, the last 
place they would have wanted to position themselves was on the wrong side of government.

In 1984, the PSA affiliated with the International Confederation of Free Trade Unions (ICFTU) as the representative of Samoa, and since it was the only significant player in Samoa's IR system, the union's scope of responsibility evolved to also cover private sector workers. The PSA has since to date being recognized as the representative of all workers in the public and private sectors. As this relationship with international agencies first developed in 1984, opportunities began to emerge for the union to take on other strategic focuses: such as education, training and other forms of professional development for members. This had diverted the union's attention from the substantive issues of pay and allowed them to focus on long-term and sustainable development for individual members as well as member organisations. With the assistance of overseas agencies (e.g., ICTFU and the ILO), the union was enabled to carry out workshops and education campaigns, and due to most training exercises taking place overseas, members were expected to gain international exposure that would also be beneficial towards diversification of Samoa's IR system.

\subsection{Employment in the private sector}

\subsubsection{The environmental contexts of IR in the private sector}

Samoa has a small, embryonic private sector made up largely (80 percent) of many small (family-owned) enterprises that have fewer than five employees (Asia Development Bank, 2007). The private sector business environment has improved over the past few years, with the government giving increasing priority to stimulating private sector development through job creation, education and skill development for both 
employers and workers. In 2006, the private sector accounted for about 58\% of GDP and two thirds of formal employment (Pacific Islands Forum Secretariat, October 2007). Also, in recent years, the growing number of construction companies as well as an expanding service industry, mainly in tourism and hospitality, has noticeably contributed to the development of the private sector.

Growth in private sector employment has evidently brought about certain opportunities as well as constraints on industrial relations and on the IR system of Samoa, with regard to labour laws and other areas related to employment. Employment in other areas such as trading banks, small manufacturing, training and other service industries has catered for a limited number of employees. Samoa's private sector is dominated by Yazaki EDS Ltd, as it has since its establishment in 1992, been Samoa's largest private employer, with approximately 1,000 workers at present.

While in many ways progress has been slow and lacking in depth, recent and continuing government reforms are designed to facilitate a more open and accessible enabling environment for business. The government has acknowledged the importance of the private sector in alleviating poverty and is committed to improving the enabling business environment: a commitment which has impacted on the IR policy framework in Samoa. The lack of jobs makes it very difficult for local government to enforce upon private sector employers by means of legislation the inclusion of such benefits and entitlements as maternity and paternity leave, long service leave and health insurances. The current legislation, however, provides for minimum wage and conditions of employment as well as payment of mandatory entitlements such as superannuation through the National Provident Funds (NPF) and accident compensation funds via the 
Accident Compensation Board (ACB). Thus, establishment of agreed terms and conditions other than those specified under the legislation is left entirely to the employer's discretion. As such, remuneration for labour relies heavily upon the forces of the labour market and the value and availability of certain skills locally.

As typical of many PICs, issues of pay disparity, increase in business costs, employment creation, social dialogue and rights at work emerge as some of the challenges facing many employers in the private sector. The employers' representative interviewed emphasized that these issues were seen as equally valid for the participation of both employers and employees in determining national rules and policies during the ILO workshop.

\subsubsection{Legis/ation}

The Labour and Employment Act of 1972 regulates employment and IR in the private sector. In practice, however, the number of employees covered under the act is far greater than the population of the private sector alone as it also applies to workers in statutory Government Corporations (e.g. Water Authority, Airport Authority, Electric Power Corporation and others).

The Minister of Labour is responsible for overall direction and control of the act but the MCIL, under general supervision of the Commissioner of Labour, is responsible for the day-to-day administration of the act. The department has the broad functions of advising workers and employers on all industrial relations matters, taking appropriate measures to ensure safe and healthy working conditions, encouraging good relationships between employers and workers and ensuring that employers, workers and other persons of 
obligation fulfill any requirements being placed upon them by means of voluntary settlements and industrial agreements and by the act and any other regulations administered by department.

Among the areas covered under the Labour and Employment Act of 1972 are: administration of regulations outlined in the Act; rules for wage protection and contract of service including termination of service and notice periods, holiday leave, hours of work and overtime; shift work; occupational health and safety regulations; and procedures for dealing with industrial disputes. All substantive provisions, for example leave, basic working conditions and safety provisions, are enforced by the Ministry of Commerce, Industry and Labour. An interview with one of the key participants noted that the establishment of terms and conditions of employment in the private sector relies largely on self-regulation and the intention of an employer to facilitate payments of other additional benefits for workers. In addition, the nature of most agreements between employers and employees are largely informal based on what one might termed as a "gentlemen's agreement". This term refers to - an informal, oral understanding resting on the sense of personal honor of the involved parties. Generally, such agreements are not enforceable through courts (Business Dictionary, 2010).

A provision for the establishment of a minimum wage by the Head of State, on the advice of Cabinet, is contained in Section 19 of the act. The minimum wage is expected to provide workers with a basic standard of living when supplemented by other subsistence activities such as farming and fishing: activities in which most families engage. At present the minimum wage stands at \$T2.00: the equivalent of NZD1.06 per 
hour. ${ }^{17}$ Under the act, members of the Advisory Committee are to consult the employers and employees at the time of determining a minimum wage before any changes are to take effect. In that regard, the act is considered to sufficiently support the participation of both employers and workers in the establishment of substantive rules such as wages and other terms of employment. Wage negotiations and policies formulations; however, in the private sector relies heavily on management prerogative and initiative. This avenue is not available in the public sector under the Public Service Commission Act of 2004 as the determining power for wage setting lies with the Commission, with the exception of a General Wage Increase (GWI) where approval from Cabinet is required. The act also expands on the employment of women and children. Under the terms of the act (amended), workers must be at least 16 years of age, except in cases of 'safe and light' work rendered to the matai; and no worker should be required to work for more than 40 hours per week. The amendment to the 'working age clause' coincides with the ILO core convention.

\subsubsection{Procedure for settling disputes in the private sector}

Another positive aspect of the Labour and Employment Act of 1972, which sets it apart from the Public Service Act of 2004, is that the Labour \& Employment Act clearly outlines procedures for assisting the settlement of industrial disputes as depicted in Figure 3. As much of the labour legislation in PICs dates from colonial times, Samoa's industrial resolution procedure was established during the time of NZ's administration of the Samoan government.

\footnotetext{
17 Section 19 (2) of the Act requires that the Minister may from time to time appoint an advisory committee on minimum wages, the duties of which shall be to review comprehensively any industry and report to him on any matter pertaining to minimum wages, standards of living, and margins for skill and to this purpose the committee shall also consult with the employers and workers concerned as it may consider it advisable.
} 


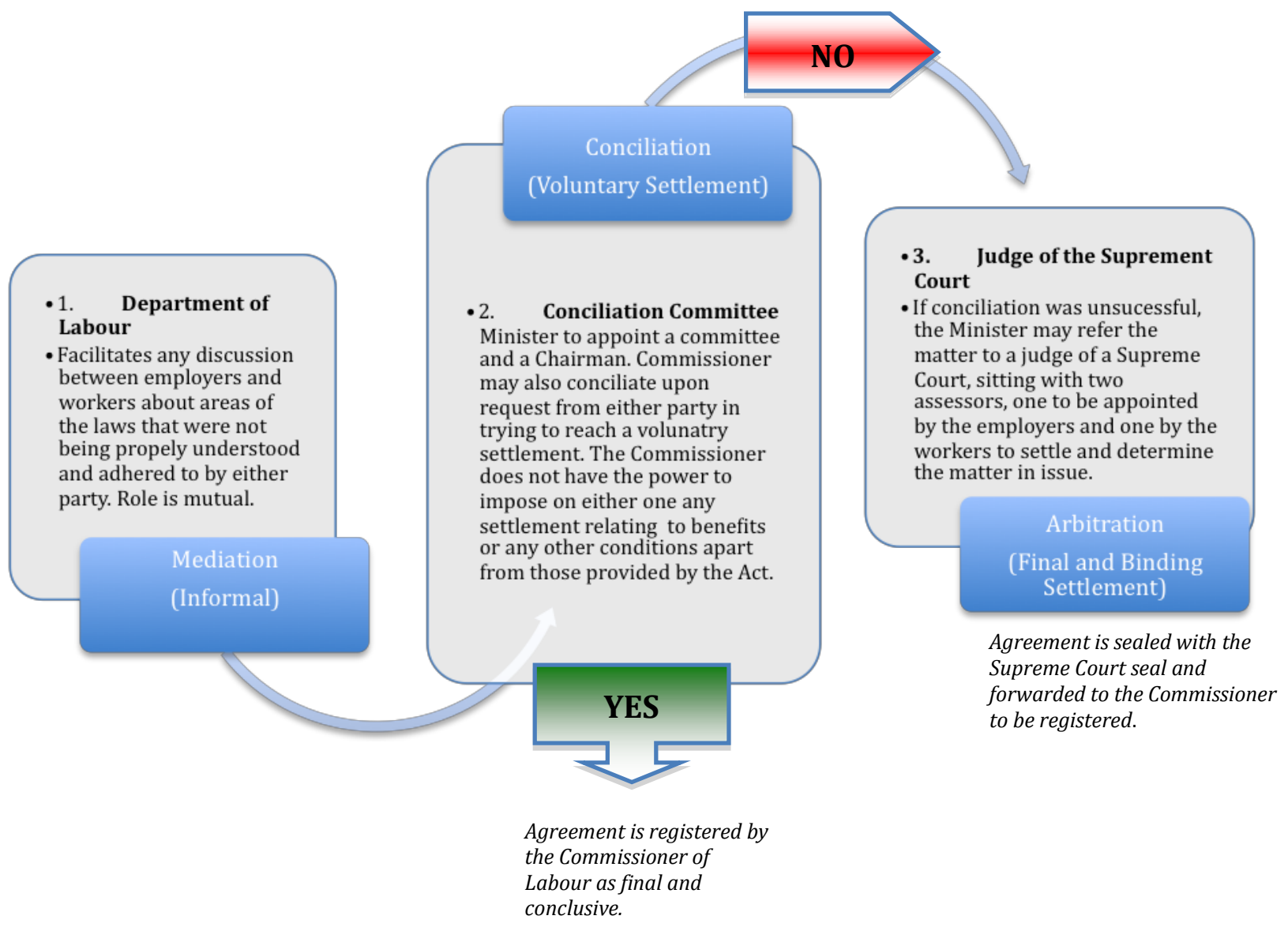

Figure 3: $\quad$ Procedures for settling an industrial dispute in the private sector

While the dispute resolution system makes no reference to unions, it applies to both an individual grievance and a union (association) of workers dispute as these would be treated as synonymous.

\subsubsection{Procedure for wage setting in the private sector}

As briefly highlighted, employers tend to favour a decentralized system of wage determination in the private sector. Likewise, the data reveal that the government insists that wage determination should be decided between employer and employee. The authority of the employers to hire and fire is also unchallenged by legal statutes and 
remains a managerial prerogative. Interviews with union representatives indicated that the state also adheres to the 'voluntarist' framework when it deals with private sector employment, by not introducing statutes that would compel employers to recognize trade unions as bargaining partners.

The organisation of industrial relations thus continues to remain highly decentralized in the private sector in that decisions with regard to pay are made primarily at the enterprise level and are determined by individual agreements between employers and employees. Because there are rarely formal rule-making arrangements that guide decision making on pay and other conditions of employment, or for resolving individual grievances, the organisation of industrial relations also remains characterized by a low degree of formalization.

\subsubsection{Unionism and collective bargaining: historical overview}

To this day, trade unions remain relatively rare outside of the private sector, although some spasmodic attempts were made during mid 1990s to establish a national union of workers to organise workers (associations) in the private sector. As mentioned earlier, unions or staff associations are usually established within the individual organisations themselves. They have very little to no direct influence on employment decisions at the national level, let alone the organisational level. In fact, participation in the making of workplace rules is almost restricted to organised groups in the formal sector. The existence, nature and scope of staff associations and their level of participation may also vary according to the types of organisations they work for, their cultural values, practices and beliefs, the leadership and management skills of the CEOs or General Managers, and the strategic choices of the organisations. This is to say that some 
associations may have virtually no role and no influence or participation in employment decisions whereas others may participate in these decision processes impotently, with no real bearing on employment relations' decisions and rules. As noted from most interviewees, the employers are usually supportive of the formation of staff associations because such an association is not considered to be a threat to the organisation and it is usually helpful to serve the needs of the employers. For instance, Yazaki's adaptation of a Japanese model of enterprise unionism typically places executives of the union in the management team. Their primary objective is to maintain a high level of employee commitment to work and to managerial prerogatives and to appease employees by convincing their representatives in staff association that the management has their interests at heart. In Samoa, this practice is very common with enterprise unionism and rarely do such workers organisations, controlled by organisational management staff, pursue employers on industrial relations matters. Thus, the majority of staff associations organise for the purpose of social networking, fundraising, organising parties and providing support for colleagues during funerals or times of personal loss.

Between 1992 and 1994, a national union called the 'Samoa National Union of Workers' (SNUW) emerged, initiating a positive move towards strengthening union (worker) participation in the making of rules governing private sector employment. The establishment of a national trade union was largely influenced by the events leading up to the Yazaki strike in 1993, in which two key participants had been heavily involved (although practically at opposite sides of the negotiation table). The two key participants mentioned herein include the then Commissioner of Labour and the Secretary General of SNUW (also a former PSA member) who is currently a Member of Parliament in New Zealand. It is worthwhile noting that the Yazaki dispute is the only recorded and 
significant dispute in the history of private sector employment in Samoa. More importantly, the Yazaki strike in many ways supported the view put forth by some of the participants that unions in Samoa do not quite have the attributes of a 'union' by international standards, which is largely due to the national government's lack of support towards establishing procedures that would govern union rights. As reported by one of the interviewees, a key former PSA member who assisted Yazaki workers in their dispute despite disapproval from the PSA executives, the Yazaki strike made him realize that there was potential for unionism in the private sector. With Yazaki workers not knowing whom to approach for guidance about their rights when both the PSA and the Commissioner of Labour failed to assist, this poor handling of the strike presented an opportunity for the interviewee and his associates to expand the labour movement so that it would include, for example, workers in the emergent segments of the private sector: tourism and hospitality, transport and construction, tobacco and the breweries, as well as the various statutory government Corporations such as Samoa Water Authority (SWA), Airport Authority (AA), Samoa Telecommunication (SamoaTel) and Electric Power Corporation (EPC). This effort led to the establishment of the SNUW in 1994.

The SNUW was established under the constitution administered by the International Confederation of Free Trade Unions (ICFTU). The constitution basically allows the establishment of free trade unions in which workers have the right and freedom to form into unions. The SNUW immediately gained support from not only the ICFTU but also the South Pacific Council of Trade Unions (SPCOTU) and the ILO. These agencies provided some financial assistance towards the running of workshops, education and training, and also paid for the Secretary General's wage. In 1995, the SNUW had about 600 financial members comprising mainly workers from the banking sector (e.g. 
Westpac Bank, the then Bank of Western Samoa (BWS), and the Development Bank) as well as some other government statutory corporations. The subscription fee was only \$T1.00 per member per fortnight and that put a huge financial strain on the union to expand its movements to cover other untapped industries such as manufacturing, hotels, construction, service and retailing and numerous smaller businesses. With the exception of airport workers, who became organised in 1992, and the then Bank of Samoa, which had a union established in the 1980s that continued through to an ANZ takeover in 1990, the vast majority of organisations and industries did not have staff associations and thus it would have been difficult and costly to create individual unions for every industry in the private sector. From the interviewee's point of view, the airport workers and bank workers were indeed organised into staff associations, but those associations were traditionally developed and supported by managers with the purpose of supporting management decisions. With the airport workers: pilots, flight attendants and traffic controllers had a lot more clout than other workers: including cleaners, security staff and customer service workers, because the former group of workers had the support of the International Transport Federation. The Airport workers reached an agreement with the airlines, which was supposed to be reviewed on a two-yearly basis. Although they had better wages and benefits as a result of that collective effort, the Airport workers only survived through a single-wage claim primarily due to the lack of a precise guideline for negotiations that would give credibility to any arranged situations between the workers and their employers. As one of the independent consultants noted, the Airport workers' failure to have their collective agreement renewed was mainly due to the fact that there was no legislation that would compel employers to negotiate with workers at any stage during the employment relationship. 
The SNUW had the makings of a union for three years before it disappeared: partly due to the departure of the main persons who had spearheaded the union movement, but mainly because the national leaders and employers were not entirely prepared to accept unionism in that context. As was discovered during the data collection, the same individuals who played a key role in establishing the SNUW also made efforts towards establishing a trade union movement called the 'Samoa Trade Union Congress' (STUC): to be based on the NZ Trade Union model of around the same time. The objective was to remove the central status given to the PSA by establishing a single trade union with new governance comprising equal representation from the PSA and the SNUW. But that arrangement did not sit well with the PSA members, hence leading to the end of the STUC movement.

Unions also faced a major challenge with trying to organise a significant number of workers in the informal sector where there is largely an absence of relevant legislation. The formal sector did not look promising either for union movement because the majority of businesses in Samoa were (and still are) considerably small in employee numbers, most of whom are family members and friends. As the majority of small businesses would have adapted to a family-oriented cultural work environment, the relevance of unionism in such an environment is questionable. Naturally, with a smaller workforce, there is an expectation that workers would easily have direct access to the employer whenever the need arises.

Based on discussions with various participants who represent the key actors in IR in Samoa, actual worker and employer participation in policy formulation and IR is quite minimal: partly due to participation being restricted to those in the formal sector. 
Furthermore, participation is almost completely limited to those who are organised: further limiting participation to the organised sector of the formal sector. Workers in the formal sector tend to be represented by those workers who are organised, mainly the PSA because it is the principal organisation of workers in the formal sector. Also, there is generally a lapse in the ability and initiative, on the part of existing organisations of employers and workers (i.e. the chamber and the PSA), to organise the significant number of informal employers and employees in Samoa.

Another perspective highlighted the importance of workers to be organised on their own free will, without this being imposed upon them by some other organisation or legislation. This viewpoint is referenced in Appendix E: Para. VI. From the review of literature, it is clear that this viewpoint reflects Dunlop's belief that workers are never disorganised in an employment relationship. While they may seem disorganised at first, the nature of their inherent organisation becomes clear as one seeks understanding of it and notes that they have been organised all along.

Samoa, like many other PICs, has no organised institutional relationship between unions as representative of workers and employers organisations, in the sense of collective bargaining partnerships, as exists in most industrialized countries. To some respondents, this is acceptable to some extent given Samoa's small and fragile economic and business environment, where it may not be feasible to have collective bargaining partners. In any context, however, Dunlop notes that industrial relations are determined by the bargaining powers of the actors involved: powers that are in turn determined by product markets, labour markets, and political leverage. 


\subsubsection{The role of the Samoa Chamber of Commerce and Industry}

The Samoa Chamber of Commerce and Industry ("the chamber") is essentially an association of businesses, corporations and business people representing in the very broadest sense the private sector business community in Samoa. Membership of the Chamber of Commerce includes the Samoa Association of Manufacturers and Exporters (SAME) and the Samoa Hotel Association (SHA). As an official member of Samoa's National Tripartite Forum, the chamber has been the representative of private sector employers in IR forums both locally and internationally. The primary objective of the chamber is to promote the best interests of private sector business and industry throughout Samoa. These interests include the creation of a healthy and sustainable work environment to foster employment relationships between employers and employees in the private sector. By presenting a collective voice of its members to government, the chamber also seeks to influence the formulation of national economic policies that lead to the maintenance of a stable and healthy climate, promotion of sustainable growth and the creation of new investment and employment opportunities.

With specific reference to employment and IR, the chamber also supports and encourages capacity building through the establishment of Samoa's In-Country Training Program (SICTP), which is seen as an avenue for smaller businesses that cannot afford to invest in employee education or to up-skill their workers.

Despite some effort from the chamber to organise employers in the private sector, some of the participants in this study were highly critical about the true nature and role of the chamber as a representative of employers, in that most of the participants do not see the chamber as having added any significant value to IR in Samoa. Thus, the chamber's main objective is purely focused on the economic prospects of the very few members it 
has, by lobbying to government for financial support. More importantly, any grants or benefits the chamber receives are dispersed only to its financial members and not to every employer in Samoa. See Appendix E: Para. VII.

Despite the uncertainties about the real role of the chamber as a representative of employers, the chamber's responsibility has notably evolved over the years to take into account various aspects of employment relations that are of great significance to the development and expansion of local businesses. In light of the chamber's presentation at the ILO workshop on 27 April 2009, they seemed very committed, positive and genuine about investing in employee training and education as a way forward for businesses and employees. They also have an explicit commitment to creating a sustainable business environment in order to secure jobs, to share benefits with workers and to create more long-term employment and developing employment in the informal sector. An excerpt representing this viewpoint is referenced in Appendix E: Para. VIII.

\subsection{Recent developments in IR in the private sector}

Additional data emerged after the initial phase of the data collection in which some changes were noted as taking place in the private sector. These changes include the review of the Labour and Employment Act of 1972: where a new bill, the Labour and Employment Bill of 2010, will provide for the formal establishment of the Samoa National Tripartite Forum with unique duties, functions and powers. There is also a new bill for maternity and paternity leave that covers both private and public sector employment, as well as another bill covering occupational safety and health (OSH). Lastly, a bill regarding long service leave and strikes, lockouts, employment agency 
registrations and work permits for foreign workers is also expected to be included in the overall review of labour legislation in 2010 .

As these changes took place in late December 2009, after the initial phase of data collection for this research, one of the Assistant CEO's in the MCIL greatly assisted with the provision of this information, though he did not participate initially in the study. However, with reference to past events, particularly the IR Bill in 1992-93 that was left idle for some time and later discarded, one must be mindful that these are only proposed changes and have not yet come to fruition; there is thus no guarantee that they will indeed take place any time soon or on whether they will ultimately amount to any significant impact on IR in Samoa. In that respect, my concern was primarily with the process by which these changes came to light: including, for example, the ways in which the MCIL came to know about specific elements or issues in the system that required immediate attention. While it is my understanding that some consultation was held during the month of December 2009, I was inclined to find out exactly who attended, and whether this consultation in reality has had any impact on the review of current legislation that led to the formation of the newly proposed Labour and Employment Bill of 2010.

\subsubsection{Review of the Labour and Employment Act of 1972}

The review of the Labour and Employment Act of 1972 has been in the pipeline for quite some time now, and it has only recently been observed to have made some progress. With the establishment of a tripartite forum as part of the new legislation, the Labour and Employment Bill of 2010 appears to be a move in a positive direction for Samoa's IR system, as it is intended to broaden the scope of union participation in the 
making of workplace rules, especially at the national level. Likewise, employers' participation is expected to also improve with this tripartite arrangement.

The new labour bill is a result of a direct intervention by the ILO, specifically aimed towards the modernization of labour laws in Samoa. Thus, the bill reflects the eight core conventions of the ILO that include, for example, regulations relating to freedom of association, collective bargaining, forced/compulsory labour, child labour and nondiscrimination, among others. As was explained by the Assistant CEO at the MCIL, several consultations were held to determine the various sections of the core conventions to be used and reflected in the bill. Invitation to participate was extended to both workers and employers in a range of industries: such as manufacturing, construction, hotel, motel, handicrafts, small-medium enterprises, traders, exporters, motor industry and supermarkets, banking and finance.

As discussed earlier, the Labour and Employment Act of 1972 has a provision for employment dispute resolution under the Conciliation and Arbitration section 37 of the act. The Arbitration Act of 1976 has been used to determine the processes for arbitration. This application of the provisions of acts passed in the 1970s, however, was not possible during the PSA strike in 1981 as it was designed primarily to deal with commercial (business) grievances. Closed doors, lockdowns and strikes have not yet been approached under the new bill, which causes the MCIL to believe that an additional legislation is likely to surface to cover those aspects of IR once the unions have organised themselves and registered under the Samoa Incorporated Societies Ordinance of 1952. The Labour department also includes in its current management 
plan a number of strategies to strengthen the relationships between employers and workers and to provide them with opportunities to formally organise among themselves.

\subsubsection{Maternity leave policy}

The increasing number of women entering Samoa's workforce has inevitably affected the outcomes of employment relations in the public sector. A recent review of the Public Service Regulation in 2009 reflects the relevance of fair labour practices governing the employment of female workers. New developments in labour practices include payment of maternity leave for female employees and flexible work hours in the public sector. The private sector is in a different situation, primarily due to IR decisions being solely dependent upon management prerogatives and discretion. Provisions for maternity leave in private sector employment clearly emerged during the PSA's presentation at the ILO workshop as one of the priority areas to be included in the review of the Labour and Employment Act of 1972. This initiative was prompted not so much by a concern for the growing population of women workers in the private sector, but by a precedent established in the public sector whereby female workers are entitled to paid-maternity leave: hence private sector employees should receive a similar treatment. According to one of the key participants in this study, maternity leave is a matter that should be approached with caution by the rule-making authority because firstly, the implications that a maternity leave policy would have on employers and workers, and secondly, the concern that implementation of such leave conditions would contradict other national policies. Maternity leave is often viewed as an incentive to have a child and this perspective would cause a potential conflict with the National Policy on Population and Sustainable Development (NPPSD). The purpose of this policy is to promote the integration of population issues into national development 
planning and assessment. This will ensure that the effects of population changes on the environment are well understood and any adverse impacts should be addressed as part of Samoa's sustainable development framework. A growing population, for instance, needs more land for food production and residential development. It also creates the need for more formal employment resulting in greater demand for commercial and industrial development (Government of Samoa, 1992).

Given the current situation, where there is no specific provision for maternity protection for female employees in the private sector, the Ministry of Commerce, Industry and Labour does not have the right to impose such policies on employers if they do not want to offer paid-maternity leave. There would also be social implications related to child bearing that impact on the well-being of a female employee and her child, which further bring to view the issue of the length of time a woman is entitled to take for maternity leave (paid or unpaid). Given the likely complications associated with implementing maternity leave policies in the private sector, the government is favourably considering an adaptation of the New Zealand model in which maternity leave is paid through the income support service. In discussion with a government agent, it was confirmed that if a maternity provision were to be enforced in the private sector, it would require the national government to pay for such leave through income taxes. Because public employees are entitled through income taxes to paid-maternity leave of 2 months and an optional 1-month of unpaid leave, it is incumbent upon the government to ensure that private sector female employees receive similar treatment. This again demonstrates the relevance of Dunlop's discussion on how a change in one element of the system affects other elements of the system. 


\subsubsection{Occupational Safety and Health regulation}

Occupational safety and health regulations also emerged as one of the key areas requiring extensive review. The Occupational Safety and Health Act of 2002 was developed with the assistance of the ILO to govern employment in both public and private sectors. The objective of the act is to ensure that safety at work becomes a priority for every employer and in this regard the onus has now been placed upon employers and workers to ensure their own safety in the workplace and the safety of other members of the public who may be affected by their operations. The establishment of the act therefore removes this responsibility from the government, which in previous years had been moderately engaged with the provision of safety and health exercises for employers in the private sector to ensure minimum safety and health practices were achieved. While the act clearly outlines the responsibilities of employers and employees, some shortfalls have been taken into account, particularly the inability of the act to succinctly identify how a breach shall be treated. These areas would be addressed in the current review of the principal Labour and Employment Act.

\subsubsection{Samoa's National Tripartite Forum}

The signing of Samoa's first ever Decent Work Country Program (DWCP) by all the representatives of employers, employees and the state took place in Samoa on 28 April, 2009, as part of the ILO workshop. Samoa's DWCP priority areas include: (1) modernization of labour law, (2) promotion of decent employment opportunities and (3) capacity building of tripartite partners and improvement of social dialogue between the key actors in IR. As briefly noted earlier, the current review of the Labour and Employment Law of 1972 will make way for a formal establishment of the Samoa National Tripartite Forum. While the Tripartite has been in existence for many years, it 
operates on an ad hoc basis with very limited functionality, as it only applies when advising workers and employers on the non-compliance of basic conditions under the act. With the proposed Labour and Employment Bill of 2010, the Tripartite Forum shall comprise of two representatives of the government agencies: including the CEO of the MCIL, who is also the chairman and the CEO of the PSC. Other members include three representatives of the agencies representing employers, namely the President of the Chamber of Commerce and Industry, the President of Samoa Association of Manufacturers and Exporters (SAME) and the Director of Small Business Enterprise Cooperation (SBEC). The employees' representatives shall include the President of the PSA, the President of the Yazaki Employees Association and two presidents of two worker associations to be appointed by the Head of State upon the advice of Cabinet. The draft bill also expands on duties and functions of the forum where would most be reflected a wider scope of worker participation in decisions affecting their employment. These include the ability to consult on issues of work security and working conditions as well as industrial, economic and social policies that have impact on worker employment. Workers' representatives will also be consulted about principles and directions for structural adjustments in the public and private sectors among other matters, such as reforms. In addition, they would also be given the ability to partake in constructing better work practices. The proposed bill also expands on the forum's power of investigation and inquiry under the Commission of Inquiry Act of 1964.

\section{Summary}

This chapter has drawn out a range of issues, reflecting on the importance of the fa'asamoa and the matai system to IR and the IR system in Samoa. The fa'asamoa, and in particular the autocracy of traditional rule-making practices, brought about some 
negative as well as positive responses. While there are some adverse affects in terms of the impact of fa'asamoa on one or more of the actors' roles in the establishment of work rules, this is not to the extent that this cultural element entirely dominates the IR system in Samoa. Rather it is seen as providing stability to Samoan society in the sense that workers become pliable to the employer's demands through silent rendering of their loyal service to the organisation and leaders. It is only through an appreciation of the cultural values inherent in Samoan society that the locus of power, as well as the distribution of such powers among the actors and in wider society, can be better understood. Overall, Samoa's system of IR is reasonably stable, in the face of inherited conflicts at the very foundation of that system which in many ways owes to the strong social institutions of Samoan society.

With reference to labour laws, which were either taken as a whole or taken partially from English common law during colonialism, (see for example, the adaptation of a dispute resolution procedure) it is difficult to be certain as to whether an adaptation of further Western laws (e.g., union laws) from industrially developed countries, as some of the participants suggested, would in the local context promote a wider participation from workers in decisions affecting their employment. Such is the current state of Samoan government labour policy that it makes no reference to union participation.

The success of Samoa's IR system is, therefore, largely dependent upon the ability of national leaders to adapt a system of rules and practices that embrace the unique values of Samoan tradition and cultural practices on the one hand, and provide ample protection of employee rights on the other hand. This suggests that balancing the 
cultural practices with strategic industrial focuses and objectives will serve to enhance the current system.

Despite the existence of a constitution that allows workers the right to freely form unions, people are only gradually coming to terms with fully functional unionism. Workers who have become formally organised within their own workforce can register, like any other functional business, under the Incorporate Societies Ordinance of 1952 either as a 'union' (which is very rare) or with a more culturally acceptable title, such as 'association'. There is also clearly no compulsory unionism at any level in Samoa. Workers are organised within their own workplace purely on a voluntary basis and with the support of the management.

At present, the public sector provides a slightly different and perhaps rosier picture with regards to minimum wage and the terms and conditions of employment. Yet, given the lapse in remuneration and employment conditions for some professional occupations, it is difficult to assume that everyone is satisfied with the current system, in particular with the issues of procedural rules governing wage negotiations between certain professional groups and the PSC. Given also the limited capacity of other professional groups (e.g., doctors, teachers, etc) and individual ministries to participate in decisionmaking, the determination of the wage structure in the public sector is one of the biggest issues of concern among government ministries.

Recent developments to the legislation governing private sector employment can be seen as a positive effort toward widening employees' participation in the formulation of national labour policies. The findings draw attention to the processes that government, 
employers and workers use to determine the system's outcomes. The events of the PSA strike in 1981, followed by the Yazaki strike in 1993 and the doctors' dispute in 2005, have undoubtedly played a part in influencing several attributes of Samoa's IR system. The employers and employees play very minimal roles in the establishment of work rules. The most significant area of development drawn out from these findings is in the implications of these changes on employers and employees. The establishment of the Tripartite Forum is of no doubt a way forward for industrial relations in Samoa and as a positive move towards promoting industrial democracy and employees' participations in employment relations decisions affecting workers employment. 


\section{Chapter Five: Conclusion}

This chapter concludes the thesis with three main focuses. First, it provides a synopsis of the main findings of the research into Samoa's IR system and considers whether these findings have fulfilled the objectives of the research as set out in Chapter 1. Second, it considers the limitations of the research methodology, followed by recommendations for future study of this nature to be located either within the context of Samoa's IR system or that of small Pacific Island Countries.

This thesis has mapped out the industrial relations system of Samoa by using Dunlop's (1958) systems approach to identify and discuss the environmental ("contextual") factors that influence several attributes of Samoa's IR system. While it is not a primary task for this research to draw any conclusions on the relevance of Dunlop's model as a methodology to describe Samoa's IR system, it is worthwhile noting that it is indicative of the merit of the Systems Model that this research is able to identify and discuss a range of inputs from Samoa's social, political and economic systems that are currently impacting on employers, employees and state relationships and the processes they utilize in making workplace rules in Samoa. In addition, the Systems Model brings to surface several attributes of Samoa's extant IR system that may be of relevance to policy makers: those with the objective of improving employment relationships in Samoa.

\subsection{Summary of the main findings}

The findings of the present research point to the conclusion that Samoa's IR system, in particular the limited capacity of employees (or unions) to partake in the establishment 
of workplace rules, is to a large extent influenced by various factors manifested in the socio-political context of Samoan society. The autocratic nature of Samoa's sociopolitical context, which is deeply entrenched in history of the fa'asamoa and fa'amatai practice of social justice and traditional rule making, impacts on various attributes of the IR system. This social organization of Samoan society, structured around matais, defines the actors' power, prestige, roles and rule making authority within the IR system. Samoa's traditional system of rules, practices and customs provides the nation's leaders with indisputable authority to unilaterally make decisions on the basis of culturally ascribed values associated with 'trust', 'respect', 'loyalty' and 'obedience'. These values are perceived by several research participants as being held in reserve for those individuals who hold positions of power and influence in Samoan society.

The findings also suggest that the relationship among employers, employees and government is based on a unitary ideology. That shared ideology reflects an acceptance of the 'natural' division between the leaders and their followers by wider society, and of the hierarchical nature of organisations. In this mindset, the manager's function concerns decision-making; whereas the employee's role is to abide by managerial decisions.

The economic context of Samoa's IR system plays an important role in the establishment of both procedural and substantive rules governing all areas of employment, which includes, for example, wages, benefits and conditions of employment, as well as employer and union rights. Due to limited resources afforded by the Samoan government: the government plays a significant role in the economy via regulations which lead to increases in the cost of doing business and also hamper entrepreneurial activity. The government also represents the biggest employer with a 
high proportion of public sector employment, which accounts for more than 40 percent of GDP, crowding out private investment in some sectors (Heritage Foundation, 2010b). In addition, the government also maintains ownership in a significant number of enterprises, such as the Electric Power Corporation, Samoa Water Authority, National Provident Fund, etc.: some of which are safeguarded by monopoly privileges.

Over recent years, the Samoan government has pursued economic reforms, but overall progress has been mixed. Whereas efficiency and economic development has been achieved, marking Samoa as the leader in the Pacific, essential economic and public sector reforms included changes, such as the removal of price subsidies from major crops and tax reforms, which streamlined and improved overall efficiency, but also removed many of the incentives that were previously available to local businesses. These reforms inevitably led to an increase in the cost of doing business in Samoa that, in turn, has affected employment conditions and the nation's overall ability to create and sustain formal employment.

The legal context of Samoa's IR system also has its roots in the social-political system. To this day, Samoa's IR system constitutes a combination of Western rules with the everyday customs and traditions of fa'asamoa. This cultural dualism of rule making is geared towards maintaining harmonious relationships among actors within the IR systems by adhering to international expectations while also conforming to traditional values of Samoan culture, which not only form part of the organisational and managerial practices, but are often used as a means for resolving disputes between employers and employees. The success of Samoa's IR system and legal framework therefore lies in its fair treatment of individual goals and values held by different social 
groupings (including employers, workers and government). This is to say, while there is evidence of convergence in labour regulations in Samoa's IR system, with reference to an adaptation of international labour laws to be used in formal sector employment, there is also a persistency from wider society to maintain Samoa's traditions of rule making in the informal sector. Therefore, employment relationships in Samoa have been influenced, not only by the environmental or contextual variables already discussed in the findings together with the nation's history, but also by distinctive values systems of the social actors and cultural features of Samoan society.

The presence of traditional values and features thus has positive influence on Samoa's IR system, but there are also negative consequences in terms of the centralising of authority over state functions and a general weakness of union representation. A conclusion that can be drawn from the legislation and from discussions with the interviewees, particularly on issues relating to wage setting in the public sector, is that each department in the public sector has no control over the determination of wages and other conditions of employment, and is not given any role in regards to what factors to consider when setting wages. This is largely due to a high level of state involvement in IR, which is also characteristic of Samoan society. The significance in the nature of state involvement in Samoa's IR system should not be underestimated, as it is likely to condition all other elements of the employment relationship. For instance, the majority of respondents believed that because the government chooses to ignore the relevance of unions in Samoa's IR system, it therefore makes no reference to unions in the legislation. Also, given the lapse in union recognition in labour legislation, there is basically nothing substantial that compels the government to consult with unions about employment conditions. Based on these viewpoints, the government's deep 
involvement in Samoa's IR has the effect that there are permanent close relations between the labour force and the state. While this is somewhat contradictory of Dunlop's approach, which has the implication that the union is a permanent actor in an IR system, it may offer an explanation for why the systems model rarely applies to the study of IR systems in the context of PICs. This is not to say that Dunlop's systems model is not valid in this context because of the marginal existence of unions. What this finding contributes to this study is the understanding that one should not be guided primarily by the extent and nature of the actor's involvement in employment decisions as a core focus. Simply because unions generally do not participate in the establishment of work rules in Samoa, this does not remove them from the IR system altogether. Unions in Samoa exist in other forms of workers' organisations such as staff associations, mainly at the enterprise level, whether or not these are seen as formal or informal arrangements.

In Dunlop's point of view, the actors in an IR system are supposed to behave as homogeneous groups with regards to their interests and their bargaining behaviour. Furthermore, he states that all three actors are operating on the basis of certain values or a certain "ideology". Dunlop's emphasis on the 'homogeneity of interest' among workers, employers and government seems to correspond with the Samoan leaders' concept of 'benevolence', which connotes the necessity for all Samoans to preserve important elements of Samoan culture that are largely aimed at maintaining 'harmonious relationships' within all facets of society. Along with the general omission of unions from playing an active role in Samoa's IR system, the government favours strategies and policies that demand workers' cooperation by also convincing them that the decisions it makes are equally representative of all other actors (i.e., employers, 
workers and wider society). This position has impacted on the workforce in Samoa, which is characterised by low union participation. However, the roles that all three actors play in an IR system, as explained by Dunlop, are equally valid in the determination of outcomes. Thus, he notes that the action of removing employers and workers from any significant responsibility towards the formation and administration of policy, is not only uncharacteristic and destructive of democratic societies, but it also leads to unreal and impractical policies. Government policies in Samoa at present make no reference to unions and their rights in labour legislation and in the designation of rules governing employment.

With a primary focus on the rule making processes and the roles each actor plays in their establishment, the thesis has directed attention to the historical conditions leading up to the system's current state, as well as the predictive value of the systems model and the relative power of actors in the system and the sources from which these actors receive their powers.

The historical precursors to the current system were gleaned from discussions of past events as to what significant activities and factors contributed to it; and in addition, interviewees were asked to consider the future and what forces are currently at play, maintaining or changing the IR environment in Samoa or the relationships between its actors. These discussions focused on recent developments in labour legislation in Samoa, such as the establishment of a tripartite system among the key participants in Samoa's IR system: the state, the chamber and the PSA; the modernisation of regulations governing employment relations; the rising education of people and their influences on the cultural environment of Samoa's workforce; and government reforms 
in the public sector, among other developments. In addition, discussions also dealt with the forces of product and labour markets, technological advancements, and budgetary constraints: which all seem to be affecting employment decisions in Samoa to the extent that union participation in industrial relations remains relatively minimal.

The predictive value of the systems model emerged from the participants' backgrounds and their recollections of the leading industrial disputes that have taken place in the history of IR in Samoa. For instance, an interest arose among some of the participants with the prospect of encouraging collective bargaining at the national level via the establishment of a single national trade union to integrate every staff association within the private sector. This prospect is associated with a belief that in order for workers to have an impact on the rule-making aspects of the workplace and the work community they must be able to share a strong and unified voice.

Contrary to this view is the argument, from some of the former PSA union members, that there is no need for a national consolidated trade union because different groups have their own individual needs, goals and objectives, which will be dealt with most effectively if workers organise themselves within their own workplace. They argue that enterprise unions or associations are likely to have a direct impact on, and an effective voice and participation in, the process of rule-making in the workplace through jointconsultation with employers.

In addition, some participants suggested that the government, instead of dominating the industrial relationship, should only be concerned with the establishment of procedural rules (e.g. dispute resolutions, wage negotiations), and then step back and let unions and 
employers (including those in the private sector) deal with labour management issues at the enterprise level. This suggestion parallels one of the fundamental arguments put forth by Dunlop in which he contends that to remove either party (i.e. employer or employee) from the rule-making processes of the workplace will lead to the passing of unrealistic decisions particularly in public sector employment where the government is both the employer and legislator.

Following Dunlop's systems model, the sources of the actors' power were also discussed with participants. Some powers were seen to be arising from the environment, such as the strategic role of certain groups of workers in the workplace or work community, and other powers were seen as naturally belonging to the actors, such as the manager's capacity to manage, to make rules and to decide whether to deal with workers' grievances or not. For instance, some of the participants noted that they only joined the PSA strike because they felt that as Chief Executive Officers at the time, their presence would add some weight and strength to help drive the issues through that would not have otherwise been felt with only the low-paid public servants involved in the strike. This focus on powerful leaders, on their reputations and positions within the workplace to influence employment decisions both at the organisational and national levels, is simply a reflection of the values instilled in the socio-political system.

Several discussions about how workers can contribute to the development of work rules governing the performance of work focused on the issue of the relative power between employers and workers. The employers would either make rules unilaterally without consulting with workers, or in some cases employers would establish rules that are beneficial to the employers alone. For the most part, unions play virtually no role in 
influencing IR outcomes, largely due to the dominant impact of the social system (Samoa's customs and traditions), and partly relating to, among other factors, the benevolent aspect that government leaders insist is integral to Samoan society. Furthermore, the structure of trade-union activity continues to be characterised by a relatively low union density and fragmentation, which is evident in the scarce occurrence of strikes and union activities. Collective bargaining continues to be rarely employed as a method for determining workplace rule in Samoa.

Samoa is a nation that is characterised by high levels of politicisation or state involvement in IR, mainly for public sector employment, but seems to be adhering to a voluntarist framework when dealing with employment relations in the private sector. In addition, Samoa's IR system is generally accepted as representing a non-unionised society, which may offer an explanation for the non-existence of any organised institution representing workers as well as employers: in the sense of collective bargaining partners. In a unionised environment as discussed by Dunlop, collective bargaining between trade unions and management is a recognised procedure for establishing rules governing employment relationships, and the resulting collective agreement establishes the application of the rules to particular circumstances. Substantive rules are the output of the collective process, which Dunlop identified under three categories: the rules governing compensation in all its forms; the duties and performance expected from workers; and those rules defining the rights and duties of workers about promotions, terminations and the deployment of workers to particular positions or jobs (Morley, et al., 2006). 
Several union participants share a belief that the 'voluntarism' ideology, which emphasises enterprise bargaining as a mechanism for establishing workplace rules, is to the convenience of employers alone. A conclusion that can be drawn from the findings, however, is that this variability in Samoa's private sector employment should not be assigned to decentralised enterprise bargaining, as this would be seen as misleading. The 'bargaining' that occurs at the enterprise level is typically in the application of unilateral determination of conditions of employment by the employer, or occasional negotiations between individual workers and employers. There is little collective representation by staff associations and such negotiations that do exist are rarely governed by formal procedural rules. This has the consequence that employee participation in public policy formulations, if existent at all, is extremely minimal.

The lack of formal employment opportunities and of dynamic job growth remains a key issue, especially in light of the large presence of inefficient state-owned enterprises. Despite some changes in the regulations governing public sector employment, which can be largely attributed to the restructuring of government ministries in the early 2000s, there has been some confusion with regards to the explicitness of the consultation process. There is an expectation, however, from individual participants, especially those employees engaged in government Ministries, that a joint determination is the most effective means for determining workplace rules.

Industrial dispute is very rare in Samoa, which besides the fa'asamoa also results from many businesses being small family operations with fewer than 5 workers. There is also a tendency for both employers and employees to avoid formal dispute procedures and rely mainly on informal practices based on principles of 'respect' and 'loyalty' towards 
the owners of the company. Such cultural practices have somewhat impacted on workers' participation, thus allowing the government and employers to exercise tight control over industrial relations, including suppression of trade union activities.

In all sectors of Samoa's labour force, collective organisation is limited among both employers and employees. Where it does exist, employers' collective organisations such as the chamber are oriented towards trading issues, commercial organisation and marketing. Industrial relationships are informal, usually based on personal and communal networks. Similarly, work organisation is informal. Even when collective agreements between employers and unions are concluded, such as in the case involving Airport workers discussed in the findings (see page 118), they do generally not carry any legal significance, but are, in effect, dependent upon the mood of the employer for continuation. The legal framework in Samoa has not been conducive to more formalised or centralised patterns of industrial relations.

Trade unions and staff associations in Samoa are generally enterprise-based. There is a broad absence of proper guidelines to deal with industrial disputes. In addition, there are two distinct dispute resolution procedures for the public and private sectors and they differ in some respects. The public sector procedures require the commission to solely determine the process by which disputes between individual workers or groups of workers and their ministries are to be resolved. These procedures are passed on to the CEOs of all ministries to be implemented and the CEOs may resolve the issue or recommend (especially when it is an issue of promotion, regarding, or reclassification) to the commission for a final decision. Dispute resolution procedure in the private sector has its roots in colonial rule, which follow that of the then NZ Arbitration process, but 
with the exception of an award system. Both public and private sector procedures adopt an individual and not a group (union) focus: as there is no mention of unions in either regulation.

Several proposed changes to current labour legislation emerged from the study. These changes came to surface as part of the ILO intervention towards the modernisation of labour laws in Samoa and other Pacific regions. The modernisation of labour legislation will inevitably influence various attributes of employment relationships and the IR system of Samoa: especially the prospect that Western law principles can disagree with the informal practices of fa'asamoa that are seen as the cornerstone of many relationships in Samoa. These discussions were extremely helpful in illustrating how changes to one or more elements of the system affect the other elements, and how some of the efforts to change one component will impact upon the other components.

\subsection{Limitation of the study}

As detailed in Chapter 3 of the thesis, there were some problems observed with regard to the selection of interview participants. The first problem is that the selection of union participants to be interviewed for this study was limited to those organizations with fifty or more members; and yet the vast majority of unions (staff associations) are very small in number, with often between 10 and 20 members. The second problem relates to the first, in that the criteria for the selection of employer participants also affected the overall number of response rates.

This limitation in the selection of participants to be interviewed was influenced by the nature and purpose of the research. As the objective of the study requires an accurate 
description of Samoa's IR system, there is a reasonable belief that only those individuals who have had some form of direct involvement in the formulation or implementation of work rules and policies will be able to provide the needed information. Because there is a reasonable expectation that smaller, family-run businesses, which constitute more than fifty percent of Samoa's labour force in the private sector, are not likely to be engaging in industrial relations matters to a significant extent, they would not possess relevant knowledge of Samoa's IR system. In short, the research has relied heavily on the prior knowledge, expertise and experience of the participants to satisfy the objective of the research. While the exclusion of smaller businesses has had no significant impact on how this research turned out and on the quality of the data collected, it does present an opportunity for future study of this nature to explore a range of labour-management issues within smaller organisations.

\subsection{Implications for future research}

Carrying out this research not only contributes to one's understanding of industrial relations and the IR system of Samoa, it also provides a range of potential areas that may be explored in future research. These may include an assessment of enterprise unionism with regards to the union's goals, values, behaviours and perceived roles within organisations and industrial relations in general. A focus on enterprise unionism (or in-house staff associations) would be relevant considering that it is a prevalent form of worker organisation in Samoa. While the findings indicate that smaller employers and staff associations are under represented and insignificant because of the smaller number of workers they employ and their limited activities in IR, they made up the larger percentage of the work population in Samoa. This in itself should warrant a study of how smaller businesses could be affected by national policies, especially if they play 
virtually no role in the establishment of work rules nor have any influence on national policies. In addition, an adaptation of an organisational as oppose to a national research focus to explore relationships between employers and employees may have the potential to bring to surface issues that of importance to policy makers and rule making authorities at the national level.

The significance of Samoan culture on the IR system may also stimulate an interest in exploring the nature of the actors' relationships, their varying sources of power and influence on IR outcomes. This is to say that further study may be undertaken to establish a possibility for causal relationship between factors arising from the Samoan culture and the government's (employer's) attitude towards industrial relations, worker protests and worker organisation. Though it must be noted herein that Prasad, Hince, \& Snell (2003) also make reference to the fa'asamoa as impacting on IR and national leaders' behaviour, potentiality in this area for future research still remains largely unrecognized. 


\section{APPENDIX A}

\section{QUESTIONS FOR ALL PERSONS INTERVIEWED:}

1. In your opinion, what is the most effective way for Samoan employees to gain a greater voice in determining industrial relations outcomes? Why?

2. What is the current role of trade unions in the industrial relations system of Samoa? How has this role evolved over time? How is union membership regulated in Samoa? Is there compulsory unionism at any level? What procedures - formal or informal-does a union undergo in order to be registered? What does union registration permit in terms of the role of trade unions in determining industrial relations outcomes in Samoa? In what ways are union activities regulated in Samoa?

3. How are industrial disputes (e.g., strikes, lockouts, secondary boycotts) regulated and/or controlled in Samoa?

4. How are employers typically represented in industrial relations in Samoa? What is the current role of employers' associations in industrial relations? How have employer representation and the role of employers' associations evolved over time?

5. Please describe the existing structure of industrial relations in Samoa. Where does your organisation fit into that structure? At what level(s) (e.g., industry $\mathrm{v}$ enterprise bargaining) does collective bargaining between unions and employers in Samoa typical take place? What share of employees in Samoa are covered by agreements derived through collective bargaining? How does public policy in Samoa influence the structure of industrial relations in Samoa?

6. What means do trade unions in Samoa employ to influence national employment policy? How effective are trade unions in Samoa at influencing national employment policy?

7. Do unions have a place in Samoa's politics? Do you think unions will be challenging the status quo in employment relations if they become more actively involved in the formation of national employment policy? Do you think that industrial relations in Samoa could be enhanced if the workers or unions became more engaged in the development and review of labour laws and policies? Why or why not?

8. What is the role of the Government in industrial relations in Samoa? What are the current legislated procedures for dealing with industrial conflicts and employment relationship problems in Samoa? In your opinion, do those procedures provide adequate support for democracy and employee participation? Why or why not? Who was primarily responsible for establishing these procedures? What other parties influenced the establishment and/or implementation of those policies and procedures? 
9. What requirements did Samoa have to fulfill in order to become a member of the ILO? Was there a provision that allows for workers' (and unions)

10. participation in national labour legislation? Does our current IR system reflect this requirement?

11. What is the role of the Commission of Labour? Do you feel that the Commission of Labour could do more to encourage a wider participation from the private sector organisations? What do you see as the Commission's main responsibility to the private companies. 


\title{
APPENDIX B
}

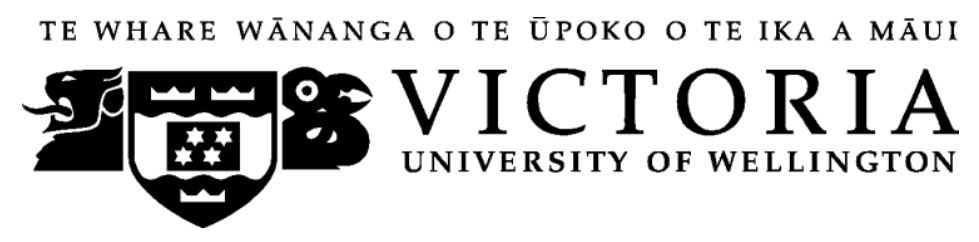

\author{
Participant Information Sheet \\ Study of the review of industrial relations system in Samoa
}

Researcher: Patricia Ah Chong-Fruean

\section{Dear Participant}

This research focuses on industrial relations in Samoa, being one of the emerging areas of interest in the study of Pacific Island economies requiring further study and development. My name is Patricia Ah Chong-Fruean and I am currently pursuing a Masters of Commerce and Administration, specializing in Human Resource Management and Industrial Relations (HRIR) at Victoria University of Wellington (VUW). As part of the requirements of that degree programme, I am conducting a research project entitled, "Mapping the industrial relations system of Samoa: An assessment of industrial democracy and workers' participation in employment relations decisions in a Pacific Island nation". The main objective of this research is to offer a broad description of the industrial relations (IR) system of Samoa, with specific emphasis on the process of making rules affecting industrial democracy and employee participation in decisions affecting their employment.

I would like to interview you for my study and ask you a series of 10 to 15 questions about your views of the IR systems in Samoa based on your experience and involvement in the development of labour policy and influence over industrial relations outcomes in this country. In general, I am interested in learning about the role(s) you (or your organisation) play in industrial relations. You are welcome to review my questions before the interview takes place. I anticipate that my interview with you will take between 50 and 60 minutes.

Victoria University of Wellington requires students to obtain approval for research involving human participants through an ethics review process. This research has received the necessary approval to proceed. Your personal details will remain confidential throughout the research process. I may quote excerpts of our conversation in the study, but I will not attribute quotations to you by name. Research findings will not be associated with the names of any specific participant. I will only identify you as a Government spokesperson or representative, a public or private sector employer representative, or as a union spokesperson or as an independent consultant

Should you agree to be interviewed, I will be in Samoa from 23 April through to 14 May 2009 to interview you along with between 14 and 19 other interview subjects. 
Given the limited time I have to complete this task, I would very much appreciate it if we could schedule your interview within the timeframe given, as soon as is reasonably possible. In the event you are not available for an interview during this period, I would appreciate it if you were to assign an appropriate spokesperson to be interviewed on behalf of your organisation or members. With the interviewee's permission, these interviews will be recorded.

After the interview, you are welcome to get in touch with me if you would like to review the interview transcript. I will keep your interview transcript in a secure location; access to the transcript will be restricted to the researcher (Patricia Ah ChongFruean) and my thesis supervisor (Dr Stephen Blumenfeld). All data related to this study will be destroyed immediately upon completion of the write-up for the research, as the data will be used exclusively for the purpose of completing a Masters thesis and related academic publications and conference presentations.

What is being asked of the government and business leaders at present is an indication of their consent for the researcher to either interview them directly or assign spokespersons to be interviewed on behalf of the organisations or members.

Please contact me if you have any questions or concerns about the research.

Patricia Ah Chong-Fruean

Victoria University of Wellington

Victoria Management School

PO Box 600

Wellington, New Zealand

e-mail: ahchonpatr@myvuw.ac.nz

telephone in New Zealand: (644) 5699610 or 0211606867 (mobile)

telephone in Samoa (+685) 22654 or (+685) 7710000 (mobile). Samoa contact phone

numbers will be available from 23 April 2009 to 14 May 2009 


\section{APPENDIX C}

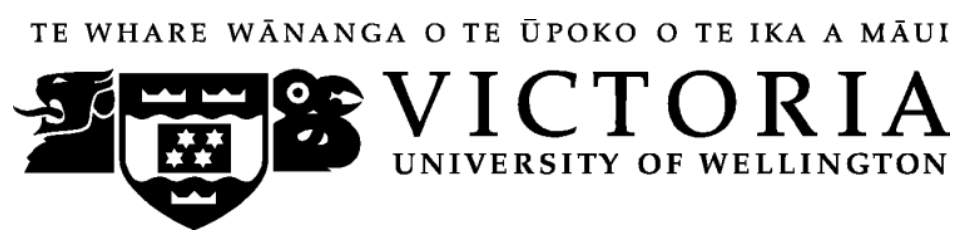

Consent to Participate in Research

Title of Project: "Mapping the industrial relations system of Samoa: An assessment of industrial democracy and workers' participation in employment relations decisions in a Pacific Island nation".

Researcher: Patricia Ah Chong-Fruean

By completing this consent form, you will allow me to interview you. Please read the statements below and tick the boxes that apply to you.

$\square$ I have been provided with adequate information relating to the nature and aims of the research project. I have understood this information and have been given the opportunity to seek further clarification.

$\square$ I understand that I may withdraw from this study at any time before 31 December 2009, without providing reasons.

$\square$ I understand that if I withdraw from the project, any data I have provided Patricia Ah Chong-Fruean will be destroyed.

$\square$ I understand that any information or opinions I provide will be kept confidential and reported in non-attributable form.

$\square$ I understand that the information I have provided will be used only for this research project.

$\square$ I understand that when this research is completed, the information obtained will be destroyed immediately upon completion of the final write-up of the project and no later than 28 February 2010.

$\square$ I agree to be tape recorded during the interview (please tick if you agree).

$\square$ I would like to review the transcript of my interview once it has been transcribed by Patricia Ah Chong-Fruean or a transcriptionist.

Name:

Signature:

Date: 


\section{APPENDIX D}

\section{Toamua united on Ale}

Written by Jasmine Netzler-lose

Saturday, 03 April 2010 11:31

It's official. It's compulsory for voters of Toamua village to vote for Ale Vena when the by-election for Faleata West is held some time this month.

Mayor Leaoaniu Patolo Ale said this was decided during a meeting of Alii ma Faipule (village council) of Toamua.

"Plans were prepared in 2008 but nothing was decided until the end of 2009 ," he said. "Our village protocols are very intact and the authority by Ali'i ma Faipule is very strong. "This is one of the reasons why we had decided to make this official - support Ale Vena in the elections.

"The authority in the village has decided and Ale Vena is the chosen one." Leaoniu said Ale was always going to be Toamua's choice.

"We were not aware that there was going to be a by-election," he said. "But since the by-election is now confirmed, we brought our plans forward."

Another senior member of the village and former Cabinet Minister, Ulu Vaomalo Ulu Kini denied suggestions the village decision violates people's rights to vote.

He said the decision reflects the unity of their village to protect the integrity of the Fono ali'i ma faipule.

He said no punishments have been decided against people who don't obey.

"That will be decided after the election," he said.

Leaoaniu said the decision was not "a threat but protocols decided by Ali'i ma Faipule should be respected.

"The voter can elect whoever they want - this is up to them. But the Ali'i ma Faipule have made the decision."

Leaoniu said the decision applies to Saina, Toamua, Puipa'a, Safune and Usoalii. 


\section{APPENDIX E}

\section{Para. l: $\quad$ An excerpt from an interview with a union representative}

Going into partnership with others and having local affiliations because you can get support from other workers' associations can strengthen and expand your network both as professional organisations and as unions. It might be true that your needs and issues may differ to others but at the same time, you are still in the same box, and while others may not fully understand you at first, once you start working on a project together, you will slowly come together and be accommodative of one another's goals and needs. [Union representative 2].

\section{Para // An excerpt representing a view about the impact of higher education for nurses on wages and employment conditions of nurses.}

The government reform in the early 90s changed the education for nurses where we then moved up to the tertiary level at the NUS. But the truth of the matter is, the Nurses Association initiated and put pressure on the PSC and the government to make these changes. In the earlier years, you were only required to complete Form 4 or Form 5 at a College to become a nurse and after doing 3 years of training, you get a certificate of nursing. With the PSC salary structure, a certificate is a certificate, and a certain wage rate is allocated for that. Therefore, no matter how hard we fight to justify that we should be receiving more based on the value of our jobs and the services we provide, we don't get anywhere. To the PSC, a Certificate is a Certificate and that is it. This led to the Association's changed of mindset so instead of fighting to get better pay and working conditions based on a Certificate and a lifetime of service, we argued for better access to higher and better educations so that we can access higher and better pay. Now an undergraduate nurse is one of the highly paid public servants there is and that lifted the standard of our practice and service to the community [Union representative 2]. 


\section{Para. I/I: $\quad$ An excerpt from an interview with an independent consultant and a member of the Remuneration Tribunal}

In Samoa, we are not so dependent on jobs for survival like people in New Zealand and other countries in the sense that factory workers and airline workers for example, are dependent on the organisation of workers and collective relations for pursuant of labour relations issues especially during negotiations with employers. The situation in Samoa is that a job is seen as though it is only a secondary attachment in that people's livelihood do not always depend on employment.

\section{Para. IV: $\quad$ Excerpts from interviews representing a view about the present status of the PSA}

Well! They have a bundle of dead woods there and we've told them, 'You better go sort yourself out or otherwise we will strike you'. They have achieved absolutely nothing in terms of assisting the public servants, yet they have had all these opportunities like they sit on some boards like the NPF, and also the Price Board and others. But they have not had an Annual General Meeting for 6 years and they have not complied with their obligations as a registered incorporated society [Government Agency Representative 1]

You are asking a very interesting question because that is the question most public servants are asking. You see! The Public Service Association as far as I can remember from the $80 \mathrm{~s}$ and the 90s, they were very effective and very instrumental in dealing with human relations and industrial relations issues. But right now, the PSA members from the ministries are asking... Where is the PSA? What are they doing? [Government Ministry].

Even if it has become a pretty useless organisation for its own membership, it could still be useful for other labour colleagues, other workers around the place. Because for as far as I can see, they have been ineffective for its own membership and its members may have accepted that and don't make a fuss about it [Independent Consultant]. 


\section{Para. V: $\quad$ An excerpt from an interview with one of the independent consultants and a former PSA member.}

At the time, there was really no structure for reporting and we cannot report to the Commission because they are like the employer. They are the employer and the government was not. I suppose you could say that the government was supposedly the independent employer and that was highlighted from the strike, because it eventually led up to the 1981 strike. We [the PSA executives] went to the Minister as the Public Service Commission was under the minister at the time. So we took all our grievances to him. The minister was a representative of the state and at the same time he was also overseeing the PSC. There was a lot of consultation but they were not independently driven. The union's concerns and issues had always been referred back to the government and the government was always meddling with them. Basically the government was dictating to the PSC how to deal with us, which was to be expected because the government appoints the Commission, and the government appoints whoever. It was a government-run show yet the law was very clear that the government was not to be the employer, it was the Public Service Commission because that came up when the government terminate, or shall I say, mass terminate the 4000 public servants during the strike. So we ended up in court.

\section{Para. VI: $\quad$ An excerpt from an interview with a representative of a government agency: $M C / L$}

It is not that workers are not organised. They are organised but they are organised only when it suits them. That is the way it should be as I've always said. We always prefer any kind of organisation of workers emanating from the workers themselves because if it comes from them because of a need that they want to address, they will understand what they are organising for. But if you want to transplant a model of a trade unionism in another country in Samoa and say, 'Look! We want you to be like this! You don't realize that you are transplanting all the inherit problems of that particular model with the model itself and it would be aggravated here because people here do not understand; they would be struggling 
to understand the model and to deal with the inherit problems that come with it that they did not know. This is why I keep on saying: we do have workers organisation which are the staff associations. If these staff associations feel that they want to organise a social club for fund raising or to go and participate in some kind of competition and support colleagues through funerals: it works! You don't have to teach them new skills because the skills for what they are organising for are useful. All we need is to support them in what they are doing.

\section{Para. VII: Excerpts representing the views about the chamber's role}

The chamber wasn't concern with industrial relations at all. They are small businesses mainly. So it was more about getting on side with the government, being on various boards, economic boards, being on the governance of the Central Bank, ACC, and trying to control some of the money. They didn't have a focus on industrial relations at all because there was no need to as far they are concerned because they could just fire anybody they want. This is mainly because there was nothing to protect the workers. If the employers didn't want their workforce, they will just let them go. The only requirement under the law was for them to pay them on a 1week's notice and then off you go and often without prior warning [Independent Consultant 1].

The Chamber of Commerce exists primarily for business mainly to advance business. Because they see themselves as a group of employers, therefore they feel the urge to represent employers. Not all companies belong to the Chamber but people belong to it not as employers, but you know, as business people, who are mainly concern about advancing in business. The whole idea of forming is to sort of come to government and put pressure on government, about things of interest to the business like customs rates and things like that and taxes [Independent Consultant 2].

[The chamber] is not a representative of employers in the context of industrial relations. They registered with the MCIL as an incorporate society but not as a representative of the employers associations in Samoa. But ever since we included them in the Tripartite and I was very frank with them at one time when I said; you have no business speaking on behalf of the employers in this country. At that time they had only 40 members and I said to them; you get all this recognition by 
government as representatives of employers and there you have only 40 members. Then they launched a membership trial because they had to increase the membership. Now I believe they are a lot better off than they were before. I can't say I know for sure how many members they have at present [Government Agency Representative 1].

Para. VIII: An excerpt from the chamber's report at its presentation at the ILO workshop on 27 April 2009

As employers, we fully endorse that employment creation, enterprise development, social protections and rights at work are inseparable, interrelated and mutually supportive and they must be given equal weighting in the development of various legislation, policy position and economic development strategies at the national level. We value continuing education and capacity building for our workers through our commitment to the coordination of Samoa's in-country training programs where we have placed priority on capacity building across all industry sector including informal employment. We believe in passing the benefits to all workers but to be able to do this financially, economically and sustainably, we must reduce costs of doing business in Samoa. We are a small economy, we are employing our families and friends: we are related and connected to everybody within our staff, we know them well as they are either in our churches or in our villages. Therefore, we want to pass on the benefits to our employees [Employers' representative]. 


\section{BIBLIOGRAPHY}

Ackers, P., \& Wilkinson, A. (2003). Understanding work and employment: Industrial relations in transition London: Oxford University Press.

Adams, R. J. (1991). Comparative industrial relations : contemporary research and theory: Routledge.

Aiono, F. (1986). Western Samoa the sacred covenant. Fiji: The University of the South Pacific : Institute of Pacific Studies.

Asia Development Bank (2007). Samoa: private sector assessment, consolidating reform for faster growth. Asia Development Bank.

Australia Government Agency (2009). AusAID Samoa country estimate program 2009-10 Retrieved March 07, from http://www.ausaid.gov.au/country

Bain, G. S., \& Clegg, H. A. (1974). A strategy for industrial relations research in Great Britain. British Journal of Industrial Relations, XII(1).

Blain, A. N. J., \& Gennard, J. (1970). Industrial relations theory: a critical review. British Journal of Industrial Relations, 8(3), 389-407.

Boer, R. d., Benedictus, H., \& Meer, H. v. d. (2005). Broadening without intensification: the added value of the European social and sectoral dialogue. European Journal of Industrial Relations, 11(1), 51-70.

Briges, W., \& Villemez (1994). The employment relationship: causes and consequences of modern personnel administration. New York: Plenum Publishing Corporation.

Business Dictionary (Ed.) (2010) Business Dictionary.

Cavana, R. Y., Delahaye, B. L., \& Sekaran, U. (2001). Applied business research: qualitative and quantitative methods. Milton, Qld: John Wiley \& Sons Australia Ltd.

Central Bank of Samoa (2009). Overview of economic developments during the third quater of the 2009. Samoa: Government of Samoa.

Clark, J., McLoughlin, I., Rose, H., \& King, R. (1988). The process of technological change. Cambridge: Cambridge University Press.

Clegg, H. A. (1976). Trade unionism under collective bargaining: a theory based on comparisons of six countries. Oxford: Blackwell.

Craig, A. W. J. (1970). Model for the analysis of industrial relations systems. Paper presented at the Canadian Political Science Association.

Dobson, J. R. (1982). What is good industrial relations? Employment Relations, 4(2). 
Doeringer (1981). Industrial relations research in international perspective Chapter in Industrial relations research in international perspective. London: McMillan.

Dülfer, P. D. E. (1996). Industrial relations and cooperatives. Paper presented at the Corporative laws.

Duncan, R., \& Voigt-Graf, C. (June 2008). Labour market scenarios for the Asian Development Decent Work Decade in the Pacific Island Countries: Regional Office for Asia Pacific.

Dunlop, J. T. (1958). Industrial relations system. New York: Holt.

Dunlop, J. T. (1987). Industrial relations : old and new The Don Wood Visiting Lecture. The Worklife Report, 5(5).

Edwards, P. K. (2003). The employment relationship and the field of industrial relations (2nd ed.). London: Blackwell Publishing.

Encyclopedia of Business (2009). Industrial relations. http://www.referenceforbusiness.com/

Flanders, A. (1965). Industrial relations: what is wrong with the system. London: Institute of Personnel Management.

Flanders, A. (1970). Management and unions. London: Faber \& Faber.

Flanders, A., \& Clegg, H. A. (1954). The system of industrial relations in Great Britain. Oxford: Basil Blackwell and Mott.

Gill, J., \& Golding, D. (1980). Conceptualising industrial relations as a training intervention. Employee Relations, 2(4), 24-28.

Gollan, P. J., Markey, R., \& Ross, I. (Eds.). (2007). Work councils in Australia: Future prospects and possibilities. Australia: Federation Press.

Government of Samoa (1992). World Summit on Sustainable Development Assessment Report. Retrieved March 30, 2009

Heritage Foundation (2010a). Index of Economic Freedom: Samoa Retrieved February 2010, from http://www.heritage.org/index/country/Samoa

Heritage Foundation (2010b). Samoa information on economic freedom: facts, data, analysis Retrieved February 28, from www.heritage.org/index/country/Samoa

Hince, K., \& McFarland, M. (1997). The Western Samoa Public Service Association: A brief history. Wellington: Industrial Relations Centre, Victoria University of Wellington.

Howard, F. G., \& Palmer, G. (1993). British industrial relations (2 ed.): Routledge. 
Hyman, R. (1975). Industrial relations: a Marxist introduction. London: Macmillan.

Hyman, R., \& Brough, I. (1975). Social values and industrial relations. Oxford: Basel Blackwell.

International Labour Organisation (2001). South Pacific Sub - Region. Paper presented at the Asian Regional Meeting.

Jackson, M. P. (1991). An introduction to industrial relations (4th ed.): Routledge.

Jamine Netzler-Iose (2010, April 03). Toamua United on Ale. Samoa Observer, from www.samoaobserver.ws

Kerr, C. (1983). The future of industrial societies. Cambridge: Harvard University Press.

Kerr, C., Dunlop, J. T., Harbison, F. H., \& Myers, C. A. (1960). Industrialism and the industrial man. International Labour Review, 82(3), 236-250.

Kirkaldy, H. S. (1947). The spirit of industrial relations with a foreword by Sir Harsidhbhai Divatia. Bombay: Oxford University Press.

Kochan, T. (1980). Collective bargaining and industrial relations: From theory to policy and practice. Homewood, IL: Richard Irwin.

Kochan, T., Katz, H., \& McKersie, R. (1986). The transformation of American Industrial Relations. New York: Basic Book.

Kochan, T., McKersie, R., \& Cappelli, P. (1984). Strategic choice and industrial relations theory. Industrial Relations, 23(1), 16 - 39.

Lawson, S. (1996). Tradition versus democracry in the South Pacific: Fiji, Tonga, and Western Samoa Available from http://books.google.co.nz

Leat, M. (2007). Exploring employee relations (2nd ed.): Butterworth-Heinemann.

Lewin, D. (1987). Industrial relations as a strategic variable. In M. M. Kleiner, R. N. Block, M. Roomkin \& S. W. Salsburg (Eds.), Human Resources and the performance of the firm (pp. 1-41). Madison: Industrial Relations Research Association.

Locke, R., Kochan, T., \& Piore, M. (1995). Reconceptualizing comparative industrial relations: lessons from international research. International Labour Review, 134(2).

Marchington, M., \& Parker, P. (1990). Changing patterns of employee relations. Hemel Hempstead: Harvester Wheatsheaf.

Margerison, C. J. (1969). What do we mean by industrial relations. British Journal of Industrial Relations, 8(2), 273-286.

Markley, R. (1993). Dunlop's general theory, revised - Industrial relations system. Monthly Labour Review, 116(8), 53-54. 
Marsh, A. (1969). Reviews: industrial relations. Journal of Management Studies, 6(2), 261263.

McDonald, D. (1997). Industrial relations and globalization: challenges for employers and organizations. Paper presented at the ILO Workshop on Employers Organisation in Asia Pacific in the twenty first century.

Mead, R., \& Andrews, T. (2009). International management relations: John Wiley \& Sons.

Meltz, N. M. (1991). Dunlop's industrial relations system as a framework for organising contributions to industrial relations theory In R. J. Adams \& Meltz (Eds.), Industrial relations theory. Metuchan, N. J: Institute of Management and Labour Relations \& Press.

Morley, M., Gunnigle, P., \& Collings, D. G. (Eds.). (2006). Global industrial relations. Ireland: Routledge.

Pacific Island Forum Secretariat (October 2007). The Pacific Plan, For Strengthening Regional Cooperation and Integration. Fiji: SPC.

Pacific Islands Forum Secretariat (October 2007). The Pacific plan, for strengthening regional cooperation and integration. Fiji: SPC.

Parker, S. R., Brown, R. K., Child, J., \& Smith, M. A. (1967). The sociology of industry (4th ed.). New York: Frederick A. Praeger.

Poole, M. (1986). Industrial relations: origins and patterns of national diversity. London: Routledge and Kegan Paul.

Poole, M. (1993). Theorizing for a global perspective. In R. J. Adams \& N. M. Meltz (Eds.), Industrial relations theory. Metuchan, N.J: Labour Relations Press.

Prasad, S., Hince, K., \& Snell, D. (2003). Employment and industrial relations in the South Pacific: Samoa, Tonga, the Cook Islands, Kiribati, Solomon Islands, Vanuatu and the Fiji Islands. Australia: McGraw-Hill.

Roche, W. (1986). Systems analysis and industrial relations: douple paradox in the development of American and British industrial relations theory. Economic and Industrial Democracy, 7(3), 3 - 28.

Rudman, R. (2002). Human Resources Management in New Zealand (4 ed.). Auckland: Pearson Education New Zealand Ltd.

Samoa Bureau of Statistics (2010). Census of population and housing 2006 Retrieved February 28, from http://www.spc.int

Schienstock, G. (1981). Towards a theory of industrial relations. British Journal of Industrial Relations, 191, 170 - 189. 
Shalev, M. (1980). Industrial relations theory and the comparative study of industrial relations and industrial relations conflict. British Journal of Industrial Relations, XVIII(1), $26-41$

Singh, R. (1976). Systems theory in the study of industrial relations : Times for a reappraisal. Industrial Relations Journal, 7, 59 - 71.

Snell, R. (1992). Western Samoa trade unionism: The 1981 Public Service strike. New Zealand Journal of Industrial Relations, 17(1), 69-84.

Somers, G. G. (1969). Bargaining power and industrial relations theory In G. G. Somers (Ed.), Essays in industrial relations theory. Iowa: Iowa State Press.

Turner, L. (1991). Democracy at work change changing world markets and the future of labour unions. Ithaca: Connell University Press.

U.S Department of State Affairs (2009). Background note: Samoa Retrieved March 02, from http://www.state.gov

UN (2008). Improving employment opportunities in Pacific island developing countries (illustrated ed.): United Nation Publication.

Walker, K. (1981). Using the systems approach effectively. Employee Relations, 3(2), 23-

25.Walker, K. (1977). Towards useful theorising about industrial relations British Journal of Industrial Relations, XV(3), 307 -316.

Wendt, A. (1981). Western Samoa's first strike: a foreign invention which became Samoan overnight? Pacific Perspective, 10(1), 45 - 56.

Williamson, O. E. (1981). The economics of organisations : the transformation cost approach. American Journal of Sociology, 87, 548-577.

Wood, S. (1978). Ideology in industrial relations theory. Industrial Relations Journal, 9(4), $42-56$.

Wood, S., Wagner, A., Armstrong, E., Goodman, J., \& Davis, J. (1975). The industrial relations system concept as a basis for theory in industrial relations. British Journal of Industrial Relations, 13(3), 291 - 308. 